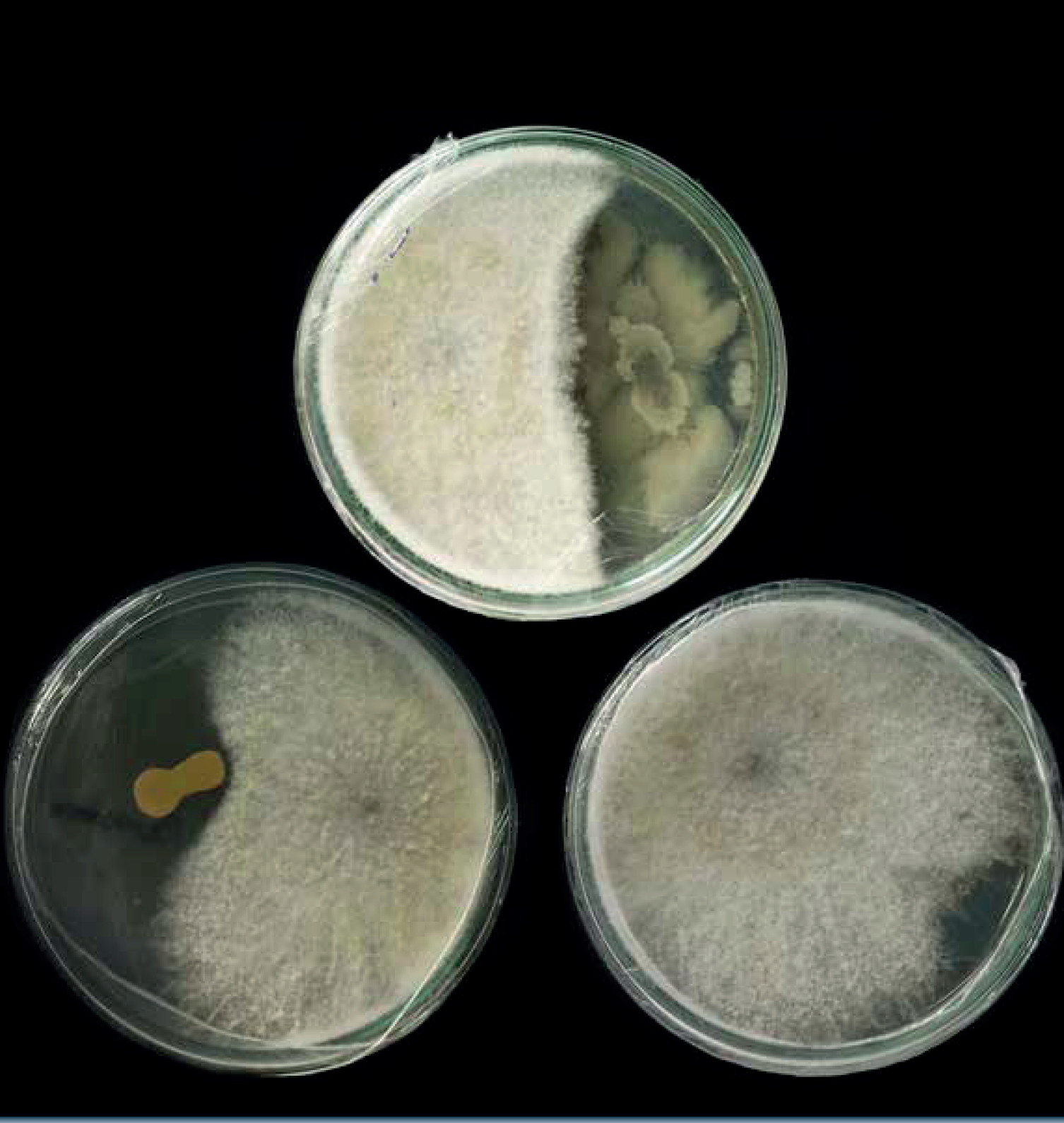

\title{
Tendencias en investigación y desarrollo $(i+d)$ relacionadas con organismos endofíticos
}

Oscar Marino Mosquera Martínez

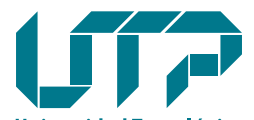

Universidad Tecnológica de Pereira

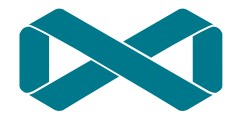

Editorial UTP
Juan Pablo Díaz Echeverry Angélica María Pineda Botero Víctor Alfonso Mejía Restrepo 
Oscar Marino Mosquera Martínez (Cali, Valle, Colombia , 1956).

Magister Scientae en Agoquímica de la Universidade Federal de Viçosa - Brasil y Químico de la Universidad del Valle .

Profesor Titular de la Escuela de Tecnología Química en la Facultad de Tecnología de la Universidad Tecnológica de Pereira.

Ha publicado artículos en revistas especializadas nacionales e internacionales.

Pertenece al Grupo de Investigación Biotecnología - Productos Naturales (GBPN)

omosquer@utp.edu.co

Juan Pablo Díaz Echeverry (Palmira, Valle, Colombia, 1983).

Magister en Ecotecnología de la Universidad Tecnológica de Pereira, Biólogo de la Universidad del Cauca.

Profesor Catedrático. Facultad de Ciencias Ambientales. Facultades de Ciencias Empresariales y Facultad de Ciencias Agrarias y Agroindustria en la Universidad Tecnológica de Pereira

Miembro de los Grupos de investigación Biotecnología - Productos Naturales (GBPN) y Enseñanza de la investigación de Operaciones (GEIO)

juan.diaz@utp.edu.co
Angélica María Pineda Botero (Manizales, Caldas, Colombia, 1979).

Administradora Ambiental de la Universidad Tecnológica de Pereira.

$\mathrm{Ha}$ publicado artículos en revistas especializadas nacionales e internacionales.

angelicazulpb@gmail.com

Víctor Alfonso Mejía Restrepo (Pereira, Risaralda, Colombia, 1993).

Químico Industrial de la Universidad Tecnológica de Pereira.

Docente de Ciencias Naturales-Química Institución Educativa Inmaculada Concepción Nariño Antioquía

vamejiaa@gmail.com

La Editorial de la Universidad Tecnológica de Pereira tiene como política la divulgación del saber científico, técnico y humanístico para fomentar la cultura escrita a través de libros y revistas científicas especializadas.

Las colecciones de este proyecto son:

Trabajos de Investigación, Ensayos, Textos Académicos y Tesis Laureadas.

Este libro pertenece a la Colección Trabajos de Investigación. 


\section{Tendencias en investigación y desarrollo (i+d) relacionadas con organismos endofíticos}

Oscar Marino Mosquera Martínez Juan Pablo Díaz Echeverry Angélica María Pineda Botero Víctor Alfonso Mejía Restrepo

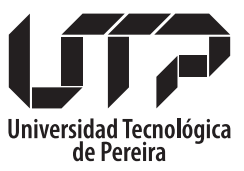

Colección Trabajos de Investigación

Facultad de Tecnología 2020 


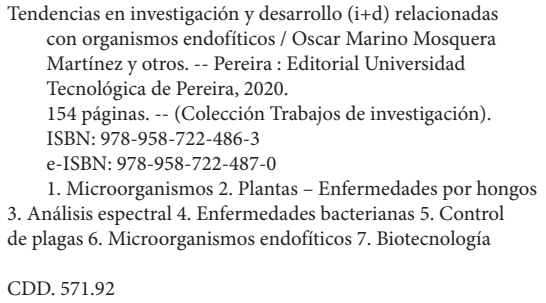

\section{Autores}

(C) Oscar Marino Mosquera Martínez

(C) Juan Pablo Díaz Echeverry

(C) Angélica María Pineda Botero

(C) Víctor Alfonso Mejía Restrepo

\section{Universidad Tecnológica de Pereira}

Pereira, Colombia

\section{Proyecto}

Desarrollo de capacidades científicas y tecnológicas en biotecnología aplicada a los sectores de la salud y la agroindustria en el departamento de Risaralda, con Código: BPIN 201200010050.

\section{Universidad Tecnológica de Pereira}

Vicerrectoría de Investigaciones, Innovación y Extensión

Editorial Universidad Tecnológica de Pereira

Pereira, Colombia

\section{Coordinador editorial:}

Luis Miguel Vargas Valencia

luismvargas@utp.edu.co

Teléfono 3137381

Edificio 9, Biblioteca Central "Jorge Roa Martínez"

Cra. 27 No. 10-02 Los Álamos, Pereira, Colombia

www.utp.edu.co

Montaje y producción:

David Restrepo Suarez.

Universidad Tecnológica de Pereira 



\section{CONTENIDO}

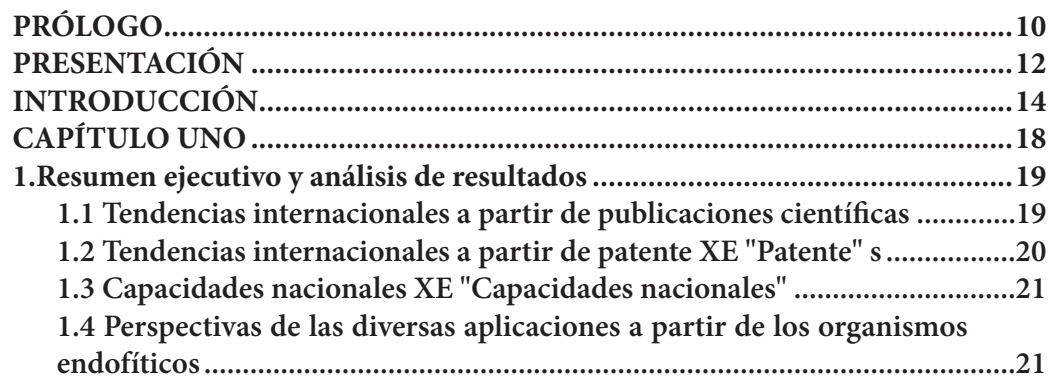

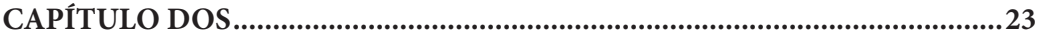

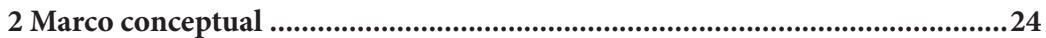

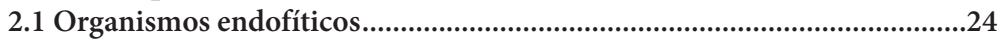

2.2 Transmisión de microrganismos endofíticos ..............................................24

2.3 Relaciones ecológicas organismos endofíticos y sus plantas hospederas. 25

2.4 Microorganismos endofíticos como fuente de productos bioactivos.......29

2.5 Bacterias endofíticas su ecología y potencialidades biotecnológicas.........31

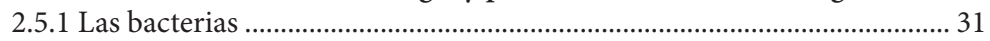

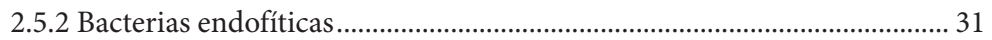

2.5.3 Colonización de bacterias endofíticas en las plantas ................................. 32

2.5.4 Investigaciones con bacterias endofíticas en plantas ................................. 33

2.6 Hongos endofíticos su ecología y potencialidades biotecnológicas...........35

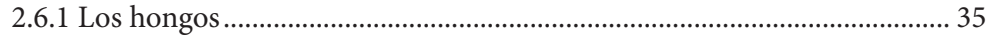

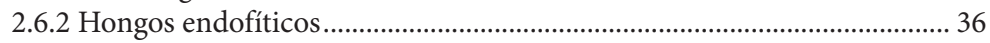

2.6.3 Clasificación de los hongos endofíticos .................................................... 37

2.6.4 Investigaciones con hongos endofíticos en diferentes tipos de plantas .. 38

2.6.5 Hongos endofíticos como fuente de productos bioactivos. ...................... 39

2.6.7 Enfoques de estudio de metabolitos secundarios de hongos endofíticos 41

2.6.8 Hongos endofíticos y su importancia en la industria ................................ 42

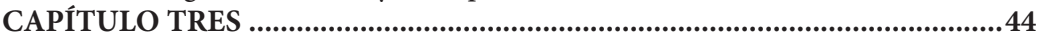

3.Proceso metodológico ................................................................................45

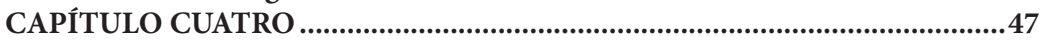

4. Análisis de tendencias internacionales en microorganismos endofíticos .....48

4.1 Análisis de tendencias a partir de la producción científica en microorganismos endofíticos...................................................................................48

4.1.1 Dinámica de publicaciones en el tema de microorganismos endofíticos para el periodo 1970 - 2015 ................................................................ 50

4.1.2 Países líderes - microorganismos endofíticos............................................. 51

4.1.2.3 Instituciones líderes - microorganismos endofíticos ............................. 52

4.1.4 Autores líderes - microorganismos endofíticos .......................................... 56

4.1.5 Principales áreas del conocimiento - Microorganismos endofíticos ....58 4.1.6 Principales journals con publicaciones relacionadas con

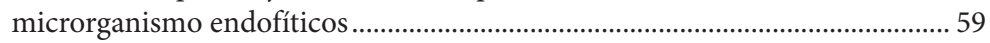

4.2 Análisis de la producción científica en hongos endofíticos........................60 
4.2.1 Dinámica de publicaciones en el tema de hongos endofíticos (HE)............... 60

4.2.2 Autores líderes - hongos endofíticos (HE) ...................................................... 61

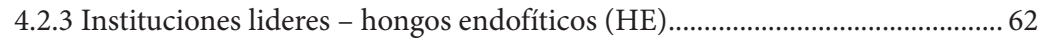

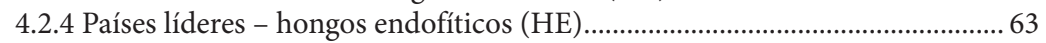

4.3 Análisis de la producción científica en bacterias endofíticas ...........................63

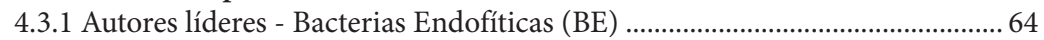

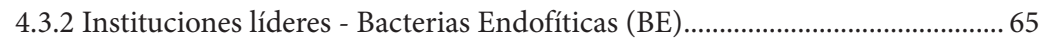

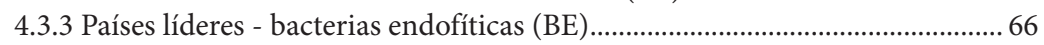

4.3.4 Principales áreas del conocimiento - bacterias endofíticas (BE) ........................66

4.4 Análisis comparativos entre hongos y bacterias endofíticas ...........................67

4.5 Análisis de tendencias organismos endofíticos 2015 - 2020 ............................. 71

4.5.1 Dinámica de publicaciones organismos endofíticos 2015 - 2020 ................... 71

4.5.2 Países líderes en microorganismos endofíticos 2015 - 2020 ........................... 72

4.5.3 Instituciones líderes - microorganismos endofíticos 2015 - 2020 ................. 73

4.5.4 Autores Líderes - Microorganismos endofíticos 2015 - 2020........................ 74

4.5.5 Principales áreas de conocimiento - Microorganismos endofíticos 2015

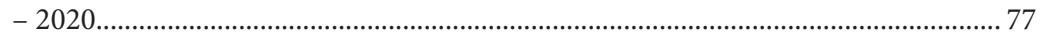

4.5.6 Principales journals con publicaciones relacionadas a microorganismos

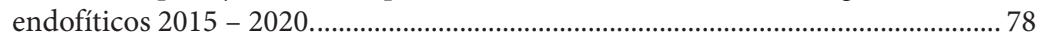

5. Análisis de patentes relacionadas con microorganismos endofíticos..................81 5.1 Dinámica general de patentes relacionadas con el tema de microorganismos endofíticos hasta el año 2015 ...................................................... 82

5.1.1 Solicitantes que lideran las patentes relacionadas con microorganismos

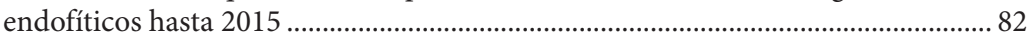

5.1.2 Países que lideran las patentes relacionadas con microorganismos

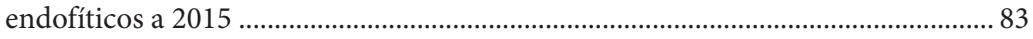

5.1.2 Co-ocurrencia de palabras claves en las patentes relacionadas con

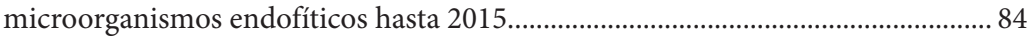

5.1.4 Patentes relacionadas con microorganismos endofíticos según la clasificación internacional de patentes - IPC.

5.2 Dinámica general de patentes relacionadas con el tema microorganismos endofíticos en el periodo de tiempo 2015 - 2020

5.2.1 Solicitantes que lideran las patentes relacionadas con microorganismos endofíticos en el periodo 2015 - 2020 ......................................................................... 89

5.2.2 Países que lideran patentes relacionadas con endofíticos en el periodo de 2015 - 2020 ........................................................................................................... 90

5.2.3 Co-ocurrencia de palabras claves en las patentes relacionadas con endofíticos en el periodo 2015 - 2020 ..................................................................... 90

5.2.4 Patentes relacionadas con microorganismos según la clasificación internacional de patentes - IPC ............................................................................... 91

CAPÍTULO SEIS ..........................................................................................................93

6. Capacidades nacionales..............................................................................................994

6.1 Análisis de capacidades nacionales......................................................................94

6.1.1 Dinámica general de publicaciones nacionales relacionadas con organismos endofíticos en Colombia hasta el 2015................................................. 94

6.1.2 Instituciones líderes - microorganismos endofíticos hasta el 2015 ............... 95

6.1.3 Dinámica general de publicaciones nacionales relacionadas con organismos endofíticos en Colombia 2015 al 2020 ..................................................... 96 
6.1.4 Instituciones líderes - microorganismos endofíticos 2015 - 2020

6.1.5 Autores a nivel nacional en investigación de organismos endófitos 2015 $-2020$ 98

6.1.6 Principales áreas de conocimiento - Microorganismos endofíticos en Colombia 2015-2020.

6.1.7 Principales journals con publicaciones relacionadas a microorganismos endofíticos 2015 - 2020 en Colombia.

6.1.8 Colaboración de Colombia con otros países en investigaciones de microorganismos endofíticos durante 2015 - 2020

CAPÍTULO SIETE

7. Perspectivas mundiales sobre las aplicaciones actuales y desarrollos de hongos y bacterias endofíticas.

7.1 Principales aplicaciones y desarrollos con hongos endofíticos 106

7.2 Principales aplicaciones y desarrollos con bacterias endofíticas .................... 106

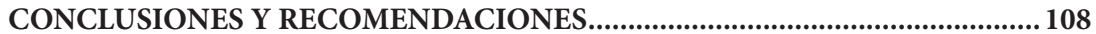

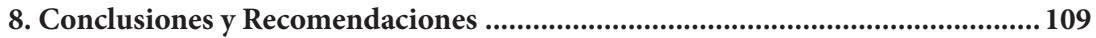

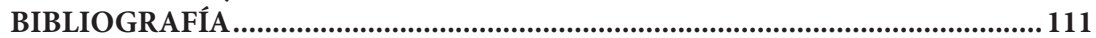

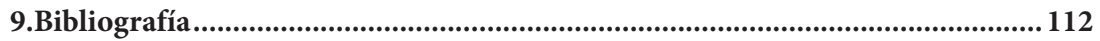

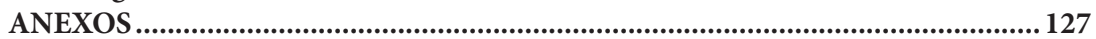

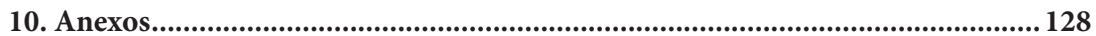

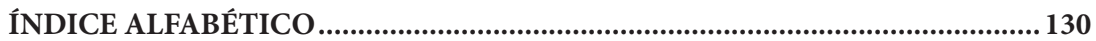

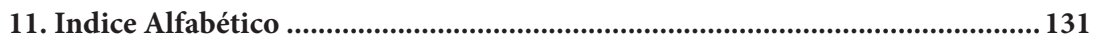

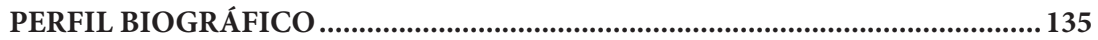




\section{FIGURAS}

Figura 1. Aplicaciones de los microorganismos endofíticos ............................................17

Figura 2. Relaciones ecológicas entre hongos endofíticos y sus hospederos.........................26

Figura 3. Relación hongo endofítico - planta hospedera.................................................. 28

Figura 4. Ruta metodológica para el desarrollo del ejercicio de vigilancia tecnología

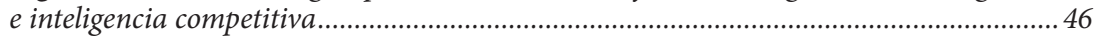

Figura 5.Ficha de planeación de ejercicios de Vigilancia Tecnológica para microorganismos endofiticos............................................................................................ 49

Figura 6. Número de publicaciones relacionadas con el tema de organismos Endofíticos por año .................................................................................................. 51

Figura 7.Distribución del número de publicaciones por país relacionadas con el tema de organismos endofiticos......................................................................................... 51

Figura 8. Distribución del número de publicaciones por país de América Latina y el Caribe relacionadas con el tema organismos Endofíticos..................................................52

Figura 9. Número de publicaciones por institución relacionadas con el tema

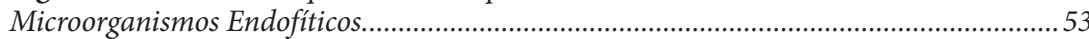

Figura 10. Número de publicaciones por Autor relacionadas con el tema

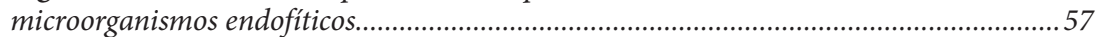

Figura 11. Distribución del número de publicaciones por área del conocimiento relacionadas con el tema microorganismos endofítico .......................................................59

Figura 12. Número de publicaciones por revista relacionadas con endofíticos ..................60

Figura 13. Número de publicaciones por año en el tema de hongos endofíticos ...............61

Figura 14. Número de publicaciones por Autor relacionadas con el tema Hongos

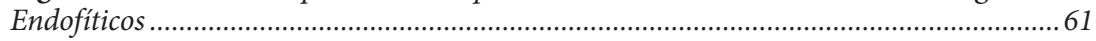

Figura 15. Número de publicaciones por institución relacionadas con el tema

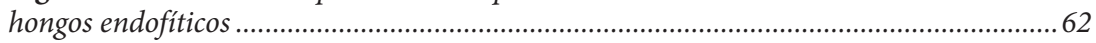

Figura 16. Número de publicaciones por país relacionadas con el tema hongos

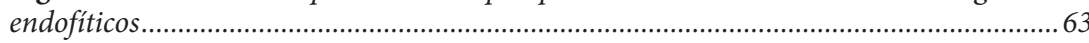

Figura 17. Dinámica de publicaciones en el tema de bacterias endofíticas (BE) en el

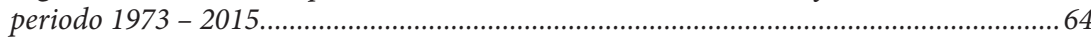

Figura 18. Número de publicaciones por autor en el tema de bacterias endofíticas

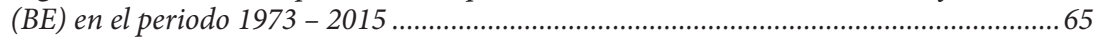

Figura 19.Número de publicaciones por Institución en el tema de bacterias endofíticas (BE) en el periodo 1973 - 2015.......................................................................6 65

Figura 20. Número de publicaciones por país en el tema de Bacterias endofíticas (BE) en el periodo 1973 - 2015 ........................................................................................... 66

Figura 21. Número de publicaciones por área del conocimiento en el tema de

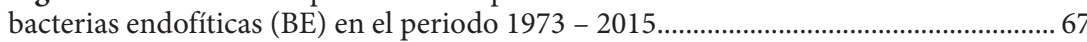

Figura 22. Porcentaje de publicaciones relacionadas con Hongos y Bacterias

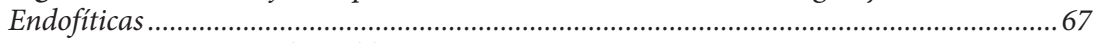

Figura 23. Número de publicaciones por año en Microorganismos, Hongos y

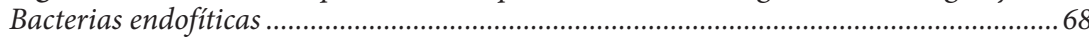

Figura 24. Número de publicaciones por área del conocimiento para hongos y

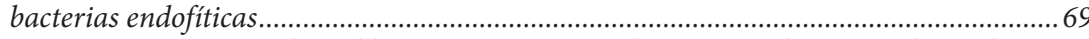

Figura 25. Número de publicaciones por país de América latina y el Caribe

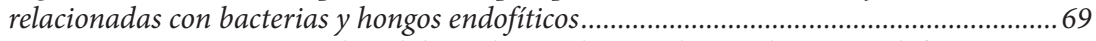

Figura 26. Co-ocurrencia de palabras claves relacionadas con hongos endofíticos .......... 70

Figura 27. Co-ocurrencia de palabras claves relacionadas con bacterias endofíticas...... 70 
Figura 28.Numero de publicaciones por año en el tema organismos endófitos 2015

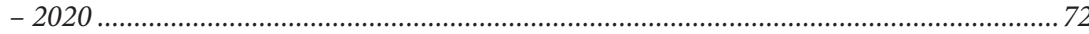

Figura 29. Distribución del número de publicaciones por país relacionadas con el tema de organismos endofíticos 2015 - 2020 ................................................................ 73

Figura 30. Distribución del número de publicaciones por país de América Latina y el Caribe relacionadas con el tema organismos Endofíticos 2015 - 2020......................... 73

Figura 31. Número de publicaciones por institución relacionadas con el tema Microorganismos Endofíticos 2015 - 2020 ................................................................. 74

Figura 32. Número de publicaciones por Autor relacionadas con el tema microorganismos endofíticos 2015 - 2020................................................................ 75

Figura 33. Distribución del número de publicaciones por área del conocimiento relacionadas con el tema microorganismos endofítico 2015 - 2020.................................. 78

Figura 34. Número de publicaciones por revista relacionadas con endofíticos ................. 79 Figura 35. Número de patentes por año en el tema de microorganismos endofíticos

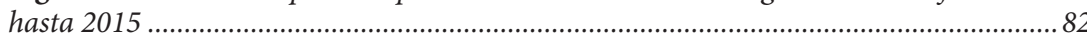

Figura 36. Número de patentes por solicitante en el tema de microorganismos

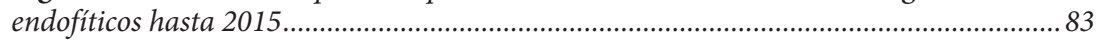

Figura 37. Número de patentes por país en el tema de microorganismos endofíticos.......83

Figura 38. Ocurrencia de palabras claves en las patentes relacionadas con

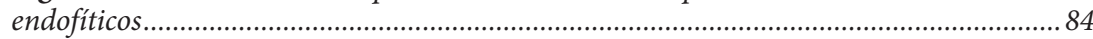

Figura 39. Dinámica de patentes relacionadas con organismos endofíticos por año

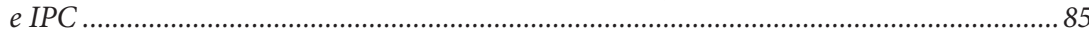

Figura 40. Evolución en el tiempo de las patentes relacionadas con organismos

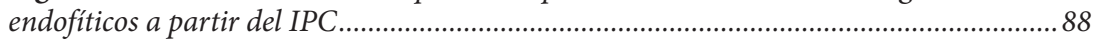

Figura 41. Número de patentes por año relacionados con microorganismos endofíticos 2015 - 2020

Figura 42. Número de patentes por solicitante relacionadas con microrganismos endofíticos 2015 - 2020

Figura 43. Número de patentes por país en el tema de microorganismos endofíticos en el periodo 2015 - 2020................................................................................................ 90

Figura 44. Ocurrencia de palabras claves en las patentes relacionadas con endófitos en el periodo 2015 - 2020............................................................................................ 91

Figura 45. Patentes relacionadas con organismos endofíticos y los códigos IPC en el periodo 2015 - 2020 ..................................................................................................... 92

Figura 46. Número de publicaciones por año relacionadas con organismos

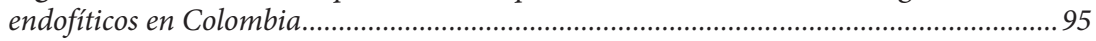

Figura 47. Instituciones Colombianas con publicaciones en organismos endofíticos....... 95

Figura 48. Número de publicaciones en Colombia por año en el tema organismos endófitos 2015 - 2020 ...................................................................................................... 96

Figura 49. Número de publicaciones por institución Nacionales relacionadas con el tema microorganismos endofíticos 2015 - 2020 ............................................................. 97

Figura 50. Número de publicaciones nacionales por Autor relacionadas con el tema microorganismos endofiticos 2015 - 2020 ...................................................................... 99

Figura 51. Distribución del número de publicaciones en Colombia por área del conocimiento relacionadas con el tema microorganismos endofítico 2015 - 2020...........102 Figura 52. Países y número de publicaciones relacionadas con las publicaciones colombianas en el periodo 2015 - 2020 


\section{TABLAS}

Tabla 1. Bacterias endofíticas aisladas de plantas de interés agropecuario

Tabla 2. Clases de hongos endofíticos según las clases de clavicipitáceos......

Tabla 3. Antecedentes de investigaciones con hongos endofíticos de diferentes tipos de planta

Tabla 4. Información de las principales Instituciones que publican temas relacionados con organismos Endofíticos.

Tabla 5. Información de los principales autores que publican temas relacionados con organismos endofíticos 58

Tabla 6. Información de los principales autores que publican temas relacionados con organismos endofíticos 2015 - 2020

Tabla 7. Descripción de la clasificación IPC en las que se encuentran las patentes relacionadas con organismos endofiticos

Tabla 8. Información de los principales autores que publican temas relacionados con organismos endofíticos 2015 - 2020 en Colombia......

Tabla 9. Principales Aplicaciones y desarrollos con hongos endofíticos 106

Tabla 10. Aplicaciones y desarrollos a partir de bacterias endofíticas. 107

\section{ANEXOS}

Anexo 1: Listado de publicaciones nacionales relacionadas con organismos endofíticos. 


\section{PRÓLOGO}

La naturaleza emerge, cada día más, como un laberinto sin fin de especies. Los seres humanos y, en particular, los investigadores que se dedican a la investigación científica se deslumbran con una miríada de especies animales y vegetales, aparentemente incontable, que existe debajo de una palabra simple: biodiversidad.

No es sorprendente ver que, asociados en diversas formas, junto a los animales y plantas, existe un número también incontable de especies de microorganismos (hongos y bacterias). En este universo, aumenta cada vez más, el gran potencial ecológico, químico, farmacológico e industrial de los organismos endofíticos, todavía poco conocidos, ya que están escondidos en el interior de las plantas.

En este documento sobre "Tendencias en investigación y desarrollo (I+D) en organismos endofíticos", los autores presentan este universo de especies endofíticas, abordando no solamente la importancia y las aplicaciones de estas especies, si no que ofrecen un mapa de países, instituciones e incluso investigadores que trabajan en esta área, en una visión global y equilibrada sobre el tema. Además, este material recopila diversos aspectos relevantes en la investigación sobre organismos endofíticos, como las tendencias en el área de patentes, aspectos metodológicos y análisis de producción científica en el área de endofíticos.

Es un trabajo exhaustivo, completo y que puede conducir a discusiones políticas, científicas y académicas sobre este tema, tan relevante en el área de biotecnología industrial en la actualidad. Espero que la lectura pueda agradarles a todos, de la misma manera que me agradó a mí; en especial a los jóvenes investigadores, para incentivarlos a embarcarse en el estudio de organismos endofíticos sobre las más diversas ópticas del trabajo científico. 
Hay un mundo de informaciones ecológicas, químicas y farmacológicas para ser descubierto en esta área. Quién sabe, no será de estos minúsculos seres, escondidos dentro de las más diversas plantas, que vendrá el descubrimiento de nuevas moléculas capaces de combatir las enfermedades sin perspectiva de cura, que aún atemorizan a la humanidad; quién sabe, también, no será en plantas nativas de países menos desarrollados que estarán escondidos organismos endofíticos que puedan, debido a sus propiedades biosintéticas, producir sustancias de interés biotecnológico, capaces de mover la economía local y promover cambios necesarios en la economía mundial.

Felicitando a los autores, les deseo a todos una excelente lectura de este material y mucha suerte en el trabajo de aquellos que se embarcarán en el mundo endofítico a partir de ahora!

Jacqueline Aparecida Takahashi Profesora Titular Directora del Grupo de Investigación Biotecnologia e Bioensaios Departamento de Química Universidad Federal de Minas Gerais Belo Horizonte-MG, Brasil 


\section{PRESENTACIÓN}

El Grupo de Investigación Biotecnología - Productos Naturales - GB-PN de la Escuela de Tecnología Química, Adscrito a la Facultad de Tecnologías de la Universidad Tecnológica de Pereira, tiene como objetivo general realizar investigación para la exploración, conservación y fortalecimiento de los bio-recursos a través de la química orgánica de productos naturales y procesos biotecnológicos.

$\mathrm{Al}$ interior de EL GB-PN - UTP, nos hemos propuesto manejar líneas de investigación que permitan explorar el potencial activo de la flora regional, a través de la bioprospección, identificación y cuantificación de metabolitos secundarios bioactivos en extractos vegetales, con importancia farmacológica y agroindustrial.

A través las líneas de investigación de interés para el GB-PN, se han desarrollado proyectos de investigación y trabajos de grado que han aportado al conocimiento de la biodiversidad, productos naturales, biotecnología vegetal, prospección de antimicrobianos y antioxidantes, valoración de productos naturales y sustancias farmacológicamente activas y su estructura química. Además de lo anterior, existe una línea general de trabajo relacionada con la protección de cosechas contra microorganismos patogénicos, a partir del estudio de biopreparados.

En el Grupo de Biotecnología-Productos Naturales GB-PN, se explora una nueva línea de investigación relacionada con el estudio de microorganismos endofíticos asociados a especies vegetales de las áreas protegidas de la Ecorregión del Eje Cafetero, como fuentes de nuevos compuestos con potencial aplicación en los sectores de la agroindustria y de la salud.

GB-PN ha realizado el aislamiento y avanza en la caracterización morfológica y molecular de organismos endofíticos y evaluación de algunas actividades biológicas, tales 
como: antioxidantes, antimicrobiana, actividad inhibitoria de la acetilcolinesterasa, actividad inhibitoria de la $\alpha$-glucosidasa y actividad neuroprotectora mediante el modelo in-vivo de Drosophila melanogaster.

A través de este documento se recopila información técnica y científica relacionada con organismos endofíticos para orientar el diseño de la estrategia investigativa de nuestro grupo GB-PN en diferentes tópicos relacionadas con estos microorganismos y sus plantas hospederas, incluyendo la divulgación a otros investigadores regionales y nacionales, para la toma de decisiones en los procesos de investigación y desarrollo. 


\section{INTRODUCCIÓN}

\section{Tendencias en investigación y desarrollo (I+D). Organismos endofíticos}

La naturaleza es una fuente de inspiración y de conocimiento inagotable. Desde tiempos inmemoriales, la humanidad se ha relacionado con la naturaleza y su entorno para poder comprenderla, obtener beneficios y satisfacer las demandas de una creciente población cada vez más exigente y consiente de la utilización de productos naturales en diferentes ámbitos económicos y sociales.

La búsqueda o prospección de nuevas sustancias y compuestos de origen natural es una prioridad para la sociedad y es un proceso que se mejora constantemente gracias a los desarrollos tecnológicos que están permitiendo el descubrimiento y avance del conocimiento biológico de los seres vivos y cómo estos, responden fisiológicamente a su entorno. Todo esto permite el uso de organismos vivos, parte de ellos o las sustancias que producen; como fuente de insumos para diferentes sectores de producción industrial, farmacéutica, agrícola y ambiental. 
Las plantas son una fuente productora de compuestos activos y, además, sus partes y tejidos representan el hábitat de microorganismos procariotas como bacterias y eucariotas como los hongos; Estos dos, se relacionan de múltiples maneras ecológicas, afectando la supervivencia de la planta que es denominada "el hospedero" y la de los microorganismos que habitan en el interior y exterior de sus tejidos; Estas interacciones de la planta-microorganismo, puede ser la clave para el descubrimiento y la caracterización compuestos de importancia económica para la sociedad (Nisa et al., 2015).

Los microorganismos endofíticos, son microorganismos que habitan durante alguna etapa de su ciclo de vida en el interior de los tejidos de la planta sin causar algún tipo de sintomatología de afección o enfermedad a su hospedero (Zhang et al., 2006), estos microorganismos endofíticos, pueden ser bacterias, actinomicetos y hongos (Tan y Zou, 2001a).

Las bacterias endofíticas, son las que llegan a colonizar los tejidos internos de las plantas y no llegan a causar daños aparentes, (Schulz y Boyle, 2005), presentando interacciones planta-microorganismo que pueden promover el crecimiento, desarrollo y supervivencia de la planta, por lo que estas bacterias endofíticas, pueden colonizar los mismos nichos ecológicos que otros microorganismos patógenos, por esa razón pueden ser considerados como agentes de control biológico (Ryan et al., 2008).

Un hongo endofítico vive en forma de micelio dentro de las plantas en una asociación biológica con la planta viva (Nisa et al., 2015) y por lo tanto el requisito mínimo para denominar un hongo endofítico es que se demuestre la presencia de las hifas en el tejido vivo (Kaul et al., 2012). Y al igual que las bacterias endofíticas; los hongos endofíticos se pueden aislar de los tejidos subterráneos como rizomas y raíces y de tejidos aéreos como tallos, peciolos, hojas, flores, frutos (Rosenblueth y MartínezRomero, 2006). 
Las bacterias y los hongos endofíticos, colonizan el interior de los tejidos vegetales (hojas, tallos y raíces) sin causar daños patológicos a su hospedero en condiciones normales (Arnold y Lutzoni, 2007). Pero con capacidad de ser fitopatológicos cuando la planta es afectada negativamente por factores ambientales (Stępniewska y Kuźniar, 2013). Por lo cual la relación simbiótica entre la planta hospedero, puede incluir el mutualismo, parasitismo, comensalismo, descomponedor; dependiendo de factores como el estadio de ciclo de vida y la influencia de los factores climáticos del medio ambiente (Ryan et al., 2008; Schulz y Boyle, 2005).

Las relaciones simbióticas entre la planta y el organismo endofítico, puede interpretarse en que él primero protege y alimenta al segundo que produce a cambio sustancias químicas activas biológicamente (factores de crecimiento, antibacterianos, antimicóticos, antivirales, insecticidas, etc.), sustancias para mejorar el crecimiento y la competitividad del hospedero en la naturaleza (G. Carroll, 1988). Esta dinámica se puede interpretar como que algunos endofíticos, tienen potencial de llegar a ser fuentes confiables de materiales o sustancias con potencial agrícola y/o farmacéutico, en la mayoría de los casos estas sustancias pueden ser producidas por los endofíticos y por las plantas hospederas (Nisa et al., 2015).

La diversidad de plantas en el planeta se estima aproximadamente en 300.000 especies y cada planta individual a su vez, es hospedero de al menos uno o más microorganismos endofíticos. Se ha considera que podría haber hasta un millón de diferentes taxones de hongos endofíticos y una cantidad aproximada de bacterias endofíticas. Por lo tanto, las posibilidades de obtener una alta gama de sustancias con algún tipo de actividad biológica (Strobel, 2003) y (Petrini, 1991).

El uso actual de los compuestos activos de las bacterias y hongos endofíticos permite visualizar las grandes potencialidades que estos tienen en los diferentes ámbitos. Algunas aplicaciones 
de los microorganismos endofíticos se muestran en la Figura 1. Aplicaciones de los microorganismos endofíticos

Figura 1. Aplicaciones de los microorganismos endofíticos

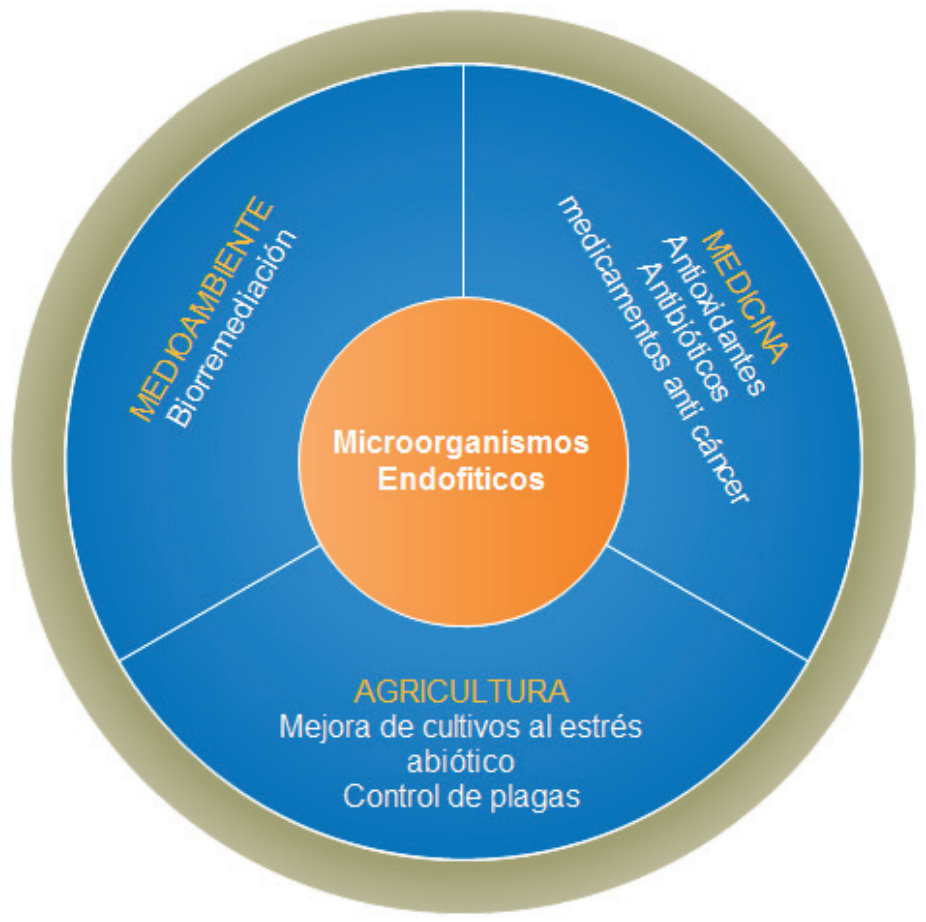

Fuente: Elaboración propia

En este sentido, el presente estudio de vigilancia tecnológica "Vigilancia tecnológica" tiene como objetivo identificar las principales tendencias en Investigación y Desarrollo (I+D), XE "Investigación y Desarrollo (I+D)" a nivel nacional e internacional, que permitan conocer instituciones líderes, autores, países, áreas del conocimiento, identificando líneas de investigación consolidadas y emergentes que permitan direccionar los esfuerzos de investigación a nivel regional y nacional. 


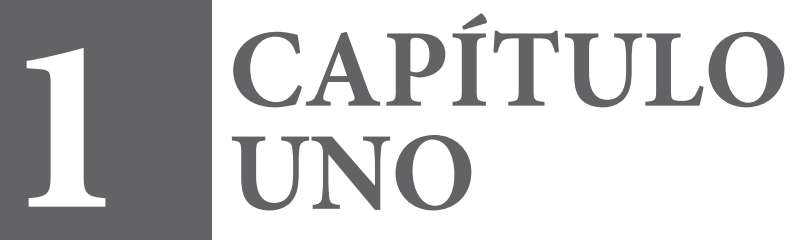




\section{Resumen ejecutivo y análisis de resultados}

\subsection{Tendencias internacionales a partir de publicaciones científicas}

Teniendo en cuenta la dinámica en el número de artículos relacionados con microorganismos endofíticos (hongos XE "Hongo" y bacteria XE "Bacteria" s) se puede inferir que a partir del año 2005 se ha presentado un incremento significativo de publicaciones científicas, con un crecimiento anual aproximado del $22 \%$ en el tema de hongos y el 13\% para el tema de bacterias.

Entre los países más activos respecto a publicaciones relacionadas con organismos endofíticos se encuentran China, Estados Unidos, India, Alemania y Brasil, con una participación del 66\% aproximadamente del total de las publicaciones. En lo que respecta a los países de América Latina y el Caribe participan con aproximadamente el 12,5\% del total de las publicaciones, siendo Brasil, Argentina y México los más destacados.

Entre las instituciones más representativas se encuentran la Universidad de Sun Yat-sen, uno de los entes académicos más reconocidos de la China; seguido de la Universidad de Sao Paulo y la Academia de Ciencias de la China. En el caso específico de las publicaciones relacionadas con bacterias endofíticas, es interesante el rol protagónico de instituciones brasileñas.

Con respecto a los autores, cabe destacar a los dos investigadores con mayor cantidad de artículos asignados, Yongcheng Lin y Zhigang She de la Universidad de Sun Yat-Sen. Los estudios de estos científicos abordan especialmente la búsqueda y evaluación actividad anticancerígena "actividad anti-cáncer" de metabolitos secundario "Metabolito secundario" s de hongos endofíticos asociados a ecosistema "Ecosistema" s de manglares. 
Al analizar las áreas del conocimiento en las que se encuentran registradas las publicaciones científicas relacionadas con microorganismos endofíticos, se observa que el $48 \%$ de las publicaciones están en el área de Agricultura "Agricultura" y las Ciencias Biológicas "Ciencias Biológicas", seguidas de la Bioquímica "Bioquímica", Genética "Genética" y Biología Molecular "Biología Molecular" con el 32\%. Otras áreas del conocimiento emergentes, asociadas posiblemente a nuevas aplicaciones de los compuestos activos "Compuestos activos" derivados de estos organismos son: medicina "Medicina", inmunología "Inmunología" y microbiología "Microbiología", medioambiente"Medio Ambiente"yfarmacéutica"Farmacéutica".

\subsection{Tendencias internacionales a partir de patente XE "Patente" s}

$\mathrm{Al}$ analizar las patentes publicadas en el periodo comprendido entre 2010 - 2015, se observa que estas se relacionan en gran parte con temas como: métodos de aislamiento XE "Métodos de aislamiento", aplicaciones agroindustriales XE "aplicaciones agroindustriales", aplicaciones en salud XE "Aplicaciones en salud" y en el área del medio ambiente (biocombustible XE "Biocombustible" s y biorremediación XE "Biorremediación" ).

Como solicitantes líderes en patente XE "Patente" s a nivel mundial se encuentran Grasslanz Technology Ltda, seguido de Gary Strobel, la Universidad del Estado de Montana, Agriculture Victoria Services Pty Ltd y la Universidad Jiliang de China.

En relación a los países líderes, se encuentran la China y los Estados Unidos como los países con más patentes asignadas; estos países cuentan con una participación de aproximadamente el $60 \%$ de las patentes publicadas. 


\subsection{Capacidades nacionales XE "Capacidades nacionales"}

En las publicaciones indexadas XE "Publicaciones indexadas" en Scopus se encuentran 21 asignadas a Colombia; lo que representa una participación muy baja en comparación con otros países de América Latina y el Caribe, como el caso de Brasil (531 publicaciones), Argentina (97 publicaciones) y México (88 publicaciones).

Las publicaciones nacionales se encuentran en el periodo comprendido entre 2001 y 2015, lo que permite evidenciar una actividad relativamente reciente en lo que se refiere a procesos de $\mathrm{I}+\mathrm{D}$ relacionados con el tema de organismos endofíticos.

Los artículos publicados sobre organismos endofíticos en los que participan instituciones y autores colombianos se han centrado en los hongos, solo un par de investigaciones ha incluido a las bacterias. Las investigaciones que involucran a los hongos endofíticos han ido desde el aislamiento e identificación de los microrganismos hasta ensayos biológicos XE "Ensayos biológicos" centrados especialmente en la búsqueda de organismos que puedan servir para el control de plagas XE "Control de plagas" en cultivos tales como maíz, tomate, cacao, frijol y plátano.

\subsection{Perspectivas de las diversas aplicaciones a partir de los organismos endofíticos}

La revisión de publicaciones relacionadas con hongos y bacterias endofíticas permite evidenciar una tendencia interesante en lo que respecta al potencial de uso y aplicaciones a partir de compuestos activos XE "Compuestos activos" derivados de estos microorganismos. Por un lado, los compuestos activos de los hongos parecen tener un espectro más amplio de aplicaciones, tanto en el sector de la salud como en el sector agrícola, mientras que las bacterias están siendo muy estudiadas por su potencial en procesos de biorremediación. 
Algunos estudios revelan el interés que instituciones, especialmente de países como China e India, tienen en la exploración de los compuestos activos de hongos endofíticos asociados a ecosistemas marinos como los manglares y hongos endofíticos presentes en las algas XE "Algas". En un estudio publicado por Manomi y colaboradores en 2014, del departamento de biología marina de la Universidad de Ciencia y Tecnología de Cochin, en India, tuvo como objetivo determinar la flora endofítica de varias macroalgas XE "Macroalgas" y perfilar el potencial enzimático XE "Enzima" y antibacterial de estos hongos. En esta investigación, se obtuvieron un total de 29 aislamientos XE "Aislamientos" y se exhibieron propiedades enzimáticas como celulasa XE "Celulasa" (59\%), amilasa XE "Amilasa" (93\%), lipasa XE "Lipasa" (86\%), gelatinasa XE "Gelatinasa" (69\%), glutaminasa XE "Glutaminasa" (66\%) y asparaginasa XE "Asparaginasa" (72\%). Siete cepas demostraron actividad antibacteriana XE "Actividad antibacteriana" contra Escherichia coli y dos fueron encontrados para ser la inhibición de Bacillus cereus. 


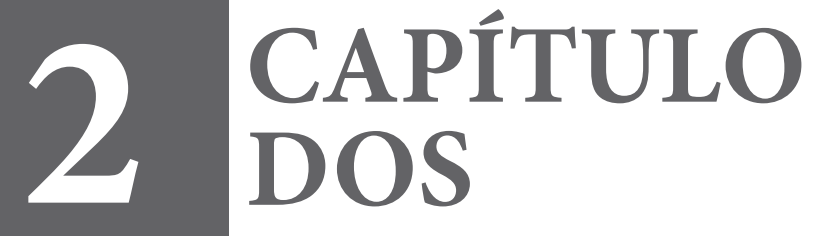




\section{Marco conceptual}

\subsection{Organismos endofíticos}

Los endofíticos se definen como microorganismos, incluyendo bacterias, hongos y actinomicetos, que habitan en los tejidos vegetales intra e intercelulares por la totalidad o parte de su ciclo de vida (Pandey et al., 2014). Tienen la capacidad de colonizar los tejidos internos de la planta de hojas "Hojas" sanas, pecíolos "Pecíolos", tallo "Tallo" s, ramas "Rama", corteza "Corteza" s, raíces "Raíz", frutas "Frutas", flores "Flores" y semillas "Semillas" sin causar ningún daño aparente o infección patógena a la planta hospedera (Carroll y Carroll, 1978; Petrini et al., 1982; Gamboa-Gaitan, 2006; Fouda et al., 2015).

\subsection{Transmisión de microrganismos endofíticos}

Tan y Zou (2001) plantearon que los endofíticos son los componentes más importantes en la diversidad de microorganismos en los vegetales. Encontrándose asociados con casi todas las especies de plantas, y que algunos son capaces de migrar internamente dentro de los tejidos de la planta para habitar follaje, tallos y corteza, así como raíces (Behie y Bidochka, 2013).

En el proceso de transmisión del hongo endofítico al hospedero, se han consideran dos vías, desde el medio ambiente a la planta y, por otro lado, desde la planta a su descendencia mediante sus semillas. Rodríguez et al. (2009) plantearon que los hongos endofíticos podían transmitirse o colonizar tejidos de las plantas mediante dos mecanismos denominados transmisión horizontal y transmisión vertical. La transmisión horizontal cuando se transmite a través de sus semillas y es vertical cuando el hongo se transmite del medio ambiente generalmente el suelo a la planta hospedera mediante las raíces, estomas de las hojas en la planta. 
Han sido aislados en todo tipo de plantas: no vasculares como musgos, hepáticas, antoceros, además de plantas vasculares sin semillas como licophytas, equisetophyta y helechos y plantas vasculares con semillas, distribuidas desde el ártico hasta los trópicos (Aly et al., 2010). Se plantea que puede existir al menos un hongo endofítico por cada planta existente (Tan y Zou, 2001).

En cuanto a la transmisión de bacterias endofíticas, Rosenblueth y Martínez-Romero (2006) describen las interacciones de las bacterias endofíticas con sus hospederos y comentan que la semilla contienen diversidad de endofíticos y que al ser transmitidos por semillas aseguran su presencia en las nuevas plántulas y que, en plantas caracterizadas por su propagación vegetativa (papas y caña de azúcar), pueden transmitir sus endofíticos sin necesidad de requerir un proceso de infección.

Además de la transmisión por la semilla, otro medio de transmisión de bacterias endofíticas es la rizósfera, en donde sobreviven las bacterias en los exudados e intersticios de las raíces primarias y secundarias colonizando desde sustrato en las uniones celulares de las raíces laterales (J. Hallmann et al., 1997), degradando las pareces celulares con la secreción de enzimas celulolíticas y pectinolíticas (K. Germaine et al., 2004).

\subsection{Relaciones ecológicas organismos endofíticos y sus plantas hospederas.}

Las relaciones ecológicas del hospedero y el hongo aún no están muy estudiadas y comprendidas totalmente, pero se presume que la relación endofítico-hospedero vegetal son una relaciones coevolutivas, pudiendo ser simbióticas generalmente pero pueden pasar a patógenas potencialmente (Schulz y Boyle, 2005), según intervengan las condiciones ambientales (Kaul et al., 2012) y estado de desarrollo fisiológico de la planta, en la cual se esté desarrollando esta relación (Aly et al., 2011) ver Figura 2. 
Figura 2. Relaciones ecológicas entre hongos endofiticos y sus hospederos

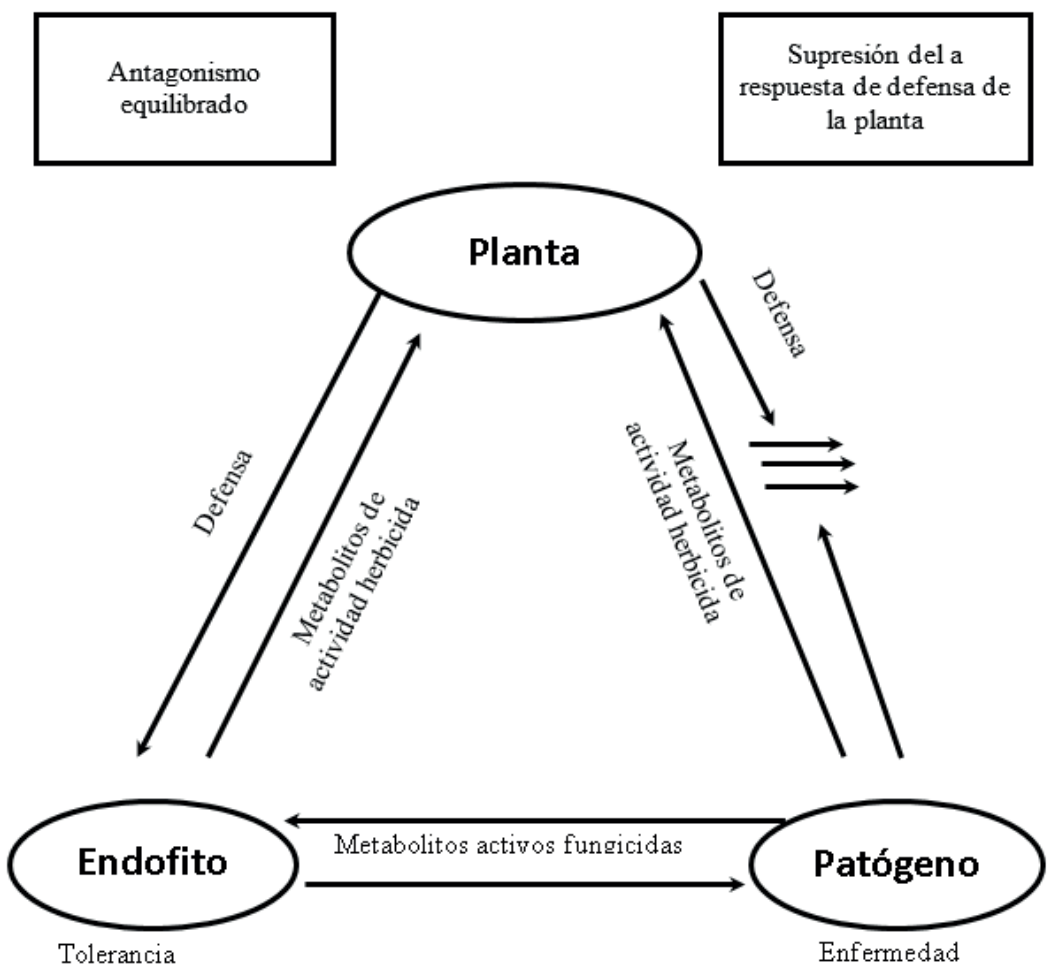

Fuente: Schulz, B., Römmert, A.-K., Dammann, U., Aust, H.-Jür., y Strack, D. (1999).

The endophyte-host interaction: a balanced antagonism? Mycological Research, 103(10), 1275-1283.

El establecimiento de estas relaciones ecológicas entre endofíticos y hospederos es influenciado por diferentes factores como ubicación geográfica, patrones climáticos, tipo de hongo y tipo de planta hospedera, estructura y diversidad de la vegetación circundante, tipo de tejidos colonizados (Huang et al., 2015). Estos factores modelan estas relaciones y condicionan la generación sustancias químicas por parte de estos endofíticos. 
Las relaciones ecológicas endofítico-hospedero se pueden clasificar como simbióticas, incluyendo; mutualismo, comensalismo, neutralismo y parasitismo (Schulz y Boyle, 2005). En este sentido, los endofíticos pueden ser patógenos sobre todo en la senescencia o envejecimiento de sus plantas huéspedes (Park et al., 2015). Entendiendo la relación simbiótica como una interacción continua en el ciclo de vida de los implicados, que manifiesta un rango del mutualismo al parasitismo (Aly et al., 2011).

Se consideran relaciones ecológicas simbióticas, cuando los individuos se benefician mutuamente. El comensalismo ocurre cuando la presencia del hongo no beneficia ni perjudica a su hospedero, lo que puede acontecer durante parte del ciclo de vida de los individuos, no obstante, dependiendo de las condiciones climáticas y el estado de envejecimiento del hospedero esta relación simbiótica puede pasar a una relación perjudicial a la planta como el parasitismo.

En el estado de equilibrio temporal, en el cual el endofítico recibe protección y nutrientes del hospedero vegetal al tiempo que el hospedero se beneficia del endofítico por los compuestos bioactivos o metabolitos secundarios elaborados por el endofítico, causando diferentes efectos en las plantas, que pueden manifestarse en el mejoramiento de eficiencia fotosintética, tolerancia al estrés hídrico o resistencia a sequias, además de la defensa contra patógenos y herbívoros, disminución de la tasa de herbivoría, actividad antinematodos, actividad antibacterianas y anti hongos patógenos (Higgins et al., 2014). Dando como resultado una comunicación química que puede fortalecer la eficiencia biológica (fitness) de los dos individuos(Kaul et al., 2012). Ver Figura 3. 
Figura 3. Relación hongo endofítico - planta hospedera

Relaciones benéficas establecidas entre el hospedero y los hongos endofíticos tales como promotores de crecimiento vegetal y resistencia a factores bióticos (herbivoría) y factores abióticos (sequias).

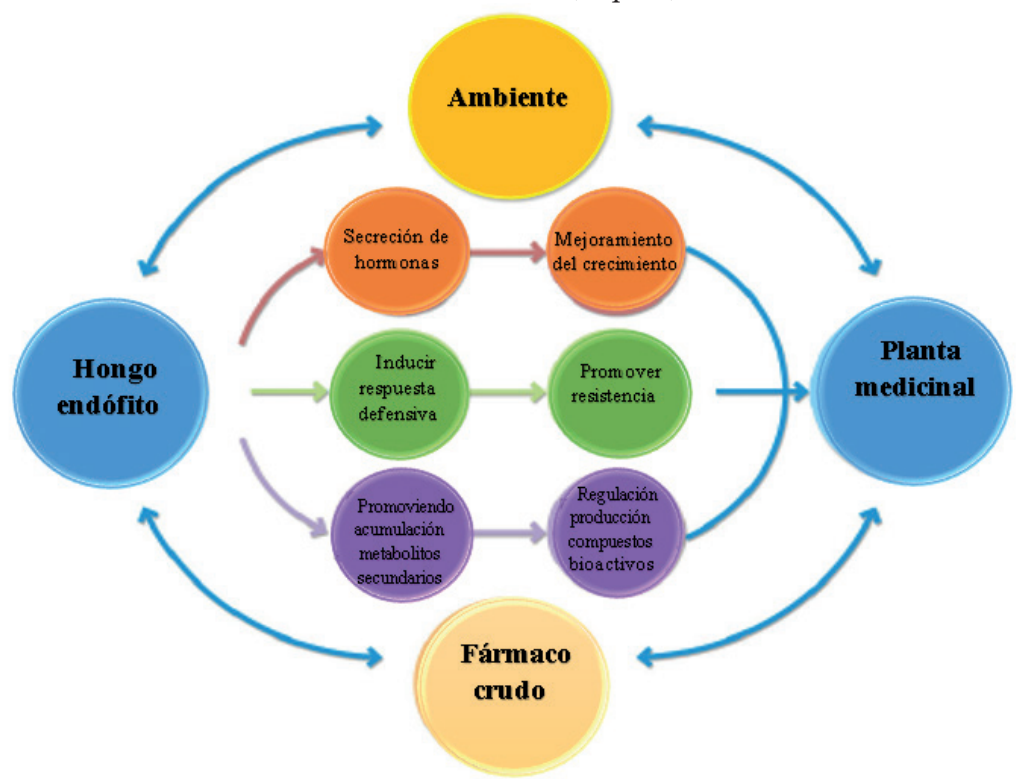

Fuente: Jia et al. (2016). A Friendly Relationship between Endophytic Fungi and Medicinal Plants: A Systematic Review. Frontiers in Microbiology, 7.

La interacción ecológica es un proceso coevolutivo que supone una intensa comunicación química por parte del hospedero y del endofítico que, generalmente, se caracteriza por la habilidad de producir metabolitos secundarios con diversas actividades biológicas y con un potencial utilidad en diferentes áreas de la industria, medicina, agricultura y otras áreas (Huang et al., 2015).

Un aspecto a resaltar es la complejidad de la evaluación de funciones ecológicas hongo-hospedero en laboratorio y a partir de un solo aislamiento del hongo, complicando el estudio de las interacciones de hospedero y endofítico por la dificultad de analizar y comparar cientos de especies de endofíticos que pueden encontrarse para una sola planta huésped (Higgins et al., 2014), Dada la selección de individuos por medio de los medios de cultivo. 
Las sustancias químicas generadas por los endofíticos pueden implicar para su hospedero vegetal una resistencia a factores ecológicos (sequía) y factores biológicos (ataque de herbívoros, enfermedades generadas por bacterias y hongos patógenos $y$ diversos parásitos). Por esta razón, aumenta la eficacia biológica de la planta hospedera y por lo tanto la supervivencia del endofítico.

Resultado de estas interacciones, las moléculas químicas generadas pueden ser descritas y empleadas por la sociedad en diferentes enfoques económicos en la industria alimenticia y nutricional, farmacéutica, agroindustria como factores de crecimiento, biosidas para plagas y parásitos, e incluso biocombustibles entre otros. Estas potencialidades confieren una oportunidad del conocimiento y uso sostenible de la diversidad de microorganismos endofíticos de diferentes especies vegetales con distribución en la eco-región del Eje Cafetero y en toda Colombia.

La diversidad de las comunidades de bacterias y hongos endofíticos apenas ha sido estudiada, pero ha demostrado que estos endofíticos pueden ser responsables de algunas de las sustancias activas identificadas en muchas plantas con utilización real o promisoria en sociedad. Teniendo en cuenta la alta diversidad botánica del país, es necesario aunar esfuerzos en la prospección e investigación de los microorganismos endofíticos asociados a diferentes especies vegetales y la evaluación de la actividad de sus metabolitos en toda clase de aplicaciones.

\subsection{Microorganismos endofíticos como fuente de productos bioactivos.}

En la naturaleza, los microorganismos producen variedad de compuestos que utilizan para su supervivencia, llamados metabolitos, estos son sustancias químicas pequeñas o de bajo peso molecular que, generalmente, son intermediarios o productos finales del metabolismo (Gupta, 2016). Estos han 
demostrado un potencial importante en diferentes ámbitos farmacéuticos e industriales los cuales son actualmente de gran atractivo para los investigadores (Tan y Zou, 2001).

Los metabolitos secundarios se clasifican convenientemente en función de su origen biosintético como terpenoides, policétidos, alcaloides, péptidos no ribosómicos y citocalasinas (Gunatilaka y Wijeratne, 2000). Además de plantas, muchos metabolitos bioactivos se originan a partir de organismos microbianos, los hongos son los principales grupos importantes de organismos eucariotas que tienen gran capacidad para producir numerosos metabolitos con actividad antimicrobiana y poseen potencial aplicación como fármacos (Fouda et al., 2015).

Los endofíticos pueden producir metabolitos bioactivos reportados en las especies vegetales que los hospedan, permitiendo una producción de sustancias químicas producidas en plantas (Stierle y Stierle, 2000; Aly et al., 2010). Además, se reporta en la bibliografía una tendencia relacionada con encontrar bioactivos novedosos o no reportados anteriormente para sus hospederos vegetales y producidos por los hongos que pueden llegar a tener un uso potencial en la medicina, industria y agricultura (SánchezFernández et al., 2013; Daley et al., 2017).

Desde el punto de vista de la biotecnología, y de la forma como se utiliza el conocimiento de los sistemas biológicos para satisfacer la necesidad de generación de bienes y servicios para la sociedad (Kusari et al., 2014), Los microorganismos endofíticos representan un potencial, derivado del hecho que sus metabolitos pueden usarse para para el control de patógenos en la agricultura y utilizarse para la elaboración de sustancias en el mejoramiento de la calidad de vida humana (Suryanarayanan et al., 2009), este hecho puede llegar a fomentar el estudio y conocimiento de la biodiversidad del país, potenciando el desarrollo de la agroindustria local generando un valor agregado (Andrews y Hirano, 1991). 
Laselección delasplantas paraprospección demicroorganismos endofíticos es muy importante, y esta búsqueda se ha centrado en dos enfoques predominantes: en primera medida a las plantas medicinales y en segundo lugar; plantas adaptadas a condiciones climáticas y ambientales extremas (Kaul, et al., 2012). En cada uno de los dos enfoques, puede esperarse que los endofíticos asociados a estas plantas puedan estar relacionados en la respuesta metabólica adaptativa conjunta.

\subsection{Bacterias endofíticas su ecología y potencialidades biotecnológicas}

\subsubsection{Las bacterias}

Las plantas pueden desarrollar asociaciones con miembros de su ecosistema para prosperar en su entorno natural, como por ejemplo con bacterias. Estas bacterias, beneficiosas para las plantas, son de una clase la cual le proporciona numerosos beneficios a sus hospederos, ayudando a tolerar el estrés tanto biótico como abiótico, que pueda afectar su desarrollo (Hallmann et al., 1997). Estas bacterias pueden vivir tanto externa como internamente en la planta. Las bacterias que viven fuera de ella son denominadas epífitas, estas pueden vivir en la superficie de las hojas de las plantas. Otra clase de bacterias que se pueden encontrar en asociación con las planta son las rizosféricas, las cuales habitan en sus raíces (Compant et al., 2010).También se pueden encontrar bacterias que viven y prosperan dentro de su planta hospedera llamadas bacterias endofíticas (Hardoim et al., 2008).

\subsubsection{Bacterias endofíticas}

Las bacterias endofíticas son microorganismos asociados a las plantas que habitan de manera ubicua en la mayoría de las especies sin causar daño aparente al hospedero (Schulz y Boyle, 2006). Se han encontrado en todas las especies de plantas que ha sido estudiadas. Por tanto, una planta libre de endofíticos es una excepción en la naturaleza (Partida-Martínez y Heil, 2011). 
Las bacterias endofíticas pueden considerarse un subconjunto de las bacterias rizosféricas (Marquez-Santacruz et al., 2010). Vivir dentro de los tejidos vegetales les permite a las bacterias endofíticas estar en contacto estrecho con la planta huésped ejerciendo un efecto benéfico directo a cambio de un suministro constante de nutrientes. De hecho, las bacterias endofíticas representan una clase de rizobacterias que han adquirido la capacidad de invadir las raíces de las plantas después establecer una población rizosférica (Compant et al., 2010).

Las plantas producen exudados radiculares para interactuar con las bacterias beneficiosas para su propia ventaja ecológica (Compant et al., 2005). Además, se ha observado que las bacterias endofíticas colonizan el interior de la planta en una secuencia de eventos similar a la colonización de la rizósfera por rizobacterias (Hallmann et al., 1997). Sin embargo, la colonización endofítica implica un conjunto de factores ambientales y genéticos. factores que permiten que una bacteria entre en la endosfera de la planta (Compant et al., 2010).

\subsubsection{Colonización de bacterias endofíticas en las plantas}

Aunque las bacterias endofíticas generalmente ingresan a las plantas a través de la zona de la raíz, las partes aéreas de las plantas, incluidos los tallos, hojas, flores y cotiledones, también se pueden colonizar. Una vez dentro de las raíces, las bacterias endofíticas ahora pueden infectar sistémicamente los tejidos vegetales adyacentes (Zinniel et al., 2002).

No está claro si la colonización bacteriana de los tejidos vegetales superiores confiere efectos beneficiosos similares en las plantas hospederas, como los que se ven con la colonización de raíces. Sin embargo, solo unas pocas bacterias pueden colonizar las partes vegetativas aéreas de sus plantas hospederas debido a los requisitos fisiológicos necesarios para ocupar estos nichos de las plantas (Hallmann, 2001). 
Las bacterias endofíticas colonizan principalmente los tejidos de las hojas desde las raíces de las plantas, pero al igual que las bacterias fitopatógenas, las bacterias endofíticas pueden lograr su entrada en las hojas desde la filosfera a través de los estomas de las hojas (Lacava y Azevedo, 2013). Por lo tanto, las bacterias que migran del suelo a Los tejidos vegetales están bien adaptados a este nicho endofítico particular. El movimiento bacteriano dentro de la planta se da gracias a los flagelos bacterianos y las corrientes de transpiración de la planta (Compant et al., 2005).

\subsubsection{Investigaciones con bacterias endofíticas en plantas}

Las investigaciones han demostraron que esta clase de endofíticos juegan un papel importante en el mejoramiento de la tolerancia de las plantas a metales pesados y aumentan los factores de translocación de metales pesados, biomasa y concentraciones de oligoelementos de plantas híper acumuladoras (Zhang et al., 2010). Este tipo de bacterias tienen la capacidad de promover el crecimiento y desarrollo de las plantas en condiciones adversas mediante diversos mecanismos como la fijación de nitrógeno, la solubilización del fosfato mineral, la producción de ácido indol acético (IAA), sideróforo y 1-aminociclopropano-1-carboxilato (ACC) (Esther et al., 2009).

Algunas clases de bacterias endofíticas como Azoarcus spp, Gluconacetobacter diazotrophicus, Herbaspirillum spp han sido aisladas de caña de azúcar y arroz, en la rizosfera del trigo se han encontrado Streptomyces, Microbiospora y Micromonospora (Sharma P. et al., 2005). Algunas especies, incluidas Azotobacter, Azospirillum, Azoarcus, Herbaspiririllum, Acetobacter, Burkholderia, Klebsiella, Pseudomonas, Enterobacter y Rhizobium, han sido aisladas del tejido vegetal de plantas como caña de azúcar, arroz, maíz, sorgo, palma de aceite y café (Bazzicalupo y Okon, 2000).

La asociación planta-bacteria endofítica ha mostrado potencial para mejorar los procesos de fitorremediación en suelos aumentando la degradación de contaminantes, como 
los herbicidas (Germaine et al., 2006), además se ha observado aumento de la absorción y translocación de metales pesados en plantas, mejorando su capacidad para tolerar los contaminantes en sus tejidos (Doty, 2008). Los mecanismos para la solubilización de minerales por la asociación planta-bacteria endofítica son poco claros, pero se pueden dar por la secreción de ácidos orgánicos de cadena corta de ligandos específicos de elementos que pueden cambiar el pH del sustrato y mejorar la quelación (Vessey, 2003). Como consecuencia, los minerales disueltos fuera de las plantas dan como resultado una mayor movilización de elementos en su interior (Puente et al., 2004).

A continuación, se muestran géneros de bacterias endofíticas aisladas de plantas de interés agropecuario

Tabla 1. Bacterias endofíticas aisladas de plantas de interés agropecuario

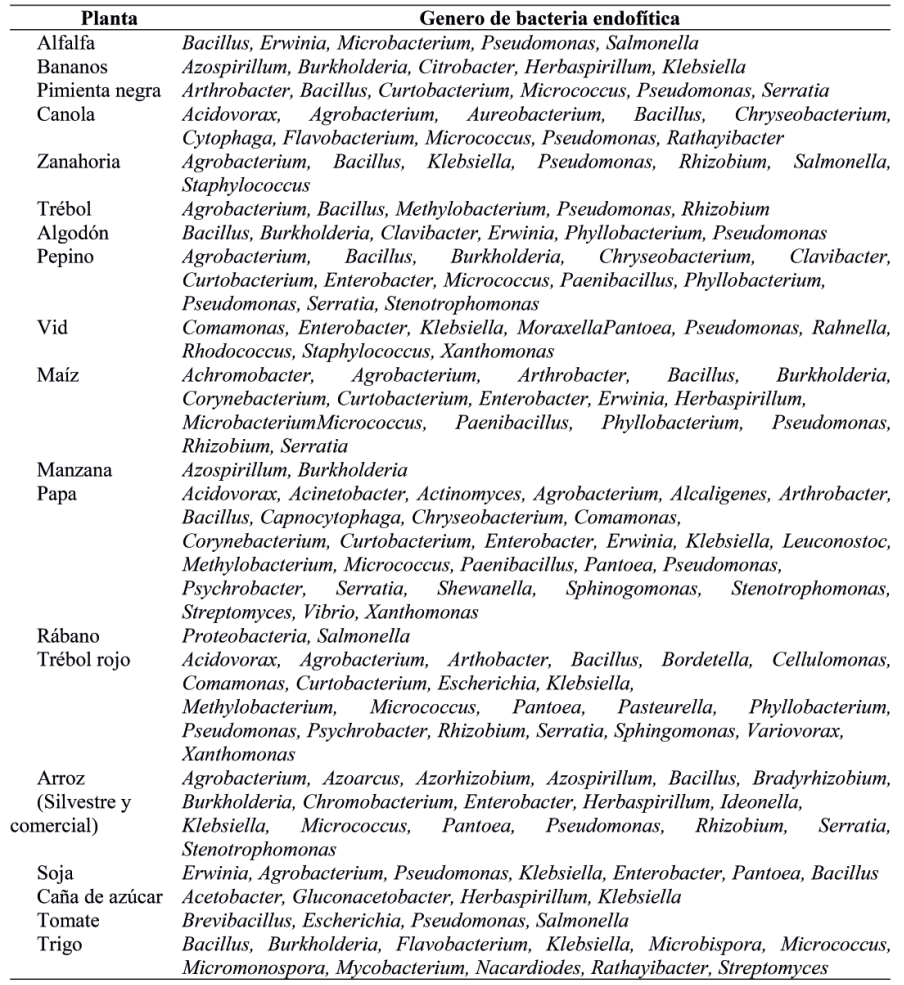

Fuente: Afzal et al. (2019) 


\subsection{Hongos endofíticos su ecología y potencialidades biotecnológicas}

\subsubsection{Los hongos}

Los hongos son organismos eucariota "Eucariota" s, quimiotrofos y heterótrofo "Heterótrofo" s que ingieren su alimento por absorción, con paredes celulares con presencia de polisacárido quitina y algunos celulosa (Lizarazo, 2017), pueden presentarse en las formas de levadura "Levadura", pseudomicelio "Pseudomicelio" o constituidos por hifas y carecen de clorofila (Vinicius, 2012). Constituyen el segundo grupo más grande de especies en la Tierra, sólo superada por los insectos, las estimaciones sugieren que hay aproximadamente 1,5 millones de especies diferentes de hongos (de Medeiros, 2010) y solo han sido descritas entre 80.000 y 120.000 (Webster y Weber, 2007).

Los hongos pueden reproducirse por medio de procesos asexuale "Asexual" s mediante división binaria "División binaria" o formando esporas "Espora" (Prats, 2006), producidas de forma sexual y asexual. Las sexuales tienen núcleo derivado de las células progenitoras, y sus esporas son haploides "Espora haploide"; dos núcleos de las células antecesoras se funden para formar un núcleo diploide (zigoto) y las estructuras que producen las esporas sexuales son, casi siempre, morfológicamente diferenciadas de las esporas asexuales. Por el contrario, las estructuras que producen las esporas asexuales se producen por simple diferenciación en la hifa de crecimiento (Arias y Piñeros, 2008).

Los hongos son clasificados en el reino fungí y se dividen en cinco filos; Chytridiomycota, Zygomycota, Glomeromycota, Ascomycota, Basidiomycota (Ruggiero et al., 2015). Otros autores han clasificado como Deuteromycota $\mathrm{u}$ hongos imperfectos a los hongos que no desarrollan estructuras sexuales o no se conoce su proceso de reproducción sexual. En la actualidad los hongos pertenecientes a esta categoría han sido redistribuidos 
en su mayoría al filo Ascomycota y otros al filo Basidiomycota, basándose en comparaciones de ADN (Solomon et al., 2013).

Son organismos que, debido a sus condiciones relativamente simples de crecimiento, se encuentran en diferentes ecosistemas, como el agua, el suelo, el aire, las plantas y los animales, siempre que haya materia organiza disponible (de Medeiros, 2010). Sin embargo, la mayoría de ellos son terrestres, habitando en el suelo o sobreviviendo en los cuerpos muertos de organismos multicelulares (Khan et al., 2014).

Los hongos también pueden presentar asociaciones mutualistas "Asociaciones mutualistas" s con otros organismos, siendo las más comunes las del tipo micorrizas, "Micorrizas" una asociación entre un hongo y las raíces de una planta, los líquenes "Líquenes", asociación entre un hongo un alga o una cianobacteria "Cianobacteria" o ambas, y endofíticos, asociación de un hongo en al interior de las hojas, raíces y tallos de una planta. (Volk, 2013)

\subsubsection{Hongos endofíticos}

Los hongos endofíticos son definidos funcionalmente como los hongos que se aparecen en los tejidos sanos de la planta sin causar ningún daño aparente o daños manifiestos (Higgins et al., 2014). Estos organismos se han encontrado asociados con casi todas las especies de plantas, y algunos son capaces de migrar internamente dentro de los tejidos de la planta para habitar follaje, tallos y corteza, así como raíces (Behie y Bidochka, 2014).

En la mayoría de los casos, sus funciones ecológicas no han sido estudiadas, en parte debido a la complejidad de la evaluación de los roles de cepas individuales en el contexto de los conjuntos que pueden comprender cientos de especies de endofítico para una sola planta huésped. Sin embargo, trabajos recientes han comenzado a revelar interacciones importantes entre endofíticos tropicales y la planta huésped; incluyendo defensa contra 
patógenos y herbívoros, alteración de la eficiencia fotosintética, y los cambios en el balance osmótico de los hospederos. (Higgins et al., 2014).

\subsubsection{Clasificación de los hongos endofíticos}

Los hongos endofíticos son un grupo polifilético, reportados en su mayoría dentro phylum Ascomicetos, también Basidiomicetos, Zygomicetos y Oomicetos en menor cantidad (SánchezFernández et al., 2013), también se han clasificado los hongos endofíticos de acuerdo a diferencias en la evolución, taxonomía, plantas anfitriones, y sus funciones ecológicas. Rodríguez (2009) clasifica a los hongos endofíticos en dos grupos; los Clavicipitáceos (C) son hongos de la familia clavicipitaceae (Ascomycota) que colonizan gramíneas y los No Clavicipitáceos (NC) que colonizan asintomáticamente diferentes tipos de plantas como plantas no vasculares, helechos, coníferas y angiospermas (Verma, Johri, y Prakash, 2014).

En la Tabla 2, se muestran las clases que puede tener los hongos endofíticos; para los hongos endofíticos clavicipitáceos (C) encontramos únicamente la clase 1, la cual consta de un reducido rango de hospederos, colonizan tallos y rizomas, con transmisión vertical y horizontal, es decir a través de las semillas $\mathrm{y} / \mathrm{o}$ son adquiridos por el hospedero en el ambiente. Por otro lado, los hongos endofíticos no clavicipitáceos (NC) presentan las clases dos, tres y cuatro; En el cual todos presentan un rango de hospederos extenso; es decir, pueden colonizar diferentes tipos de plantas, se destaca la clase 4 que colonizan las raíces y tejidos no aéreos del hospedero y clase 3 que colonizan estructuras aéreas, y la clase 2 que puede colonizar rizomas y tejidos aéreos en el hospedero. 
Tabla 2. Clases de hongos endofíticos según las clases de clavicipitáceos

\begin{tabular}{|c|c|c|c|c|}
\hline \multicolumn{2}{|r|}{ Clavicipitáceos } & \multicolumn{2}{|c|}{ No Clavicipitáceos } & \multirow[b]{2}{*}{ Clase 4} \\
\hline Criterio & Clase 1 & Clase 2 & Clase 3 & \\
\hline $\begin{array}{l}\text { Rango del } \\
\text { hospedero }\end{array}$ & Reducido & Extenso & Extenso & Extenso \\
\hline $\begin{array}{l}\text { Tejidos que } \\
\text { colonizan }\end{array}$ & Tallo y rizomas & $\begin{array}{l}\text { Tallos, hojas y } \\
\text { rizomas }\end{array}$ & $\begin{array}{l}\text { Tallos, hojas } \\
\text { corteza flores, } \\
\text { frutos }\end{array}$ & Raíces \\
\hline $\begin{array}{l}\text { Colonización en } \\
\text { planta }\end{array}$ & Extensiva & Extensiva & Limitada & Extensiva \\
\hline $\begin{array}{l}\text { Biodiversidad en } \\
\text { planta }\end{array}$ & Baja & Baja & Alta & Desconocida \\
\hline Transmisión" & $\begin{array}{c}\text { Vertical y } \\
\text { horizontal }\end{array}$ & $\begin{array}{c}\text { Vertical y } \\
\text { horizontal }\end{array}$ & Horizontal & Horizontal \\
\hline $\begin{array}{l}\text { Función } \\
\text { ecológica }\end{array}$ & $\begin{array}{l}\text { Incrementa la } \\
\text { biomasa de la } \\
\text { planta, confieren } \\
\text { tolerancia a la } \\
\text { sequía y producen } \\
\text { metabolitos } \\
\text { secundario tóxicos } \\
\text { para los herbívoros }\end{array}$ & $\begin{array}{l}\text { Incrementa la } \\
\text { biomasa de la } \\
\text { planta, confieren } \\
\text { tolerancia al } \\
\text { estrés biótico y } \\
\text { abiótico y } \\
\text { protegen contra } \\
\text { los hongos } \\
\text { patógenos por } \\
\text { acción de los } \\
\text { metabolitos } \\
\text { secundarios }\end{array}$ & $\begin{array}{c}\text { Inducen } \\
\text { resistencia a las } \\
\text { enfermedades, } \\
\text { protección contra } \\
\text { los herbívoros y } \\
\text { modifican la } \\
\text { sensibilidad al } \\
\text { estrés abiótico } \\
\text { mediante la } \\
\text { producción de los } \\
\text { metabolitos } \\
\text { secundarios }\end{array}$ & $\begin{array}{c}\text { Inhiben el } \\
\text { crecimiento de } \\
\text { patógenos y } \\
\text { producen } \\
\text { metabolitos } \\
\text { secundarios } \\
\text { tóxicos para los } \\
\text { herbívoros }\end{array}$ \\
\hline
\end{tabular}

*Transmisión de hongos endofíticos en las plantas: vertical, a través de las semillas, y horizontal, se adquieren del medio ambiente.

Fuente: Sánchez-Fernández, R. E., Sánchez-Ortiz, B. L., SandovalEspinosa, Y. K. M., Ulloa-Benítez, Á., ArmendárizGuillén, B., García-Méndez, M. C., y Macías-Rubalcava, M. L. (2013:134). Hongos endofíticos: Fuente potencial de metabolitos secundarios bioactivos con utilidad en agricultura y medicina. TIP. Revista especializada en ciencias químico-biológicas, 16(2), 132-146.

\subsubsection{Investigaciones con hongos endofíticos en diferentes tipos de plantas}

En la Tabla 3, se muestra en cronológico los hallazgos relacionados con actividades biológicas, productos naturales y usos potenciales de diferentes estudios relacionados con hongos endofíticos. 
Tabla 3. Antecedentes de investigaciones con hongos endofiticos de diferentes tipos de planta

\begin{tabular}{|c|c|c|c|}
\hline Especie vegetal & Endofíticos & $\begin{array}{l}\text { Act. Biológica / } \\
\text { característica }\end{array}$ & Referencia \\
\hline $\begin{array}{l}\text { Artemisa annula } \\
\text { (Asteraceae) }\end{array}$ & Colletotrichum sp. & Antimicrobiana & Lu et al., 2000 \\
\hline$n / a$ & Penicillum sp. & Anticáncer & Stierle y Stierle, 2000 \\
\hline$n / a$ & Paecilomyces sp. & Antitumoral & Huang et al., 2001 \\
\hline $\begin{array}{l}\text { Eucryphia cordifolia } \\
\text { (Cunoniaceae) }\end{array}$ & Gliocladium sp. & Antibióticos & Stinson et al., 2003 \\
\hline $\begin{array}{l}\text { Papa, yuca, maíz y } \\
\text { caña de azúcar }\end{array}$ & $n / a$ & $\begin{array}{l}\text { Incremento de sustancias } \\
\text { nitrogenadas }\end{array}$ & Dibut et al., 2004 \\
\hline Cynodon dactylon & Aspergillus fumigatus & $\begin{array}{l}\text { Actividades relacionadas } \\
\text { con el ergosterol y ácido } \\
\text { helvólico }\end{array}$ & Liu et al., 2004 \\
\hline$n / a$ & $\begin{array}{l}\text { Trichoderma sp., Phoma, } \\
\text { Alternaria, Acremonium } \\
\text { sp. y Stachybotrys sp. }\end{array}$ & Diferentes actividades & Bérdy, 2005 \\
\hline $\begin{array}{l}\text { Urospermum } \\
\text { picroides }\end{array}$ & $n / a$ & Actividad citotóxica & Aly et al., 2008 \\
\hline $\begin{array}{l}\text { Ixeris repens } \\
\text { (Asteraceae) }\end{array}$ & Penicillum citrinum & $\begin{array}{l}\text { Factores de crecimiento } \\
\text { vegetal - giberelinas }\end{array}$ & Khan et al., 2008 \\
\hline $\begin{array}{l}\text { Fagonia cretica } \\
\text { (Zygophyllaceae) }\end{array}$ & Microdochium bolleyi & $\begin{array}{l}\text { Isocumarinas con } \\
\text { actividades antifúngicas }\end{array}$ & Zhang et al., 2008 \\
\hline $\begin{array}{l}\text { Mentha pelegium } \\
\text { (Lamiaceae) }\end{array}$ & $\begin{array}{l}\text { Stemphylium } \\
\text { globuliferum }\end{array}$ & $\begin{array}{l}\text { Actividad citotóxica } \\
\text { compuesto activo } \\
\text { altersolanol }\end{array}$ & Debbab et al., 2009 \\
\hline $\begin{array}{l}\text { Juniperus communis } \\
\text { (Cupressaceae) } \\
\text { Enebro }\end{array}$ & Aspergillus fumigatus & Anticáncer & Kusari et al., 2009 \\
\hline $\begin{array}{l}\text { Ginkgo biloba } \\
\text { (Ginkgoaceae) }\end{array}$ & Chaetomium globosum & $\begin{array}{l}\text { Antifüngicas contra } \\
\text { Mucor miehei }\end{array}$ & Qin et al., 2009 \\
\hline$n / a$ & $\begin{array}{l}\text { Beauveria sp. y } \\
\text { Lecanicillium } \mathrm{sp} .\end{array}$ & $\begin{array}{l}\text { Antagonismo } \\
\text { Bioinsecticida }\end{array}$ & Ownley et al., 2010) \\
\hline$n / a$ & Trichoderma viride & Antitumoral & Ahmed et al., 2010 \\
\hline $\begin{array}{l}\text { Plantas de bosques } \\
\text { tropicales }\end{array}$ & $n / a$ & Antimalárica & Rosa et al., 2010 \\
\hline$n / a$ & Phomopsis sp. & $\begin{array}{l}\text { Antimaláricos, } \\
\text { Antituberculosis, } \\
\text { Nematicidas, } \\
\text { Antifúngicos, } \\
\text { Antibacterianos, } \\
\text { Antiinflamatórios }\end{array}$ & Kaul et al., 2012 \\
\hline $\begin{array}{l}\text { Actinidia } \\
\text { macrosperma } \\
\text { (Actinidiaceae) }\end{array}$ & $n / a$ & $\begin{array}{l}\text { Citotóxicos y } \\
\text { antitumorales }\end{array}$ & Lu et al., 2012 \\
\hline
\end{tabular}

${ }^{*} n / a=$ Sin información.

\subsubsection{Hongos endofíticos como fuente de productos bioactivos.}

En la naturaleza, los microorganismos producen variedad de compuestos que utilizan para su supervivencia, llamados metabolitos, estos son sustancias químicas pequeñas o de bajo peso molecular que generalmente son intermediarios o productos finales del metabolismo (Gupta, 2016). Estos, han demostrado 
un potencial importante en diferentes ámbitos farmacéuticos e industriales los cuales son actualmente de gran atractivo para los investigadores (Tan y Zou, 2001).

Los metabolitos secundarios se clasifican convenientemente en función de su origen biosintético como terpenoides, policétidos, alcaloides, péptidos no ribosómicos y citocalasinas (Gunatilaka y Wijeratne, 2000). Además de plantas, muchos metabolitos bioactivos se originan a partir de organismos microbianos, los hongos son los principales grupos importantes de organismos eucariotas que tienen gran capacidad para producir numerosos metabolitos con actividad antimicrobiana y poseen potencial aplicación como fármacos (Fouda et al., 2015).

Los endofíticos pueden producir metabolitos bioactivos reportados en las especies vegetales que los hospedan, permitiendo una producción de sustancias químicas producidas en plantas (Stierle y Stierle, 2000; Aly et al., 2010). Además se reporta en la bibliografía una tendencia relacionada con encontrar bioactivos novedosos o no reportados anteriormente para sus hospederos vegetales y producidos por los hongos que pueden llegar a tener un uso potencial en la medicina, industria y agricultura ( Sánchez-Fernández et al., 2013; Daley et al., 2017).

El potencial de los hongos endofíticos en la producción de compuestos bioactivos hace importante la obtención y aislamiento diferenciándolos de los organismos epifitos que también se encuentran al tiempo en la superficie de los hospederos vegetales (Silva-Hughes et al., 2015), lo que conlleva a formular tratamientos de esterilización de las zonas externas de los tejidos vegetales y posteriormente cultivando selectivamente los endofíticos en medios nutritivos para su caracterización (Pinheiro et al., 2017).

A partir de este paso es posible aplicar en laboratorio diferentes tipos de cultivo para generar en estos hongos la expresión de metabolitos secundarios, generalmente en cultivos en fase liquida o sólida y poder obtener extractos para conocer 
su potencial químico (Arora et al., 2016; Bhattacharya et al., 2018; Pinheiro et al., 2017). Procesos como la esterilización de superficie, cultivo y aislamientos de los hongos endofíticos y generación de extracciones químicas son los temas de acción de este trabajo de grado.

\subsubsection{Enfoques de estudio de metabolitos secundarios de hongos endofíticos}

En los últimos años, se han destacado entre otras, dos líneas de investigación muy interesantes a partir del conocimiento de los M. S producidos por hongos endofíticos; Búsqueda de metabolitos identificados y producidos por plantas y búsqueda de metabolitos novedosos no reportados. La primera línea, se fundamenta en búsqueda de hongos endofíticos con metabolitos que también producen especies vegetales, especialmente sus plantas hospederas. Y, por otro lado, una segunda línea de investigación donde se estudian metabolitos novedosos o no identificados en plantas $u$ otros organismos.

En la primera, se han identificado y reportando productos naturales que antes eran obtenidos de plantas, lo que viene siendo analizado como fuentes alternativas de esas sustancias químicas, lo que podría generar ventajas en la producción y el costo de estos metabolitos a partir de microorganismos (Aly et al., 2010), Sin embargo la producción sostenible de productos naturales vegetales por parte de endofíticos aún no se ha optimizado (Kusari, Pandey, y Spiteller, 2013).

Un hallazgo representativo en el uso de bioactivos de hongos endofíticos tiene que ver con la producción de Paclitaxel o taxol (Stierle., 1993), el cual es un agente anticancerígeno utilizado para el tratamiento del cáncer de cuello uterino (Stierle, 2000). Sustancia que ya se obtenía a partir del árbol Taxus baccata, lo que en su momento hacia costoso y limitada la producción de este compuesto. En la segunda línea, los hongos endofíticos son prospectados como fuente de metabolitos secundarios novedosos, 
que no coinciden con los bioactivos reportados en sus hospederos vegetales (Souvik Kusari et al., 2014; Panaccione et al., 2014; Sánchez-Fernández et al., 2013).

\subsubsection{Hongos endofíticos y su importancia en la industria}

La biosíntesis por microorganismos es muy importante para la industria, aportando metabolitos primarios y secundarios, (Demain, 2000), los hongos endofíticos son de importante uso en la agronomía y en la medicina y también tomados como modelos para estudiar aspectos teóricos de la relación planta microorganismo (Gamboa-Gaitán, 2006).

La utilización de los hongos en la industria es histórica, pero, a partir de 1940, con el hallazgo de Alexander Fleming de la penicilina como antibiótico generado a partir del Penicillum notatum, se dio la posibilidad de utilizar productos naturales o metabolitos secundarios de microorganismos y plantas para mejorar la calidad de vida de las personas. En la actualidad la búsqueda continua, y es como los hongos endofíticos pueden ser una fuente promisoria y poco explorada de productos naturales con muchas formas químicas (Aly et al., 2010).

Supliendo nuevas fuentes de fármacos, especialmente para tratar varias problemáticas de la humanidad como el cáncer, desordenes neuronales, infecciones, enfermedades cardiovasculares, metabólicas e inmunológicas, desordenes genéticos (Suryanarayanan et al., 2000), de igual manera se ha relacionado con la industria de los alimentos, cosméticos y agroinsumos (Sánchez-Fernández et al., 2013).

A diferencia de los metabolitos primarios, los metabolitos secundarios no están directamente relacionados en procesos esenciales para el organismo o célula, pero tienen funciones ecológicas y generalmente. En la naturaleza los microrganismos producen M. S con diferentes funciones: hormonas sexuales, ionóforos o transportadores de iones, armas competitivas para otras bacterias, hongos, protistas, insectos y plantas, agentes 
simbióticos, y efectores de diferenciación. (Demain, 2000). Y en el caso de los y la industria, los aminoácidos, nucleótidos, vitaminas, solventes, y ácidos orgánicos (Demain, 2000) son los más demandados.

Los producidos por microorganismos, que a menudo son denominados como productos naturales y son utilizados para requerimientos secundarios como defensa a otros microorganismos, mejoramiento de la supervivencia en la competencia con otras especies y facilitar los procesos reproductivos, son utilizados en la microbiología industrial para la producción de alimentos, aminoácidos y antibióticos (Gupta, 2016).

La actividad biológica de los M. S, han sido estudiada por diferentes autores en busca de resultados que permitan el tratamiento de enfermedades crónicas como el cáncer, diabetes (Singh et al, 2014), antinflamatorios (Firáková et al., 2007), antioxidantes (Huang et al., 2007), además de antibióticos, toxinas, pesticidas, factores de crecimiento de plantas y animales (Demain, 2000).

La importancia económica de los radica en que pueden llegar a exhibir actividades biológicas de diferente índole y con potencial en diferentes áreas de la industria; tales como agroquímicos, alimentos, y farmacéuticos, en el caso de los hongos, estas sustancias son generadas a partir de los procesos del metabolismo primario, que en sus productos finales o intermediarios, ser modificados al reaccionar con diferentes enzimas dando como resultado un variado número de sustancias con estructuras químicas diversas (Gunatilaka y Wijeratne, 2000). 


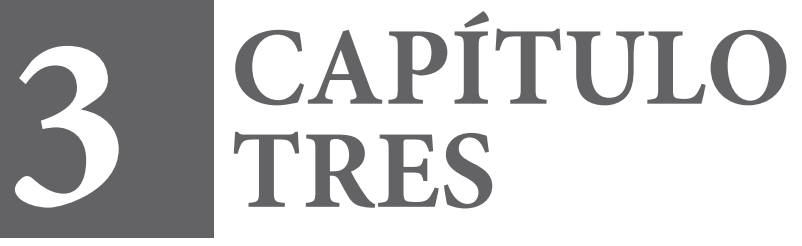




\section{Proceso metodológico}

El acercamiento a las tendencias en investigación y desarrollo con respecto a microorganismos endofíticos, se llevó a cabo utilizando la vigilancia tecnológica, la cual se define como un proceso sistemático en el que se capta, analiza y difunde información de diversa índole -económica, tecnológica, política, social, cultural, legislativa-, mediante métodos legales, con el ánimo de identificar y anticipar oportunidades o riesgos, para mejorar la formulación y ejecución de la estrategia de las organizaciones (Sánchez y Palop, 2002).

Para el desarrollo del presente ejercicio se tuvieron en cuenta las fases contempladas en la ruta metodológica (Figura 4) para ejercicios de vigilancia tecnológica e inteligencia competitiva, descritas en las cuatro fases que integran el proceso son: identificación y planeación, búsqueda y captación de la información, organización, depuración y análisis de la información y, por último, la fase de la socialización de resultados como se describe en la figura 4. 
Figura 4. Ruta metodológica para el desarrollo del ejercicio de vigilancia tecnología e inteligencia competitiva

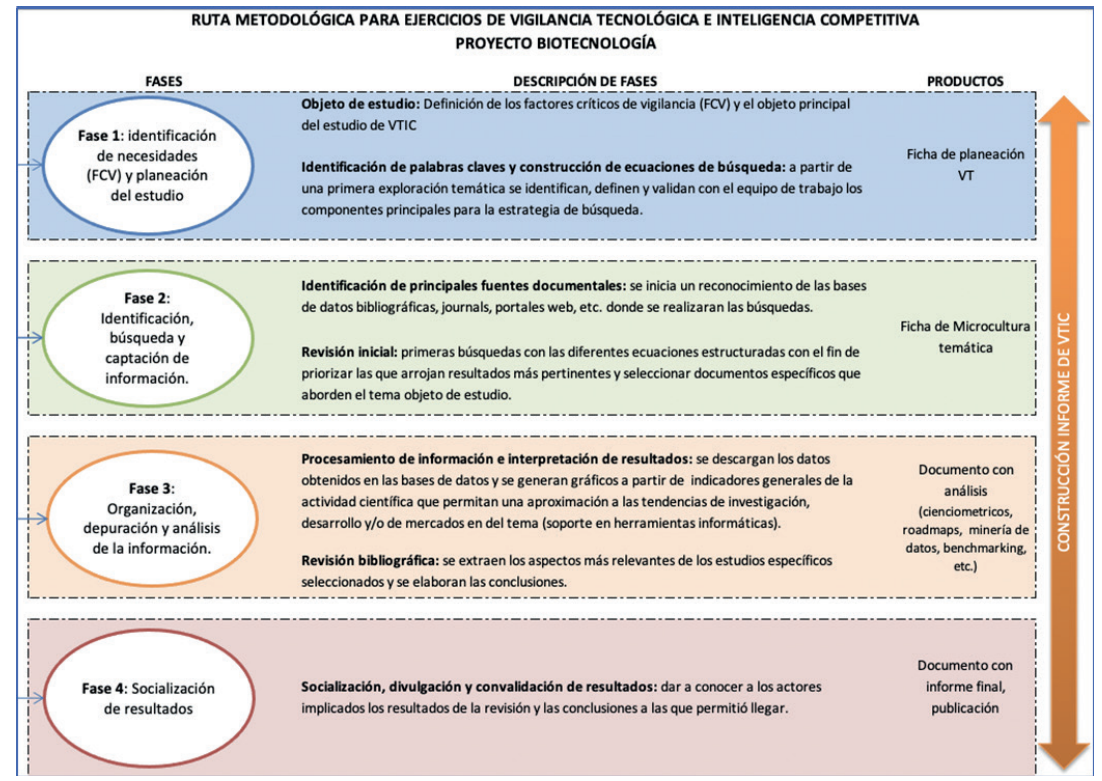

Fuente: Elaboración propia. 


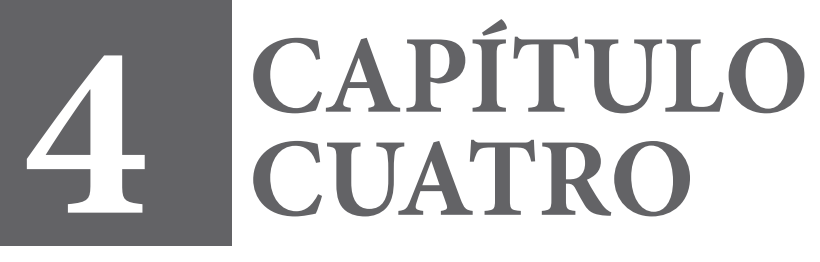




\section{Análisis de tendencias internacionales en microorganismos endofíticos}

4.1 Análisis de tendencias a partir de la producción científica en microorganismos endofíticos

Para la revisión bibliográfica y el análisis de tendencias "Análisis de tendencias" se tomó como punto de partida la información consignada en la ficha de planeación del ejercicio en la Figura 5. Una vez validadas las ecuaciones de búsqueda con los investigadores del grupo GB-PN, se consultaron bases de datos de publicaciones científicas y de patentes, tales como: Science Direct, Web of Science, Scopus, Patentscope, Espacenet, entre otras. Teniendo en cuenta los resultados obtenidos, se priorizó la base de datos Scopus (Elsevier, B.V. 2015), con la cual se obtuvieron la mayor cantidad de resultados, lo que permitió a partir de datos cienciométricos "Datos cienciométricos", conocer la actividad científica del tema central de estudio, en el periodo comprendido entre 1970 y 2015. 
Figura 5.Ficha de planeación de ejercicios de Vigilancia Tecnológica para microorganismos endofíticos

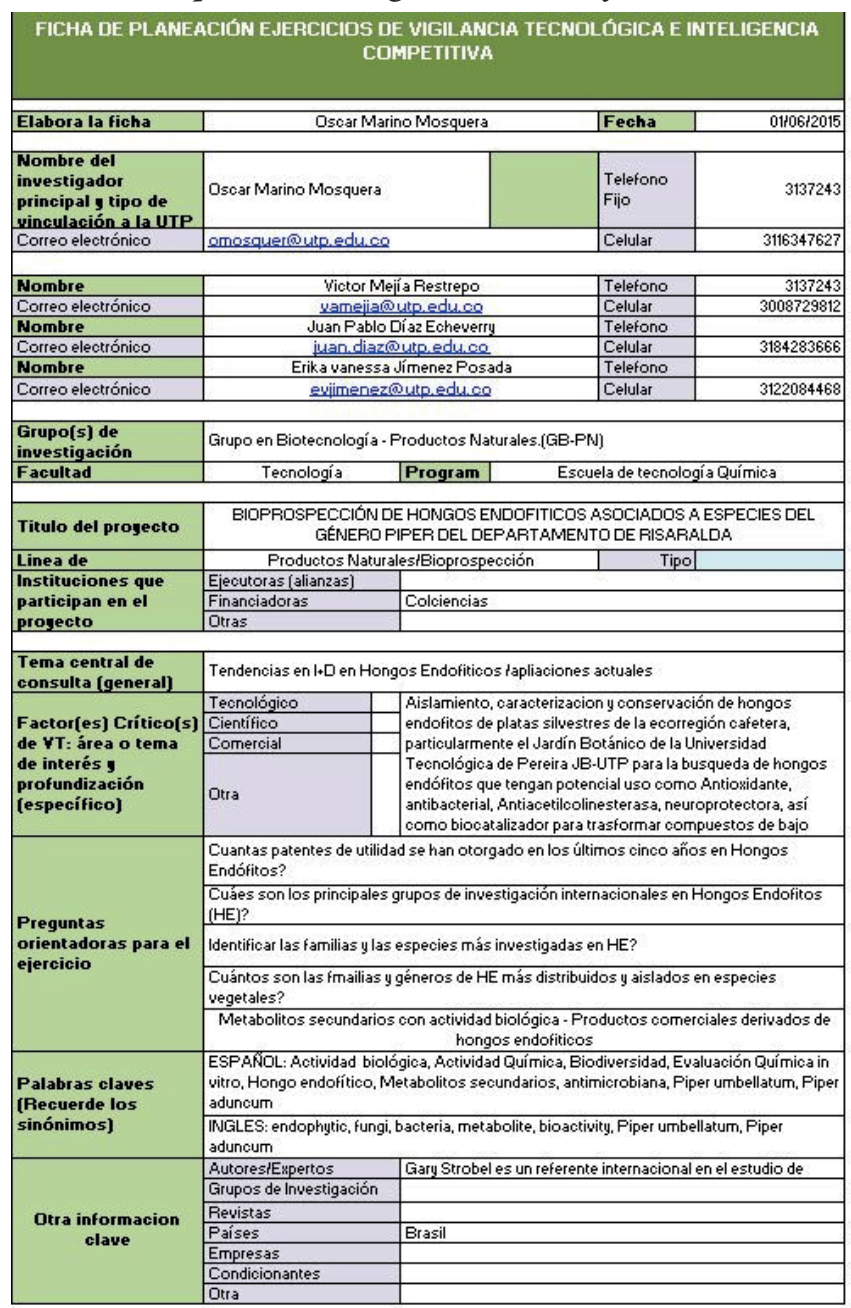

Fuente: Elaboración propia.

El análisis se complementó con información obtenida en bases de datos (BD) que cuentan con licencia vigente por parte de la UTP, tales como: BCC Research y Goldfire Innovator. En el caso de BCC Research, esta BD permite acceder a estudios de mercados especializados relacionados con el área de la biotecnología, y en lo que respecta al Goldfire Innovator, facilita la consulta a la Web profunda y el acceso a documentos completos de patentes. 
La estrategia de búsqueda se estructuró a partir de tres (3) ecuaciones de búsqueda, utilizando operados Booleanos con el objetivo de abordar tres aspectos fundamentales:

- Dinámica de publicaciones "Dinámica de publicaciones" y análisis de organismos endofíticos

- Dinámica de publicaciones y análisis de tendencias "Análisis de tendencias" en hongos endofíticos

- Dinámica de publicaciones y análisis de tendencias en bacterias endofíticas

Para realizar el análisis de las tendencias en $\mathrm{I}+\mathrm{D}$ relacionadas con microorganismos endofíticos, se realizó la búsqueda utilizando la ecuación TITLE-ABS-KEY (endophytic). A continuación, se presentan los principales resultados obtenidos.

\subsubsection{Dinámica de publicaciones en el tema de microorganismos endofíticos para el periodo $1970-2015$}

En la consulta realizada en la base de datos Scopus (Elsevier, B.V. 2015) utilizando la ecuación de búsqueda TITLE-ABS-KEY (endophytic) se obtuvo como resultado un total de 7062 artículos en el periodo comprendido entre 1970 y 2015.

Como se observa en la Figura 6, a partir del año 2000 se presenta un incremento significativo en las publicaciones relacionadas con este tema, con un porcentaje de crecimiento anual en los últimos 5 años de aproximadamente del $\mathbf{2 0 \%}$. Esta dinámica de crecimiento de las publicaciones puede ser relacionada, en parte por el avance en las investigaciones de compuestos activos derivados de organismos endofíticos, específicamente con aplicación en el tratamiento de enfermedades y de la obtención de productos comerciales como es el caso del Taxol "Taxol" para el tratamiento del cáncer; así como el incremento en el número de grupos de investigación trabajando en el tema. 
Figura 6. Número de publicaciones relacionadas con el tema de organismos Endofíticos por año

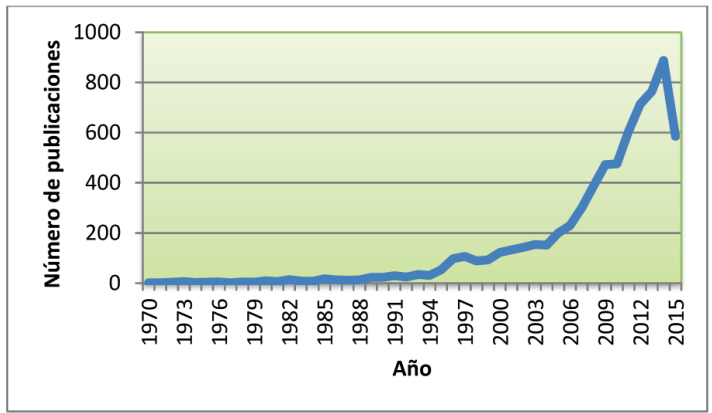

Fuente: Elaboración propia de acuerdo con la base de datos de Scopus (Elsevier, B.V. 2015).

\subsubsection{Países líderes - microorganismos endofíticos}

Como se observa en la Figura 7, China lidera las publicaciones, participando con el 23,61\%; seguido de los Estados Unidos con el $16,83 \%$. Otros países que se destacan son India (9,75\%), Alemania (8,43\%) y Brasil (7,49\%), con más de 500 publicaciones cada uno.

Figura 7.Distribución del número de publicaciones por país relacionadas con el tema de organismos endofíticos

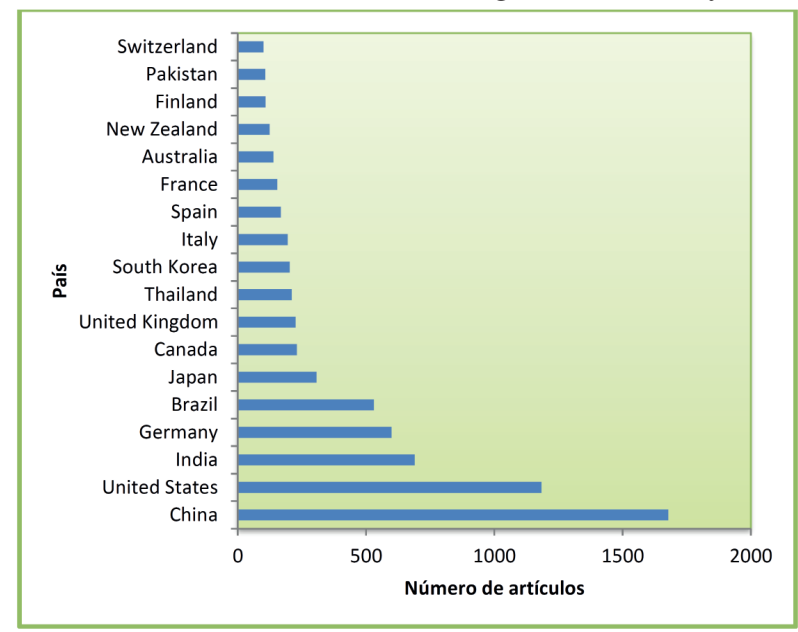

Fuente: Elaboración propia de acuerdo con la base de datos de Scopus (Elsevier, B.V. 2015). 
En lo que respecta a la región de América Latina y el Caribe, puede apreciarse en la Figura 8, que participa con 888 publicaciones distribuidas en 15 países, lo que representa un 12,57 \% del total de publicaciones a nivel internacional. Brasil es el país líder con 531 publicaciones (60\%), seguido de Argentina con 97 publicaciones (11\%) y México con 88 publicaciones (10\%).

Figura 8. Distribución del número de publicaciones por país de América Latina y el Caribe relacionadas con el tema organismos Endofiticos.

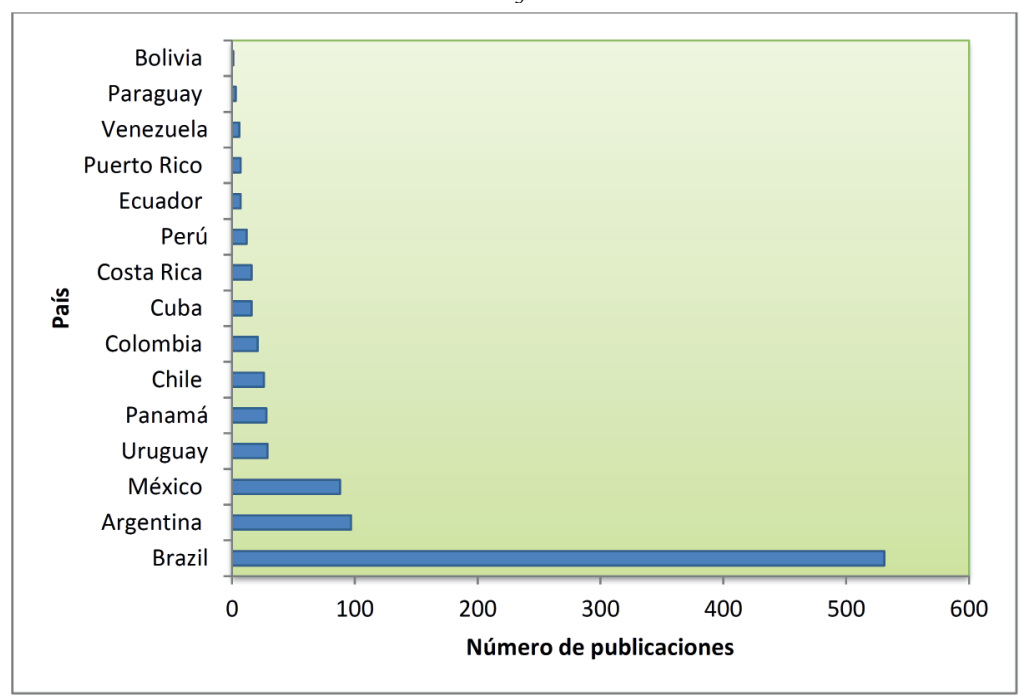

Fuente: Elaboración propia de acuerdo con la base de datos de Scopus (Elsevier, B.V. 2015).

\subsubsection{Instituciones líderes - microorganismos endofíticos}

En Figura 9, se puede apreciar que de las primeras 10 Instituciones líderes a nivel mundial en el tema de endofíticos seis de ellas son chinas; dos brasileras, una estadounidense y una alemana. Las dos Universidades líderes son la Sun Yat-Sen University, con 160 publicaciones y la Universidad de Sao Paulo con 149 publicaciones. 
Al comparar datos en relación con las publicaciones de estas dos Instituciones líderes, como se muestra en la Tabla 4, se observa que la Universidad de Yat-Sen presenta un alto porcentaje de las publicaciones relacionadas con endofíticos hacia el área de la Química y las Ciencias Agrícolas (76\%), mientras que la Universidad de Sao Paulo se enfoca en áreas como la Bioquímica, Genética y Biología Molecular e Inmunología y Microbiología (78\%).

Figura 9. Número de publicaciones por institución relacionadas con el tema Microorganismos Endofíticos.

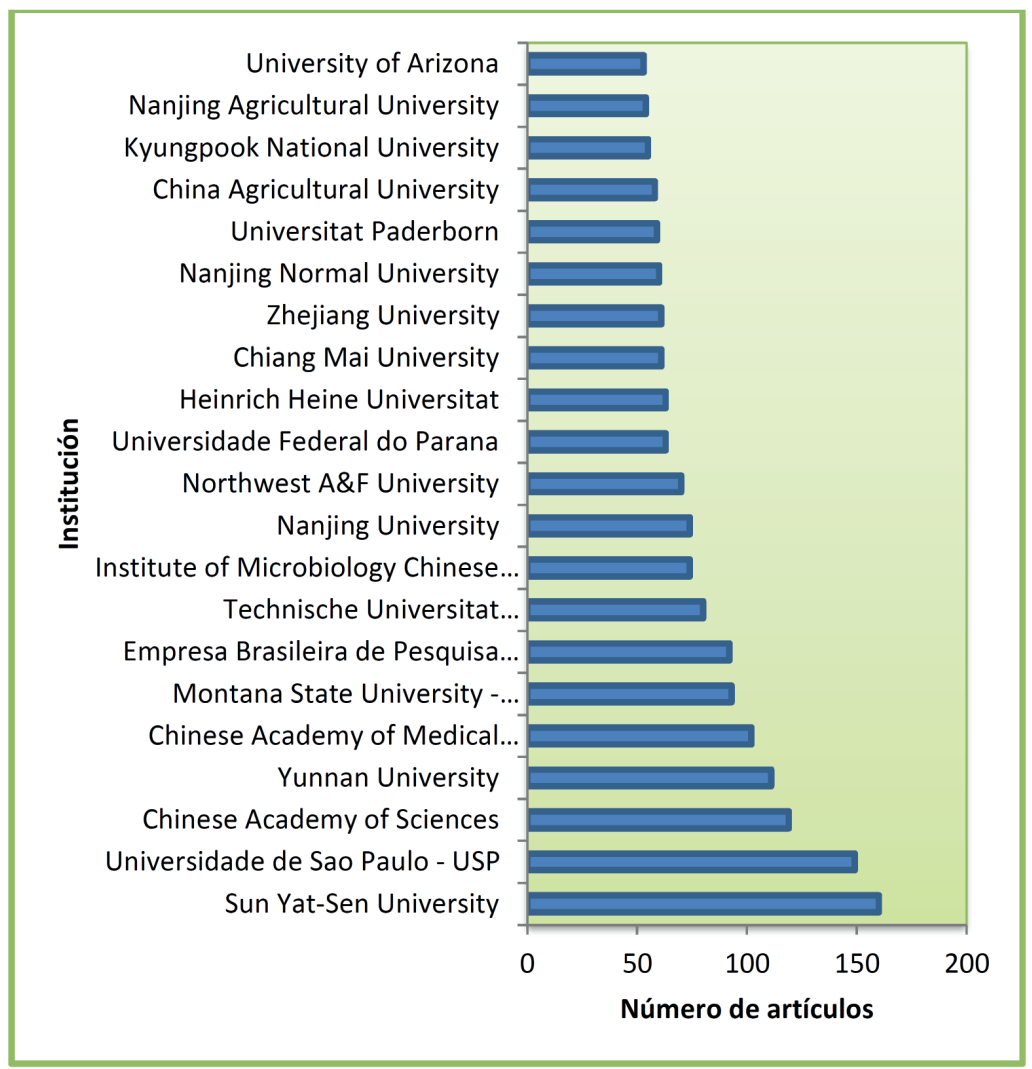

Fuente: Elaboración propia de acuerdo con la base de datos de Scopus (Elsevier, B.V. 2015). 
A continuación, se resume información respecto a las Instituciones líderes antes mencionados. Se resalta el número total de publicaciones, el número de documentos relacionados con la ecuación de búsqueda, los países con los que más colabora y las principales áreas temáticas ver Tabla 4.

Tabla 4. Información de las principales Instituciones que publican temas relacionados con organismos Endofíticos

\begin{tabular}{|c|c|c|c|}
\hline Institución & $\begin{array}{c}\text { Total de } \\
\text { publicaciones }\end{array}$ & $\begin{array}{l}\text { Número de } \\
\text { publicaciones } \\
\text { en endofíticos }\end{array}$ & $\begin{array}{l}\text { Países con las que más } \\
\text { colabora en publicaciones } \\
\text { relacionadas con } \\
\text { endofíticos }\end{array}$ \\
\hline $\begin{array}{l}\text { Sun Yat-Sen } \\
\text { University }\end{array}$ & 50.636 & 160 & $\begin{array}{l}\text { - } \quad \text { Hong Kong } \\
\text { - } \quad \text { Reino Unido } \\
\text { - } \quad \text { Arabia Saudita } \\
\text { - Estados Unidos }\end{array}$ \\
\hline $\begin{array}{r}\text { Universidad } \\
\text { de Sao Paulo }\end{array}$ & 152.829 & 149 & $\begin{array}{l}\text { - Estados Unidos } \\
\text { - España } \\
\text { - Holanda }\end{array}$ \\
\hline
\end{tabular}




\section{Áreas del conocimiento en las que más publica}
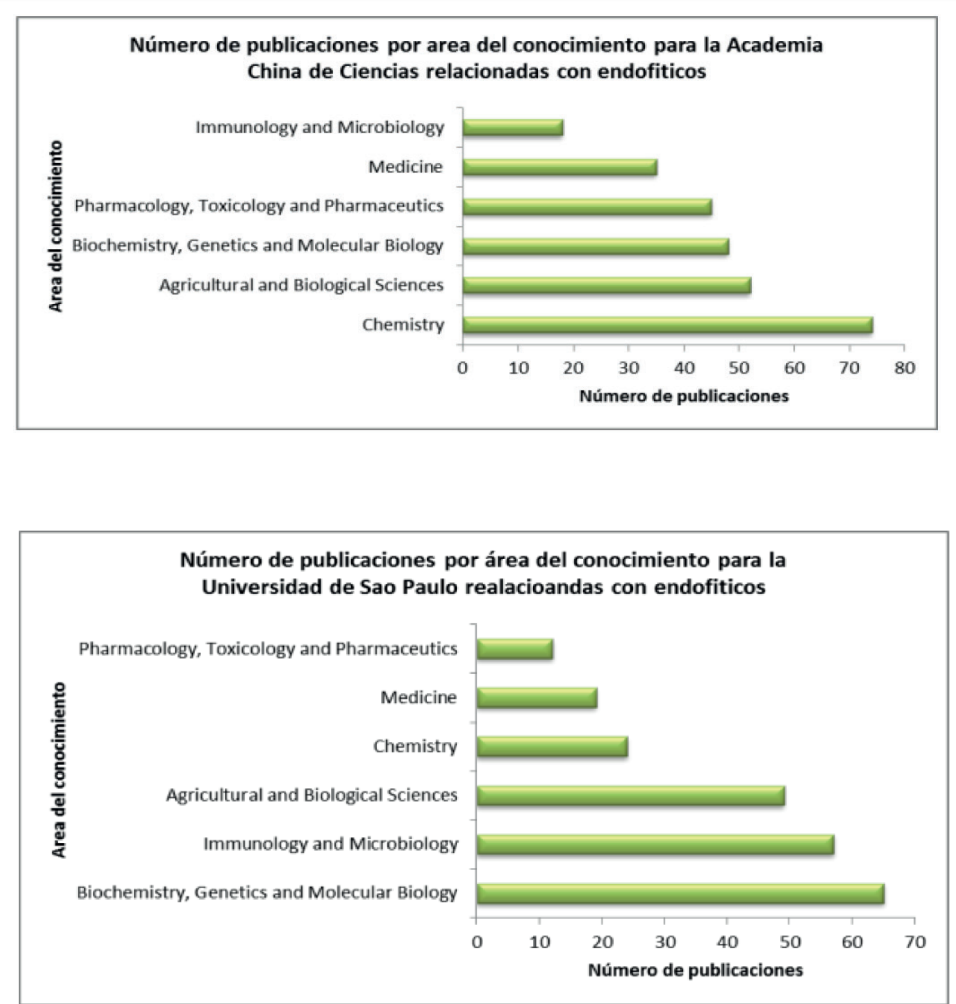

Fuente: Elaboración propia de acuerdo con la base de datos de Scopus (Elsevier, B.V. 2015). 


\subsubsection{Autores líderes - microorganismos endofíticos}

En Figura 10, se encuentran los autores destacados por el número de publicaciones relacionadas con endofíticos, sobresale Yongcheng Lin y Zhigang She de la Universidad de Sun Yat-Sen; los estudios de estos dos autores relacionados a la documentación, búsqueda y evaluación actividad anticancerígena de metabolitos secundarios de hongos endofíticos asociados al ecosistema de manglar.

En tercer lugar, del ranking de las publicaciones se encuentra Gary Strobel de la Universidad del Estado de Montana, las investigaciones más recientes de este científico se encuentran direccionadas hacia aspectos como combustibles derivados de hongos, uso de hongos para la conversión de desechos agrícolas en hidrocarburos, actividad antimicótica de hongos endofíticos, entre otros.

Finalmente, se destacan los estudios publicados por la investigadora Barbara E. Schulz, del Instituto de Microbiología de la Universidad Técnica de Brunswick, en Alemania. Algunas de las publicaciones más recientes de esta autora están relacionadas con actividad antimicrobial de hongos endofíticos, y el aislamiento de extractos químicos de hongos endofíticos como: Microsphaerol y Seimatorone.

A continuación, se resume, en la Tabla 5, la información asociada a los autores antes mencionados: el número de documentos relacionados con la ecuación de búsqueda publicados por cada autor, la afiliación completa tanto departamento como institución o universidad, el total de citaciones que han tenido sus publicaciones y el número de documentos en los que han sido citados, el número total de documentos publicados, el número de co-autores que han participado en sus publicaciones y las principales áreas temáticas. 
Figura 10. Número de publicaciones por Autor relacionadas con el tema microorganismos endofíticos.

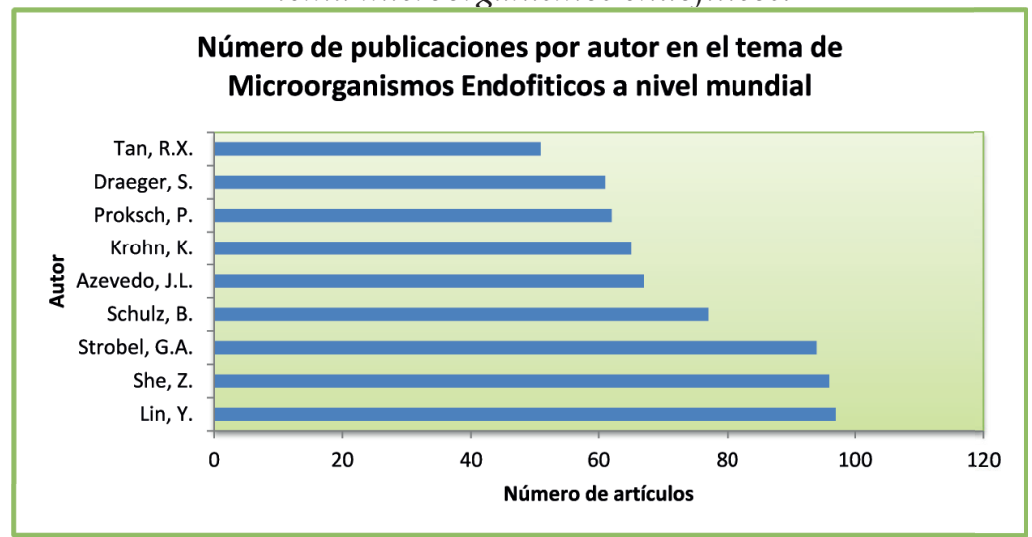

Fuente: Elaboración propia de acuerdo con la base de datos de Scopus (Elsevier, B.V. 2015). 
Tabla 5. Información de los principales autores que publican temas relacionados con organismos endofíticos

\begin{tabular}{|c|c|c|c|c|c|c|c|}
\hline Autor & $\begin{array}{c}\text { No. } \\
\text { documentos } \\
\text { publicados } \\
\text { en la } \\
\text { búsqueda }\end{array}$ & Afíliación & $\begin{array}{l}\text { Total } \\
\text { citacione } \\
\mathrm{s}\end{array}$ & $\begin{array}{c}\text { No de } \\
\text { docs. en que } \\
\text { es citado }\end{array}$ & $\begin{array}{l}\text { No total } \\
\text { de docs. } \\
\text { publicados }\end{array}$ & $\begin{array}{r}\text { No. de } \\
\text { co-autores }\end{array}$ & Área temática \\
\hline Lin, Yongcheng & 97 & \begin{tabular}{l}
\multicolumn{1}{c}{ Sun Yat-Sen } \\
University, School \\
of Chemistry and \\
Chemical \\
Engineering, \\
Guangzhou, China
\end{tabular} & 2811 & 1505 & 235 & 150 & $\begin{array}{l}\text { Chemistry, Pharmacology, } \\
\text { Toxicology and Pharmaceutics, } \\
\text { Biochemistry, Genetics and } \\
\text { Molecular Biology } \\
\text { Agricultural and Biological } \\
\text { Sciences, Medicine }\end{array}$ \\
\hline She, Zhigang & 96 & $\begin{array}{l}\text { Sun Yat-Sen } \\
\text { University, School } \\
\text { of Chemistry and } \\
\text { Chemical } \\
\text { Engineering, } \\
\text { Guangzhou, China }\end{array}$ & 2037 & 1048 & 181 & 150 & $\begin{array}{l}\text { Chemistry, Pharmacology, } \\
\text { Toxicology and Pharmaceutics, } \\
\text { Biochemistry, Genetics and } \\
\text { Molecular Biology, Medicine, } \\
\text { Agricultural and Biological } \\
\text { Sciences, }\end{array}$ \\
\hline $\begin{array}{l}\text { Strobel, Gary } \\
\text { Allan }\end{array}$ & 94 & $\begin{array}{l}\quad \text { Montana State } \\
\text { University, } \\
\text { Department of } \\
\text { Plant Sciences, } \\
\text { Bozeman, United } \\
\text { States }\end{array}$ & 8255 & 3989 & 243 & 150 & $\begin{array}{l}\text { Biochemistry, Genetics and } \\
\text { Molecular Biology } \\
\text { Agricultural and Biological } \\
\text { Sciences, Immunology and } \\
\text { Microbiology, Chemistry, } \\
\text { Pharmacology, Toxicology and } \\
\text { Pharmaceutics, Medicine, }\end{array}$ \\
\hline $\begin{array}{l}\text { Schulz, Barbara } \\
\text { E. }\end{array}$ & 75 & $\begin{array}{l}\quad \text { Technische } \\
\text { Universitat } \\
\text { Braunschweig, } \\
\text { Institute of } \\
\text { Microbiology, } \\
\text { Braunschweig, } \\
\text { Germany }\end{array}$ & 3550 & 2251 & 129 & 150 & $\begin{array}{l}\text { Chemistry, Pharmacology, } \\
\text { Toxicology and Pharmaceutics, } \\
\text { Agricultural and Biological } \\
\text { Sciences , Biochemistry, } \\
\text { Genetics and Molecular } \\
\text { Biology , Medicine , } \\
\text { Immunology and Microbiology }\end{array}$ \\
\hline $\begin{array}{l}\text { Azevedo, João } \\
\text { Lúcio }\end{array}$ & 67 & $\begin{array}{l}\quad \text { Universida de } \\
\text { de Sao Paulo - } \\
\text { USP, Department } \\
\text { of Genetics, Sao } \\
\text { Paulo, Brazil }\end{array}$ & 2277 & 1582 & 133 & 150 & \begin{tabular}{l}
\multicolumn{2}{c}{ Biochemistry, Genetics and } \\
Molecular Biology and \\
Immunology \\
Microbiology , Agricultural \\
and Biological Sciences \\
Medicine, , Environmental \\
Science,
\end{tabular} \\
\hline Krohn, Karsten & 64 & \begin{tabular}{l}
\multicolumn{1}{c}{ Universitat } \\
Paderborn, \\
Department of \\
Chemistry, \\
Paderborn, \\
Germany
\end{tabular} & 5359 & 3537 & 351 & 150 & $\begin{array}{l}\text { Chemistry, Pharmacology, } \\
\text { Toxicology and Pharmaceutics, } \\
\text { Biochemistry, Genetics and } \\
\text { Molecular Biology } \\
\text { Agricultural and Biological } \\
\text { Sciences, Medicine, }\end{array}$ \\
\hline Proksch, Peter & 62 & $\begin{array}{l}\quad \text { Heinrich Heine } \\
\text { Universitat, } \\
\text { Institute of } \\
\text { Pharmaceutical } \\
\text { Biology and } \\
\text { Biotechnology, } \\
\text { Dusseldorf, } \\
\text { Germany }\end{array}$ & 8925 & 5829 & 484 & 150 & $\begin{array}{l}\text { Pharmacology, Toxicology } \\
\text { and Pharmaceutics } \\
\text { Biochemistry, Genetics and } \\
\text { Molecular Biology } \\
\text { Chemistry, Agricultural and } \\
\text { Biological Sciences } \\
\text { Medicine , Environmental } \\
\text { Science , Immunology and } \\
\text { Microbiology, }\end{array}$ \\
\hline Draeger, Siegfried & 61 & $\begin{array}{l}\quad \text { Technische } \\
\text { Universitat } \\
\text { Braunschweig, } \\
\text { Institute of } \\
\text { Microbiology, } \\
\text { Braunschweig, } \\
\text { Germany }\end{array}$ & 2230 & 1442 & 85 & 150 & $\begin{array}{l}\text { Chemistry, Pharmacology, } \\
\text { Toxicology and Pharmaceutics, } \\
\text { Agricultural and Biological } \\
\text { Sciences , Biochemistry, } \\
\text { Genetics and Molecular } \\
\text { Biology, Medicine, }\end{array}$ \\
\hline
\end{tabular}

Fuente: Elaboración propia de acuerdo con la base de datos de Scopus (Elsevier, B.V. 2015)

\subsubsection{Principales áreas del conocimiento - Microorganismos endofíticos}

En la Figura 11, se aprecian las diferentes áreas del conocimiento en las que se clasifican las publicaciones. El 48\% de las publicaciones están en el área de Agricultura y las Ciencias Biológicas, seguidas de la Bioquímica, Genética y 
Biología Molecular con el 32\%. Es interesante observar cómo van emergiendo otras áreas, donde se ha encontrado potencial de aplicación de los compuestos derivados de organismos endofíticos, tales como: Medicina, Inmunología y Microbiología, Medio Ambiente y Farmacéutica.

Figura 11. Distribución del número de publicaciones por área del conocimiento relacionadas con el tema microorganismos endofítico

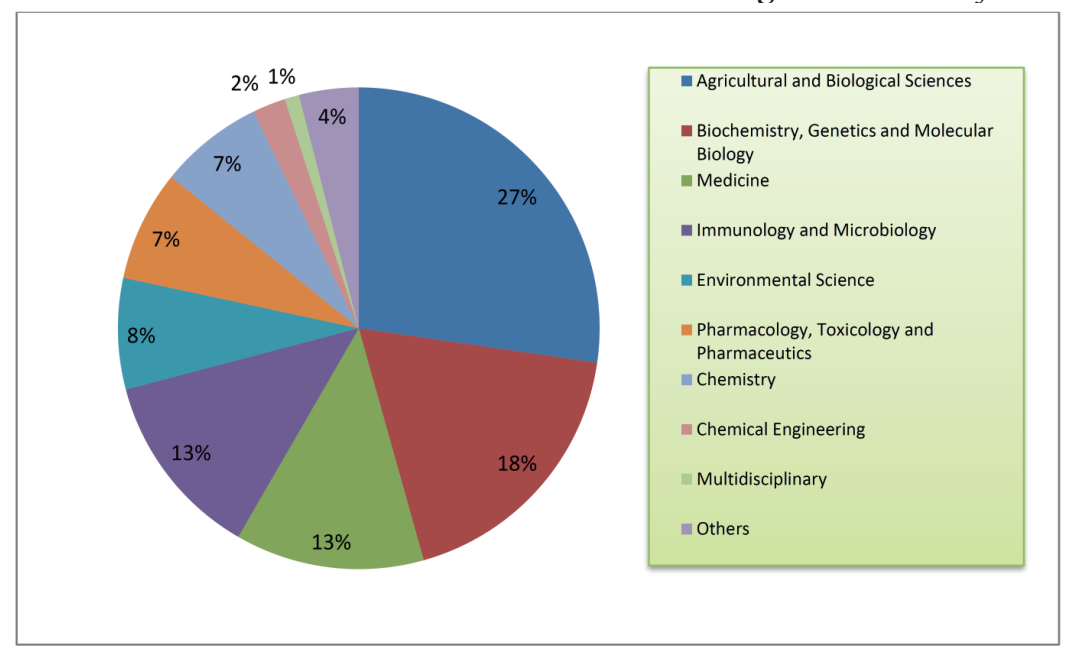

Fuente: Elaboración propia de acuerdo con la base de datos de Scopus (Elsevier, B.V. 2015).

\subsubsection{Principales journals con publicaciones relacionadas con microrganismo endofíticos}

Al observar el número de artículos por journal, se identifican como los más relevantes, con más de 100 publicaciones, los siguientes: World Journal of Microbiology and Biotechnology (122), Plant and Soil (111), Journal of Natural Products (110) y Plos One (108). En la Figura 12, se logra apreciar que la dinámica en publicaciones se incrementa a partir del año 2000 en adelante, donde se diversifican las áreas del conocimiento, y por lo tanto los Journals en las que se publican los resultados de investigación relacionados con organismos endofíticos. 
Figura 12. Número de publicaciones por revista relacionadas con

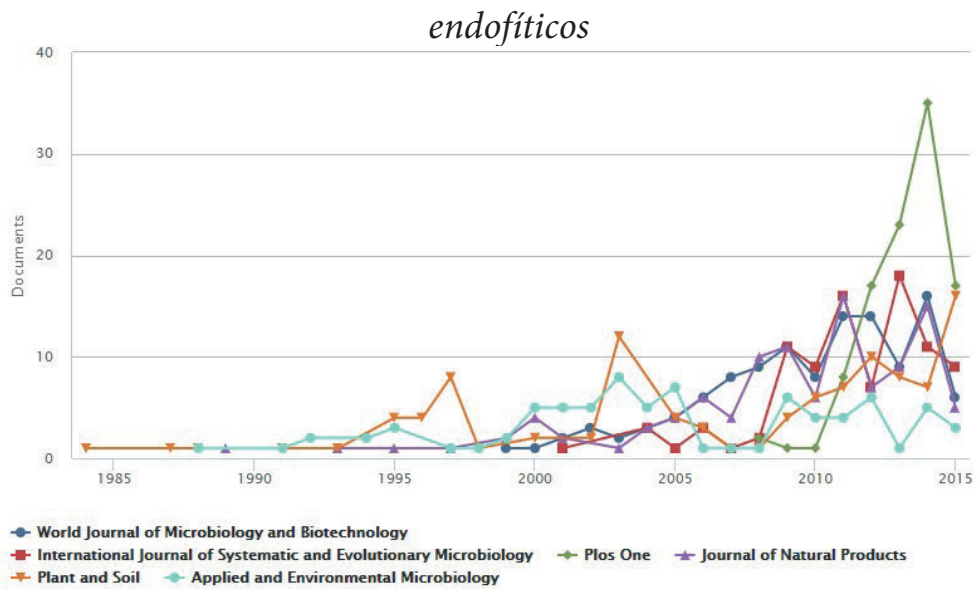

Fuente: Elaboración propia de acuerdo con la base de datos de Scopus (Elsevier, B.V. 2015).

En los últimos cinco años, se nota un incremento significativo en publicaciones a través del PLOS One; organización editorial sin ánimo de lucro, que publica una serie de revistas de acceso abierto influyentes en todas las áreas de la ciencia y la medicina: PLOS one, PLoS Biology, PLoS Medicine, PLoS Computational Biology, PLoS Genetics, PLoS Patógenos y enfermedades tropicales PLoS.

\subsection{Análisis de la producción científica en hongos endofíticos}

Para el análisis, específicamente en hongos endofíticos, se utilizó la ecuación de búsqueda TITLE-ABS-KEY (endophytic fungi), la cual arrojó un total de 4170 artículos, para un periodo de tiempo comprendido entre 1975 y 2015.

\subsubsection{Dinámica de publicaciones en el tema de hongos endofíticos (HE)}

En la Figura 13, se observa que la dinámica de publicaciones relacionadas específicamente con $\mathrm{HE}$ presenta un comportamiento ascendente, con un porcentaje de crecimiento anual de aproximadamente el $22 \%$. 
Figura 13. Número de publicaciones por año en el tema de hongos endofíticos

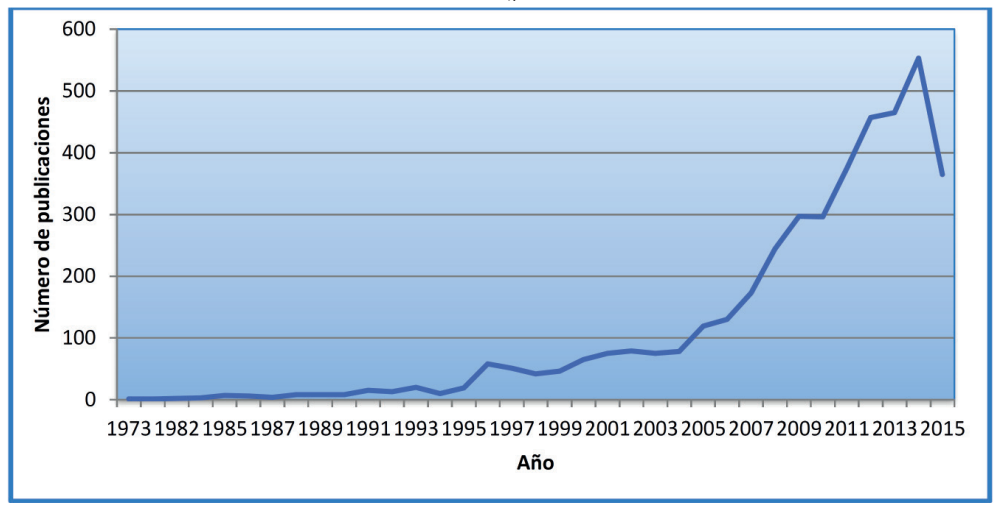

Fuente: Elaboración propia de acuerdo con la base de datos de Scopus (Elsevier, B.V. 2015).

\subsubsection{Autores líderes - hongos endofíticos (HE)}

Como autores destacados en las publicaciones relacionadas específicamente con hongos endofíticos, como se observa en la Figura 14, continúan liderando Yongcheng Lin y Zhigang She de la Universidad de Sun Yat-Sen; quienes, como se indicó anteriormente, han focalizado sus estudios en la búsqueda y evaluación actividad anticancerígena de metabolitos secundarios de hongos endofíticos asociados al ecosistema de manglar.

Figura 14. Número de publicaciones por Autor relacionadas con el tema Hongos Endofíticos

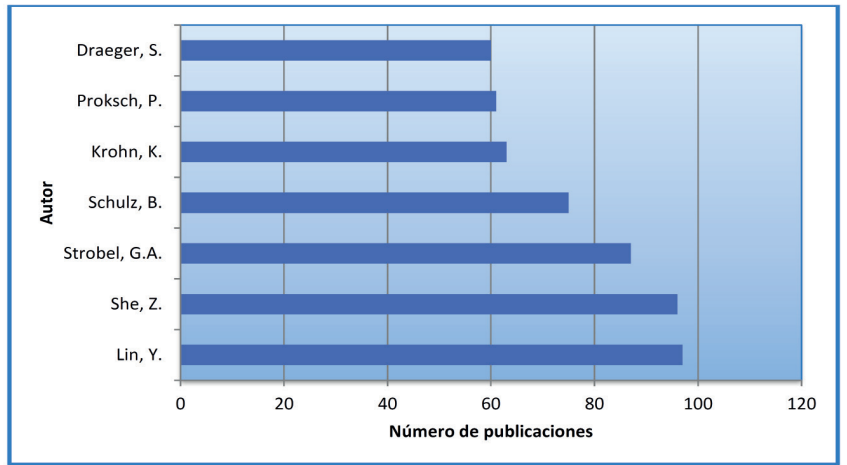

Fuente: Elaboración propia de acuerdo con la base de datos de Scopus (Elsevier, B.V. 2015). 


\subsubsection{Instituciones lideres - hongos endofíticos (HE)}

En lo que respecta a las instituciones, continúa liderando la Universidad de Sun Yat-Sen con 147 publicaciones, seguido de la Academia China de Ciencias Médicas con 95. De esta última institución cabe resaltar que el $48 \%$ de sus publicaciones están asociadas al área de la Farmacología "Farmacología" y Toxicología "Toxicología". Entre sus investigadores destacados, con una participación del $49 \%$ del total de publicaciones asignadas a esta institución, se encuentran Shunxing Guo, del Institute of Medicinal Plant Development ver Figura 15.

Las investigaciones de Shunxing se relacionan en gran parte con estudios y análisis de la diversidad de hongos endofíticos asociados a plantas medicinales de la China. Algunos géneros y/o especies estudiadas son: la Salvia, Orquídea, especies como Dalbergia odorífera. Sus publicaciones más recientes se relacionan con el análisis (diversidad genética) del hongo medicinal Polyporus umbellatus.

Figura 15. Número de publicaciones por institución relacionadas con el tema hongos endofíticos

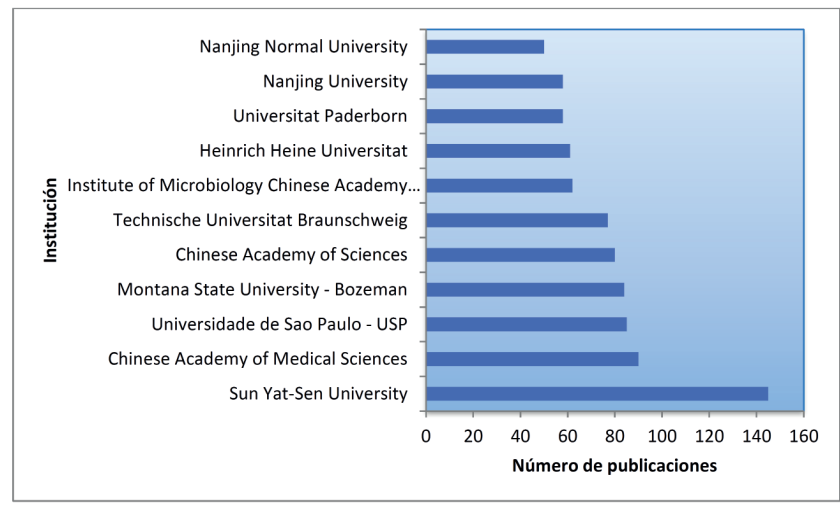

Fuente: Elaboración propia de acuerdo con la base de datos de Scopus (Elsevier, B.V. 2015). 


\subsubsection{Países líderes - hongos endofíticos (HE)}

Los países líderes en publicaciones de hongos endofíticos coinciden con los líderes en publicaciones de microorganismos endofíticos analizado anteriormente. En este sentido, como se observa en la Figura 16 incluir, los países más destacados en publicaciones relacionadas con hongos endofíticos son: China y Estados Unidos, seguidos de India y Alemania.

Figura 16. Número de publicaciones por país relacionadas con el tema hongos endofíticos

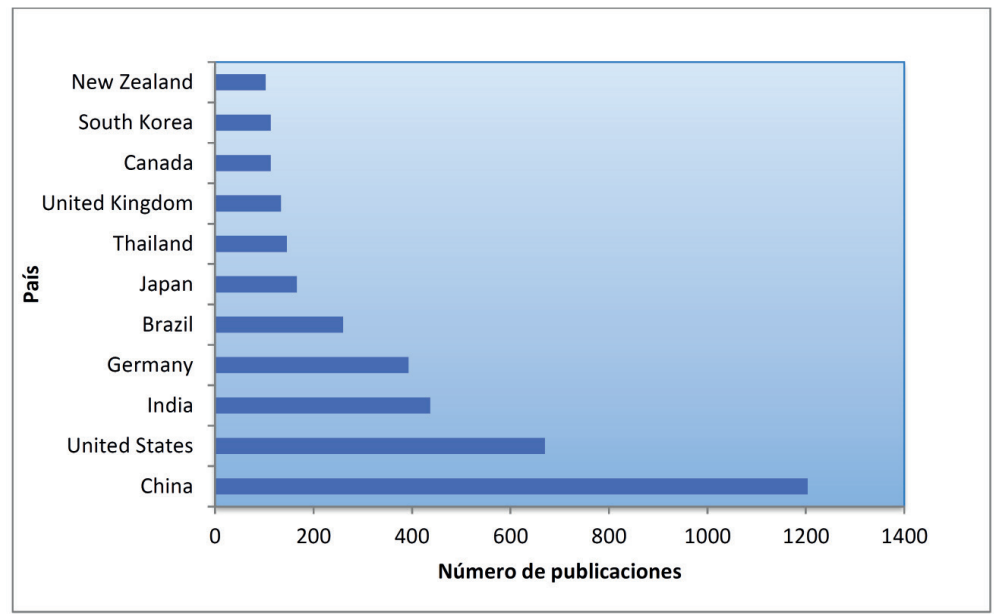

Fuente: Elaboración propia de acuerdo con la base de datos de Scopus (Elsevier, B.V. 2015).

\subsection{Análisis de la producción científica en bacterias endofíticas}

En la búsqueda específica de Bacterias Endofíticas se utilizó la ecuación de búsqueda TITLE-ABS-KEY (endophytic bacteria), la cual arrojó un total de 2319 artículos, para un periodo de tiempo comprendido entre 1973 y 2015.

En el tema de bacterias endofíticas, como se aprecia en la Figura 17, se ha presentado un incremento significativo a partir del año 2008, con un porcentaje de crecimiento anual entre el 2008 y el 2015 de aproximadamente el 13\%. 
Figura 17. Dinámica de publicaciones en el tema de bacterias endofiticas (BE) en el periodo 1973 - 2015

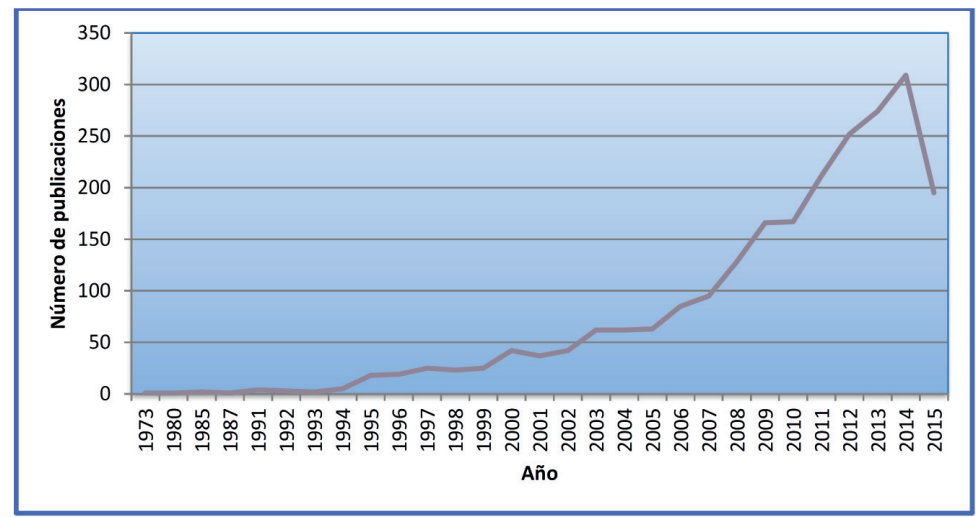

Fuente: Elaboración propia de acuerdo con la base de datos de Scopus (Elsevier, B.V. 2015).

\subsubsection{Autores líderes - Bacterias Endofíticas (BE)}

En lo que respecta a autores líderes, se observa en la Figura 18 que el investigador João Lúcio Azevedo, del departamento de Genética de la Universidad de Sao Paulo, con 44 artículos. Los temas en los que se han direccionado los estudios más recientes (2014 -2015) de este investigador se relacionan con: diversidad de bacterias endofíticas en especies vegetales amazónicas, diversidad de hongos endofíticos en cultivos orgánicos "Cultivos orgánicos" de café, prospección biotecnológica de actividad antibacteriana "Actividad antibacteriana" y antagonista "Antagonista" de hongos endofíticos, aislamiento y bioprospección de enzimas de bacterias endofíticas asociadas a plantas del ecosistema de manglar brasilero.

Otra autora destacada es la investigadora del Departamento de Ambiente y Salud en Viena (Austria), Angela Sessitsch, los temas en los que se han direccionado los estudios más recientes (2014 -2015) de este investigador se relacionan con: potencial de bacterias endofíticas en procesos de biorremediación de suelos "Biorremediación de suelos". 
Figura 18. Número de publicaciones por autor en el tema de bacterias endofíticas (BE) en el periodo 1973 - 2015

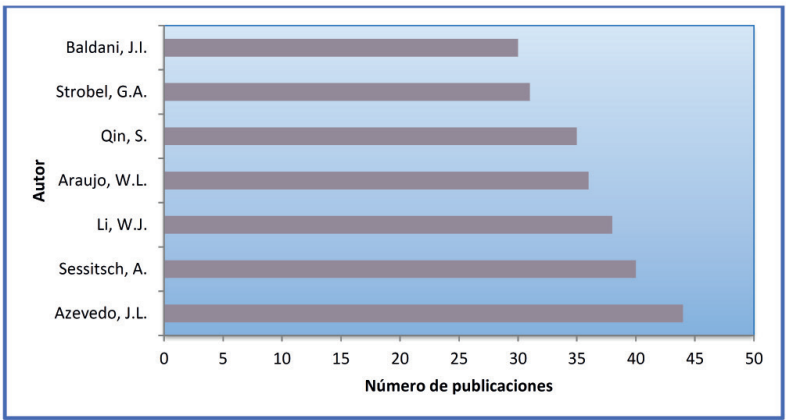

Fuente: Elaboración propia de acuerdo con la base de datos de Scopus (Elsevier, B.V. 2015).

\subsubsection{Instituciones líderes - Bacterias Endofíticas (BE)}

En lo que a instituciones líderes en publicaciones relacionadas con bacterias endofíticas se refiere, como se logra apreciar en la Figura 19, las más destacadas son la Universidad de Sao Paulo, seguido de la Empresa Brasilera de Investigación Agropecuaria y la Universidad de Yunnan de la China. En este escenario de las bacterias endofíticas, Brasil cuenta con un interesante protagonismo, con instituciones emergentes como la Universidad Federal de Paraná y la Universidad Federal de Rio de Janeiro.

Figura 19.Número de publicaciones por Institución en el tema de bacterias endofíticas (BE) en el periodo 1973 - 2015

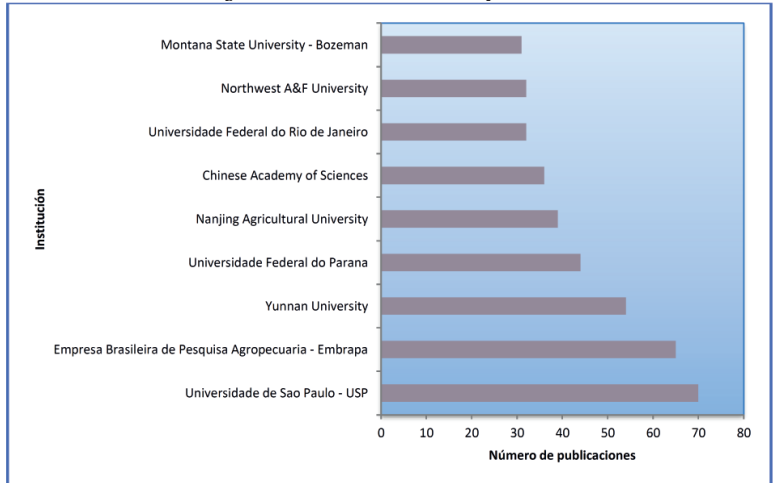

Fuente: Elaboración propia de acuerdo con la base de datos de Scopus (Elsevier, B.V. 2015). 


\subsubsection{Países líderes - bacterias endofíticas (BE)}

Como se observa en la Figura 20, la gran potencia en publicaciones relacionadas con organismos endofíticos, en este caso específico de bacterias endofíticas es China, que cuenta con una participación del 21,64\% del total de publicaciones. Otros países destacados son Brasil, Estados Unidos e India.

Figura 20. Número de publicaciones por país en el tema de Bacterias endofíticas (BE) en el periodo 1973 - 2015

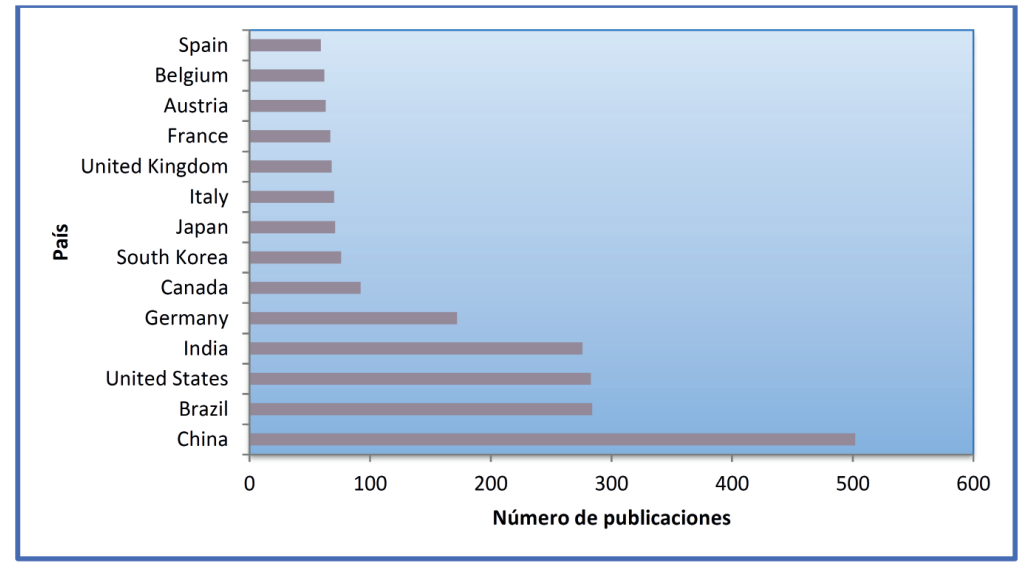

Fuente: Elaboración propia de acuerdo con la base de datos de Scopus (Elsevier, B.V. 2015).

\subsubsection{Principales áreas del conocimiento - bacterias endofíticas (BE)}

En lo que respecta a las áreas del conocimiento donde se registran la mayor cantidad de publicaciones relacionadas con bacterias endofíticas, como se observa en la Figura 21, aproximadamente el $51 \%$ de los artículos están en áreas como la Agricultura y Ciencias Biológicas y la Inmunología y Microbiología. Otras áreas emergentes son: Bioquímica, genética y Biología Molecular, Ciencias Ambientales y Medicina. 
Figura 21. Número de publicaciones por área del conocimiento en el tema de bacterias endofíticas (BE) en el periodo 1973 - 2015

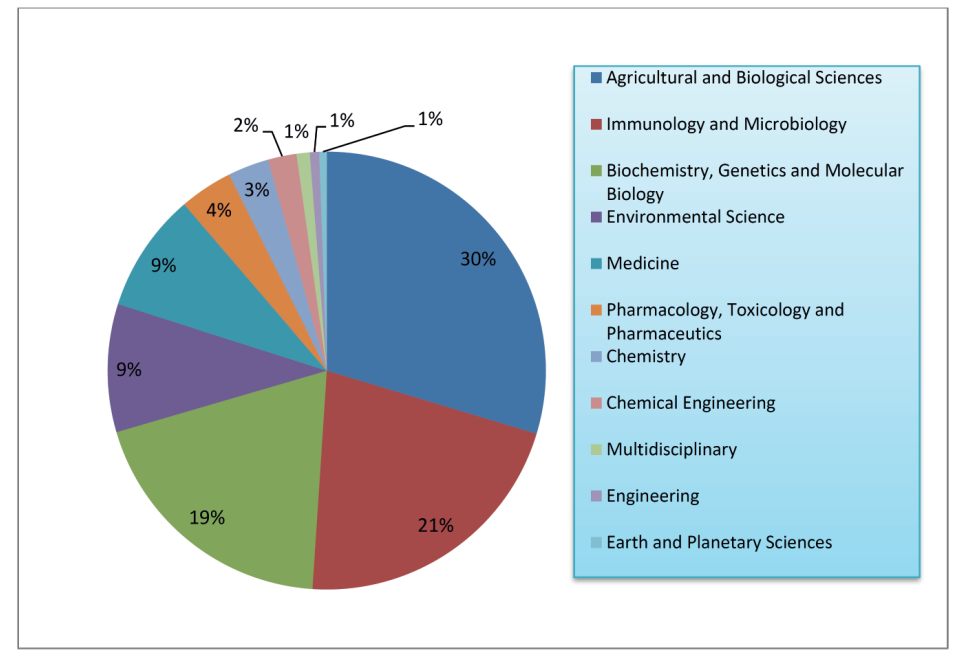

Fuente: Elaboración propia de acuerdo con la base de datos de Scopus (Elsevier, B.V. 2015).

\subsection{Análisis comparativos entre hongos y bacterias endofíticas}

Al realizar un comparativo general de las tendencias en $\mathrm{I}+\mathrm{D}$ relacionadas con hongos y bacterias endofíticas, se encuentra, tal como se observa en la Figura 22, que aproximadamente el 59\% del total de publicaciones en microorganismos endofíticos se relacionan con hongos y un 33\% con bacterias.

Figura 22. Porcentaje de publicaciones relacionadas con Hongos y

\section{Bacterias Endofíticas}

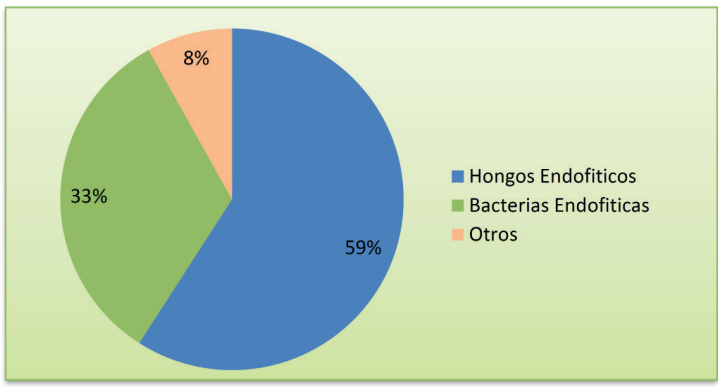

Fuente: Elaboración propia de acuerdo con la base de datos de Scopus (Elsevier, B.V. 2015). 
De otro lado, al observar la dinámica en el tiempo de las publicaciones, como se muestra en la Figura 23, se puede identificar una tendencia creciente en el número de publicaciones tanto para hongos como para bacterias endofíticas.

Al analizar el número de publicaciones por área del conocimiento para hongos y bacterias endofíticas, tal como se muestra en la Figura 24, se aprecia un número predominante de artículos relacionados con hongos para las diferentes áreas. Sin embargo, en el caso de las bacterias endofíticas, es interesante el protagonismo de estas publicaciones en el área de la Inmunología "Inmunología" y Microbiología "Microbiología".

De otro lado, al comparar el número de publicaciones en hongos y bacterias endofiticas por país de América Latina y el Caribe, como se muestra en la Figura 25, se evidencia nuevamente el liderazgo de Brasil en el tema de bacterias; seguido de México. En el caso de Argentina, como segundo país lider en publicaciones, se observa un predominio en el tema de hongos.

Figura 23. Número de publicaciones por año en Microorganismos, Hongos y Bacterias endofiticas

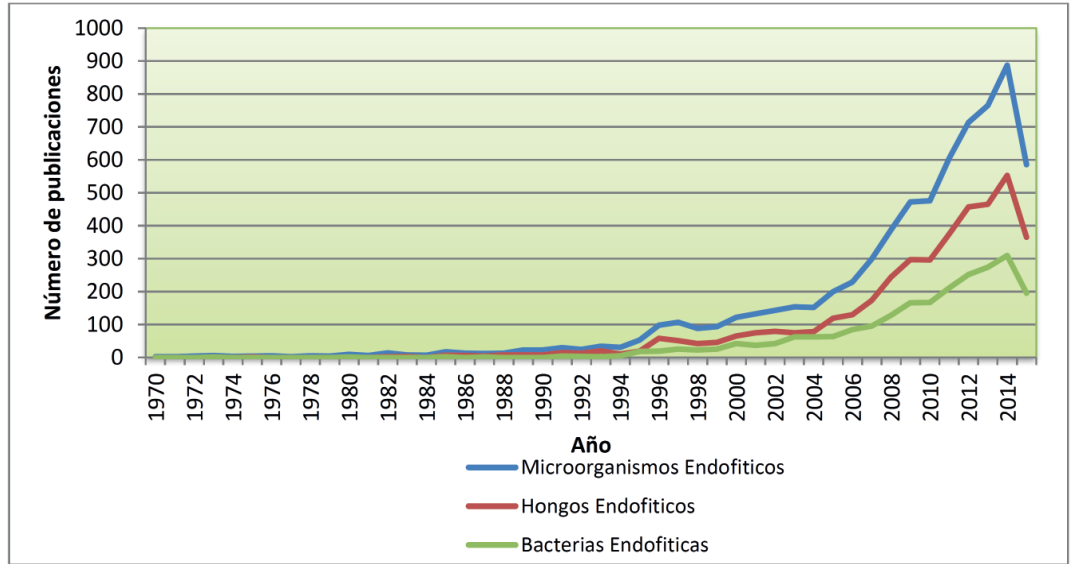

Fuente: Elaboración propia de acuerdo con la base de datos de Scopus (Elsevier, B.V. 2015). 
Figura 24. Número de publicaciones por área del conocimiento para hongos y bacterias endofíticas

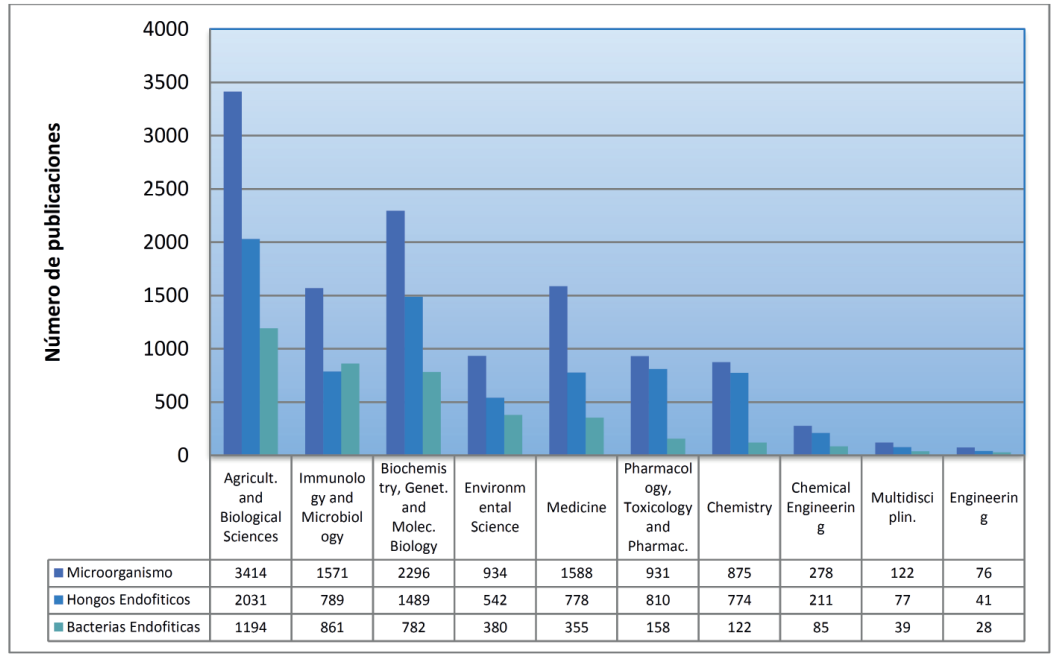

Fuente: Elaboración propia de acuerdo con la base de datos de Scopus (Elsevier, B.V. 2015).

Figura 25. Número de publicaciones por país de América latina y el Caribe relacionadas con bacterias y hongos endofíticos

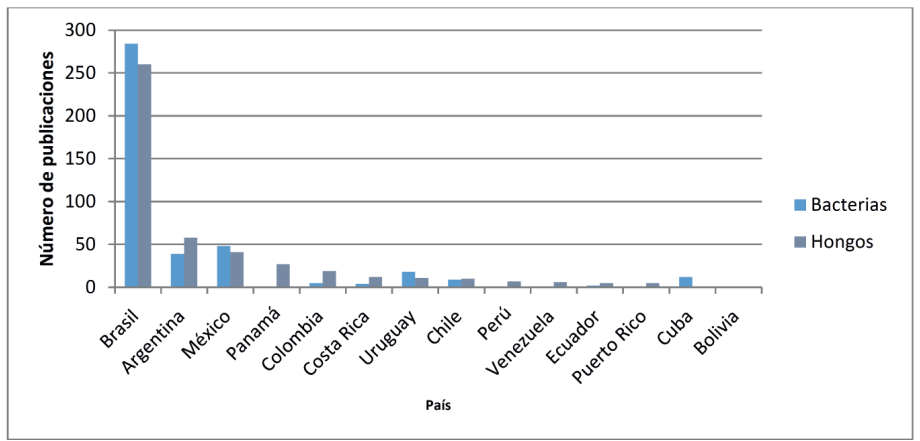

Fuente: Elaboración propia de acuerdo con la base de datos de Scopus (Elsevier, B.V. 2015).

Finalmente, al analizar la co- ocurrencia de palabras claves relacionadas con hongos y bacterias endofíticas, se procedió a agrupar las palabras claves similares en términos más generales. Como se puede observar en las Figura 26, en lo que respecta a hongos endofíticos la mayor cantidad de palabras están 
relacionadas con tipos de hongos, aplicaciones y metabolitos secundarios "Metabolitos secundarios", mientras que en el tema de bacterias, como se aprecia en la Figura 27, sobresalen los términos que hacen referencia a tipos de bacterias, técnicas moleculares "Técnicas moleculares" y partes de la planta.

Figura 26. Co-ocurrencia de palabras claves relacionadas con hongos endofíticos

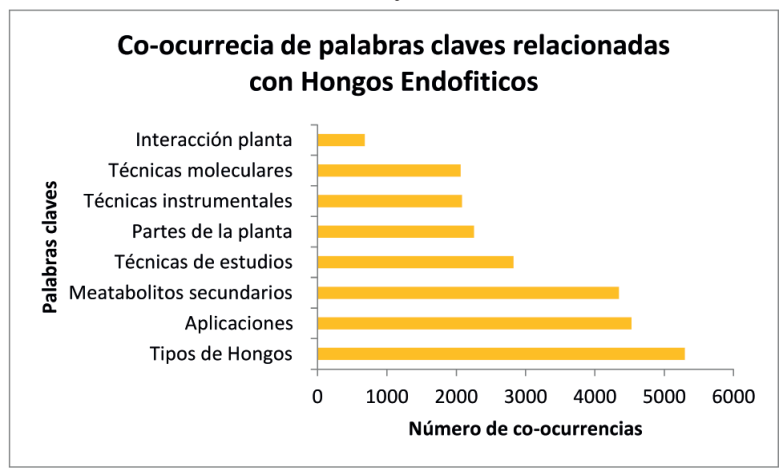

Fuente: Elaboración propia de acuerdo con la base de datos de Scopus (Elsevier, B.V. 2015)

Figura 27. Co-ocurrencia de palabras claves relacionadas con bacterias endofiticas

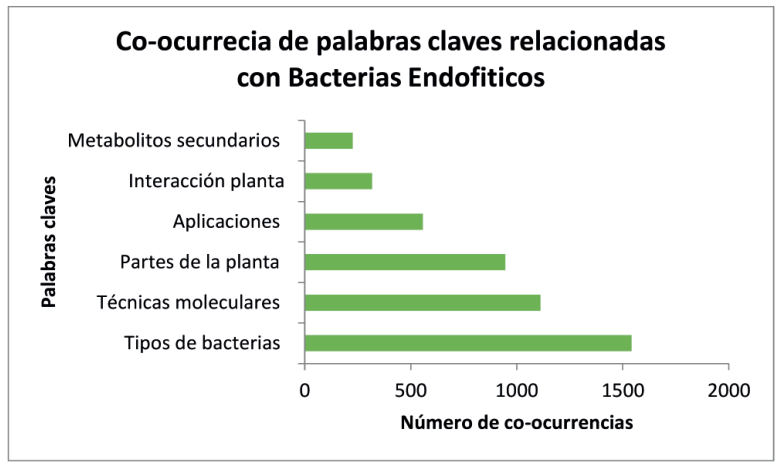

Fuente: Elaboración propia de acuerdo con la base de datos de Scopus (Elsevier, B.V. 2015) 
4.5 Análisis de tendencias organismos endofíticos 2015 - 2020

Para dar un alcance de la actualidad de publicaciones en organismos endofíticos, se procede a realizar la revisión bibliográfica y el análisis de tendencias que cubre el periodo de tiempo desde el 2015 al año 2020, aplicando la ecuación de búsqueda a los periodos mencionados TITLE-ABS-KEY ENDOPHYTIC AND ( LIMIT-TO ( PUBYEAR, 2020 ) OR LIMIT-TO ( PUBYEAR, 2019) OR LIMIT-TO ( PUBYEAR, 2018 ) OR LIMIT-TO ( PUBYEAR, 2017 ) OR LIMIT-TO ( PUBYEAR, 2016 ) OR LIMIT-TO ( PUBYEAR, 2015 ) ). Consultando bases de datos de publicaciones científicas y de patentes, especialmente Scopus (Elsevier, B.V. 2020), con estos datos cienciométricos, analizar la actividad científica actual sobre el tema de estudio, en el periodo comprendido desde 2015 al 2020.

\subsubsection{Dinámica de publicaciones organismos endofíticos 2015 - 2020}

Para el análisis específicamente en organismos endofíticos, se utilizó la ecuación de búsqueda para este periodo de tiempo la cual arrojó como resultado, un total de 7677 artículos, para un periodo de tiempo comprendido entre 2015 - 2020.

En la Figura 28, analizamos el número de publicaciones por año y podemos observar que aún se mantiene un crecimiento por año superior al del $12.3 \%$ en las publicaciones, especialmente evidenciado al crecimiento en las publicaciones relacionadas con el área de las ciencias biológicas, agricultura con temáticas como bacterias endofíticas promotoras de crecimiento de las plantas y organismos endofíticos como control biológico. 
Figura 28.Numero de publicaciones por año en el tema organismos endófitos 2015 - 2020

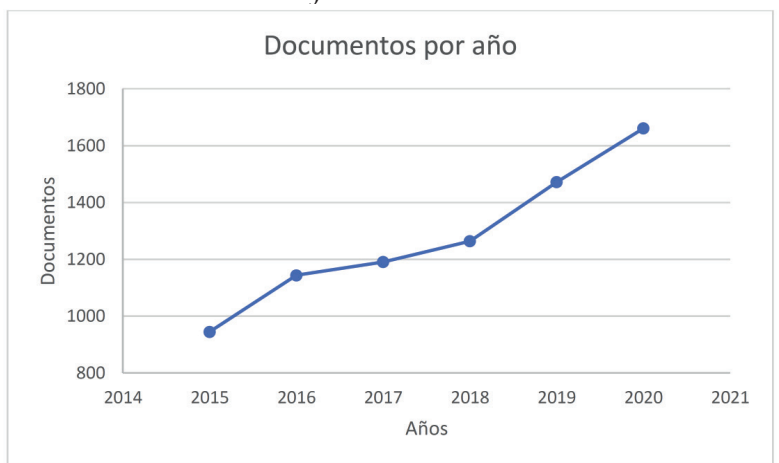

Fuente: Elaboración propia de acuerdo con la base de datos de Scopus (Elsevier, B.V. 2020).

\subsubsection{Países líderes en microorganismos endofíticos 2015 - 2020}

Como se puede observar en la Figura 29, China con 2359 documentos que equivalen al $30.7 \%$ de total de las publicaciones el país ha continuado con la hegemonía sobre los demás territorios del globo, sin embargo, en segundo lugar es tomado con un $15.2 \%$ de las publicaciones por India, en lugar de Estados Unidos (9.9\%) que ocupa el tercer lugar, el cuarto lugar es ocupado por Brasil (7.0\%) como primer país de América Latina y el Caribe con 536 publicaciones.

En lo que concierne a la región de América latina y el Caribe, puede apreciarse en la Figura 30, que los países participan con 914 publicaciones distribuidas en 15 países, lo que representa el $11.91 \%$ de las publicaciones a nivel mundial. Es Brasil el país que sigue liderando con 536 publicaciones (6.98\%), seguido de México con 120 publicaciones (1.56\%) y Argentina con las publicaciones con 95 publicaciones (1.24\%), Chile (0.60\%), en cuarto lugar, con 46 publicaciones y Colombia (0.42\%), ocupa el quinto puesto con 32 publicaciones. 
Figura 29. Distribución del número de publicaciones por país relacionadas con el tema de organismos endofíticos 2015 - 2020

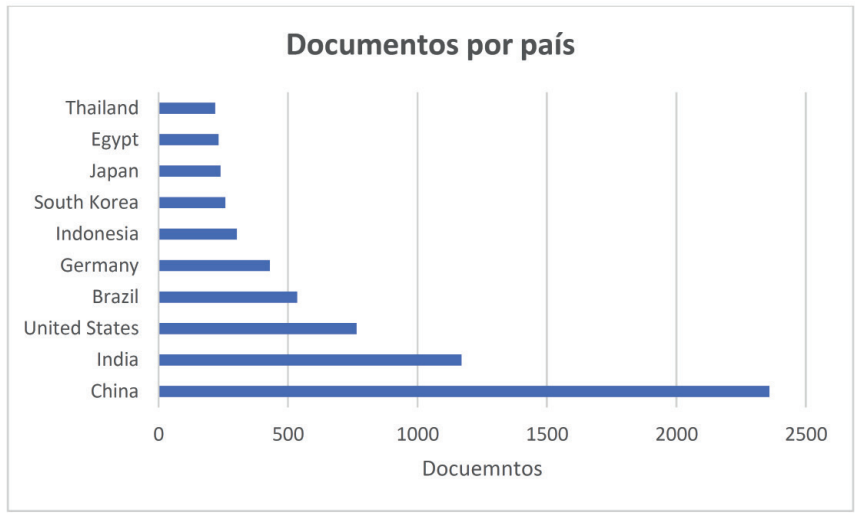

Fuente: elaboración propia de acuerdo con la base de datos de Scopus (Elsevier, B.V. 2020).

Figura 30. Distribución del número de publicaciones por país de América Latina y el Caribe relacionadas con el tema organismos Endofíticos 2015 - 2020

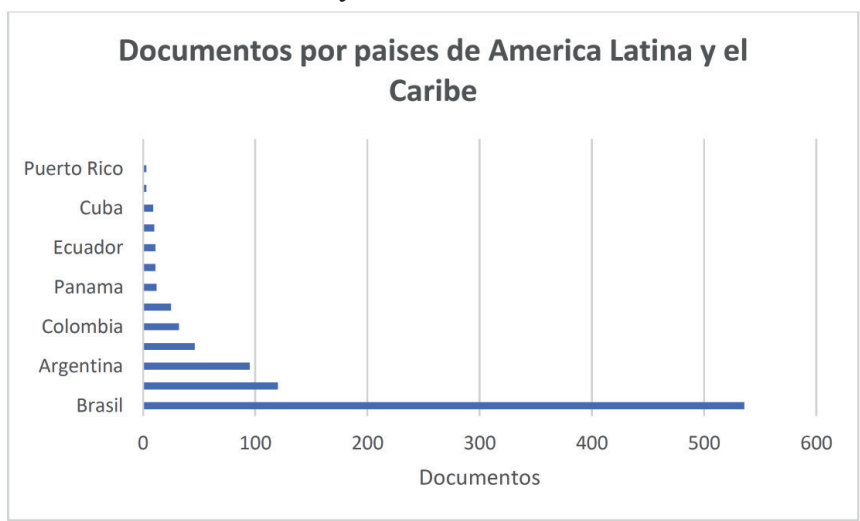

Fuente: Elaboración propia de acuerdo con la base de datos de Scopus (Elsevier, B.V. 2020).

\subsubsection{Instituciones líderes - microorganismos endofíticos 2015 - 2020}

Relacionado con las instituciones líderes, en la Figura 31, se pueden apreciar las primeras 10 instituciones a nivel mundial, relacionadas con las publicaciones sobre endofíticos, ocho 
son instituciones chinas que suman 1386 publicaciones, y las dos instituciones restantes, ubicadas en Brasil aportan 212 publicaciones. La institución líder es la Academia China de Ciencias con 330 publicaciones, seguido Ministerio de Educación de China con 313 publicaciones. En tercer lugar, es ocupado por la Academia China de Ciencias Agrícolas con 147 registros. Instituciones de América Latina son Universidad de Sao Paulo - USP (124) y Empresa Brasileira de Pesquisa Agropecuaria Embrapa (88).

Figura 31. Número de publicaciones por institución relacionadas con el tema Microorganismos Endofíticos 2015 - 2020

Documents by affiliation

Compare the document counts for up to 15 affiliations.

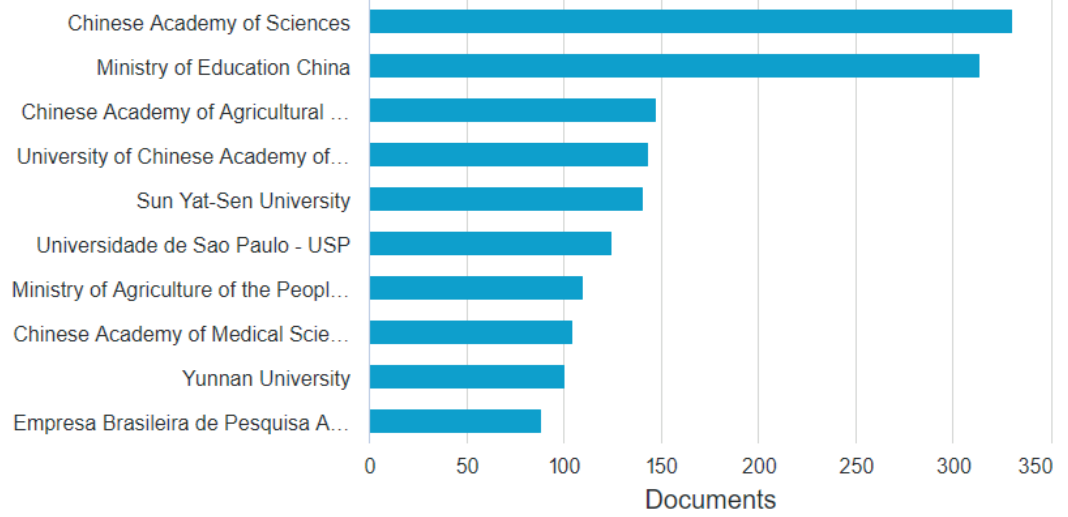

Fuente: Elaboración propia de acuerdo con la base de datos de Scopus (Elsevier, B.V. 2020).

\subsubsection{Autores Líderes - Microorganismos endofíticos $2015-2020$}

En la Figura 32, se encuentran destacados 10 diferentes autores y el número de publicaciones relacionadas con endofíticos, de los cuales se ubica en primer lugar Peter Proksch de la Universidad Heinrich Heine Düsseldorf, en Dusseldorf, Alemania, cuenta con 68 publicaciones relacionadas con el estudio de productos naturales bioactivos y fitoquímicos a partir de hongos endofíticos 
de plantas de mangle y el tratamiento anticáncer, entre los que sobresalen investigaciones en el área farmacéutica especialmente en la búsqueda y evaluación anticáncer de compuestos derivados de policétidos de hongos endofíticos Pestalotiopsis clavispora aislado del mangle Rhizophora harrisonii.

Figura 32. Número de publicaciones por Autor relacionadas con el tema microorganismos endofíticos 2015 - 2020.

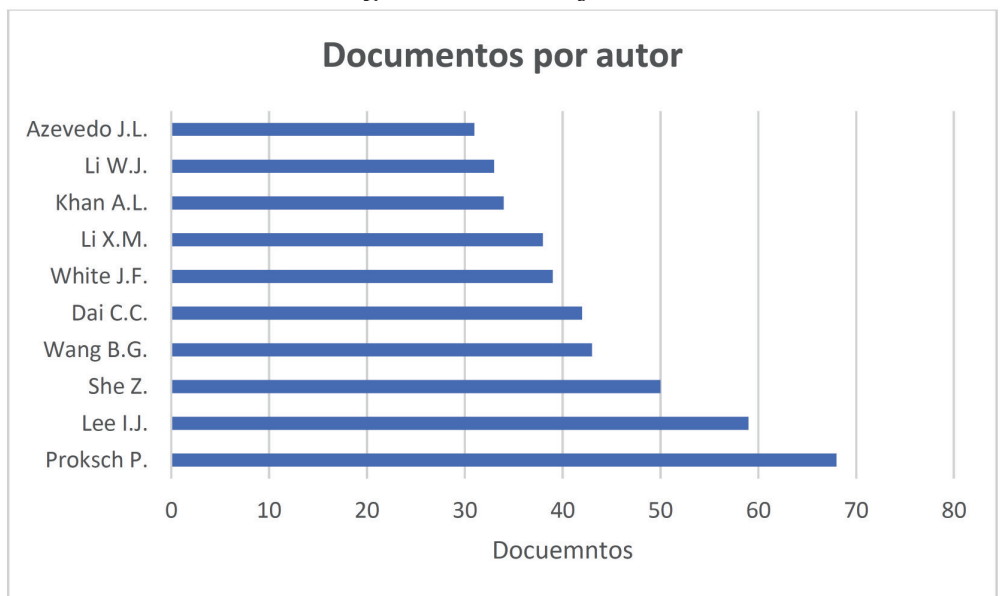

Fuente: Elaboración propia de acuerdo con la base de datos de Scopus (Elsevier, B.V. 2020).

En segundo lugar, encontramos a Injung Lee de la Universidad Nacional Kyungpook, Daegu en Corea del Sur, quien cuenta con 59 publicaciones en áreas de la microbiología y medioambiente, relacionadas con bacterias endofíticas, en tópicos como la fitorremediación de metales pesados basado en rizósfera bacteriana. En cuanto a hongos endofíticos, sobresalen investigaciones sobre el rol de los hongos endófitos en cultivos comerciales y la resistencia al estrés abiótico y su efecto en el crecimiento de las plantas y la disminución de la necesidad de fertilizantes.

En tercer lugar, en el ranking se ubica Zhigang She de la Universidad de Sun Yat-Sen, Guangzhou en China. Con 50 publicaciones relacionadas con productos naturales a partir 
de diferentes hongos endofíticos aislados de plantas de mangle (Rhizophoraceae), analizando la riqueza de compuestos químicos bioactivos aislados de estos endofíticos; como sesterpenos (Terpenos), Isocoumerinas, polocétidos y preusomerina. Estas publicaciones se enfocan en los métodos de elucidación de las moléculas y evaluaciones de sus actividades biológicas.

En la Tabla 6, podemos encontrar a manera de resumen, la información asociada a los autores más representativos en publicación de hongos endofíticos para el periodo 2015 al 2020, con su afiliación completa, el total de citaciones de sus publicaciones y la cantidad de documentos en los que han sido citados, el número total de documentos publicados, el número de co-autores que han participado en sus publicaciones y las principales áreas temáticas. 
Tabla 6. Información de los principales autores que publican temas relacionados con organismos endofíticos 2015 - 2020

\begin{tabular}{|c|c|c|c|c|c|c|c|}
\hline Autor & $\begin{array}{l}\text { No. } \\
\text { documentos } \\
\text { publicados en } \\
\text { la buisqueda }\end{array}$ & Afiliación & $\begin{array}{c}\text { Total } \\
\text { citaciones }\end{array}$ & $\begin{array}{l}\text { No de docs. } \\
\text { en que es } \\
\text { citado. }\end{array}$ & $\begin{array}{l}\text { No total de } \\
\text { docs. } \\
\text { publicados }\end{array}$ & $\begin{array}{l}\text { No. de } \\
\text { co- } \\
\text { autores }\end{array}$ & Área temática \\
\hline Peter Proksch & 68 & $\begin{array}{l}\text { Universidad } \\
\text { Heinrich Heine } \\
\text { Düsseldorf, } \\
\text { Alemania }\end{array}$ & 18754 & 12178 & 685 & 1151 & $\begin{array}{l}\text { Farmacología, Toxicología y } \\
\text { Farmacología, } \\
\text { Genética y Bioquímica, } \\
\text { Química. }\end{array}$ \\
\hline Injung Lee & 59 & $\begin{array}{l}\text { Universidad } \\
\text { Nacional } \\
\text { Kyungpook, Corea } \\
\text { del Sur }\end{array}$ & 9078 & 5942 & 326 & 531 & \begin{tabular}{l}
\multicolumn{1}{c}{ Ciencias Biológicas y } \\
Agrícolas, Bioquímica, Genética y \\
Biología Molecular, Inmunología y \\
Microbiología
\end{tabular} \\
\hline Zhigang She & 50 & $\begin{array}{l}\text { Universidad } \\
\text { Sun Yat-Sen, } \\
\text { China }\end{array}$ & 5432 & 5432 & 255 & 487 & 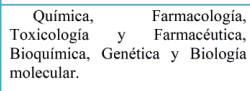 \\
\hline Bingui Wang & 43 & $\begin{array}{c}\text { Academia } \\
\text { China de Ciencias, } \\
\text { China }\end{array}$ & 5979 & 3525 & 227 & 290 & $\begin{array}{l}\text { Farmacología, Toxicología y } \\
\text { Farmacología, Bioquímica, } \\
\text { Genética y Biología Molecular, } \\
\text { Ciencias Biológicas y Agrícolas. }\end{array}$ \\
\hline Chuanchao Dai & 42 & $\begin{array}{l}\text { Universidad } \\
\text { Normal de } \\
\text { Nanjing, China }\end{array}$ & 2325 & 1507 & 171 & 291 & \begin{tabular}{llr}
\multicolumn{1}{c}{ Ciencias } & \multicolumn{2}{c}{ Biológicas } \\
Agrícolas, Bioquímica, Biología \\
molecular y Genética, Ciencias \\
Ambientales, Microbiología e \\
Inmunologia.
\end{tabular} \\
\hline James F. White & 39 & $\begin{array}{c}\text { Rutgers } \\
\text { University - New } \\
\text { Brunswick, } \\
\text { Estados Unidos }\end{array}$ & 6322 & 4218 & 189 & 324 & $\begin{array}{l}\text { Ciencias Biológicas y } \\
\text { Agrícolas, Bioquimica, Genética y } \\
\text { Biología Molecular, Microbiología } \\
\text { y Microbiologia. }\end{array}$ \\
\hline Xiaming $\mathbf{L i}$ & 38 & $\begin{array}{c}\text { Academia } \\
\text { China de Ciencias }\end{array}$ & 4672 & 2553 & 172 & 120 & $\begin{array}{l}\text { Farmacología, Toxicología y } \\
\text { Farmacéutica, Química, Genética y } \\
\text { Biología Molecular }\end{array}$ \\
\hline $\begin{array}{l}\text { Abdul Latif } \\
\text { Khan }\end{array}$ & 34 & $\begin{array}{l}\text { Universidad de } \\
\text { Nizwa, Oman }\end{array}$ & 5550 & 3632 & 192 & 280 & \begin{tabular}{lcr}
\multicolumn{1}{c}{ Ciencias } & \multicolumn{2}{c}{ Biológicas y } \\
Agrícolas, & Bioquímica, Biología \\
Molecular & $y$ & Genética, \\
Microbiología e Inmunología.
\end{tabular} \\
\hline Wenjun Li & 33 & $\begin{array}{c}\text { Instituto de } \\
\text { Ecología y } \\
\text { Geografia de } \\
\text { Xinjiang y } \\
\text { Academia de } \\
\text { Ciencias de China, } \\
\text { China }\end{array}$ & 12086 & 6798 & 678 & 1290 & $\begin{array}{l}\text { Microbiología y Microbiología, } \\
\text { Ciencias Biologicas y Agrícolas, } \\
\text { Bioquímica, Biología Molecular y } \\
\text { Genética. }\end{array}$ \\
\hline $\begin{array}{l}\text { João Lucio de } \\
\text { Azevedo }\end{array}$ & 31 & $\begin{array}{r}\text { Universidad de } \\
\text { Sao Paula, Brasil }\end{array}$ & 5412 & 3891 & 205 & 402 & \begin{tabular}{lrr}
\multicolumn{1}{c}{ Bioquímica, } & Biología \\
Molecular & y & Genética, \\
Microbiología e & Inmunología, \\
Ciencias Biológicas y Agrícolas.
\end{tabular} \\
\hline
\end{tabular}

Fuente: Elaboración propia de acuerdo con la base de datos de Scopus (Elsevier, B.V. 2020)

\subsubsection{Principales áreas de conocimiento - Microorganismos endofíticos 2015 - 2020}

En la Figura 33, se muestran las áreas del conocimiento en las que se catalogan las publicaciones en el periodo comprendido entre 2015 al 2020. La principal área es Ciencias Agrícolas y Biológicas con el $25.4 \%$ de las publicaciones, seguido de Bioquímica, Genética y Biología Molecular con el 18.5\%, en tercer 
lugar y con el $12.8 \%$ se ubica Inmunología y Microbiología, sin embargo, se puede resaltar otras áreas emergentes de investigación en medicina (10.1\%), Farmacología, Toxicología y Farmacéutica (8.0\%), Ciencias Ambientales (7.9\%), Química (6.8\%), Ingeniería Química (2.3\%), entre otros.

Figura 33. Distribución del número de publicaciones por área del conocimiento relacionadas con el tema microorganismos endofítico 2015 - 2020

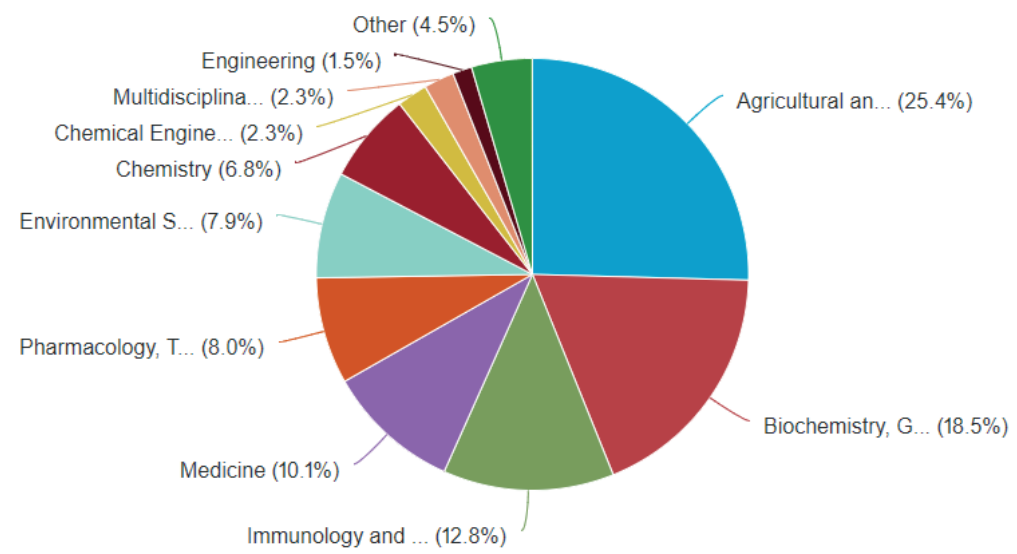

Fuente: Elaboración propia de acuerdo con la base de datos de Scopus (Elsevier, B.V. 2020).

\subsubsection{Principales journals con publicaciones relacionadas a microorganismos endofíticos 2015 - 2020.}

En la Figura 34, se muestran las dinámicas de publicación desde el 2015 de los Journal con más de 100 publicaciones durante el periodo de tiempo, tales como; Frontiers In Microbiology (198), International Journal Of Systematic And Evolutionary Microbiology (145), Natural Product Research (136), Plos One (108), Scientific Reports (101). 
Se puede observar que, a partir del 2015, todas las revistas han tenido publicaciones constantes año tras año hasta el 2020. Estas publicaciones registran temas muy variados, lo que reflejan la variedad de ejes temáticos desde los cuales se abordan las investigaciones con hongos endofíticos en los últimos años. Además, se observa el crecimiento anual de las publicaciones del Journal Natural Product Research a partir de 2018 hasta el 2020.

Figura 34. Número de publicaciones por revista relacionadas con endofíticos

Documents per year by source

Compare the document counts for up to 10 sources.

Compare sources and view CiteScore, SJR, and SNIP data

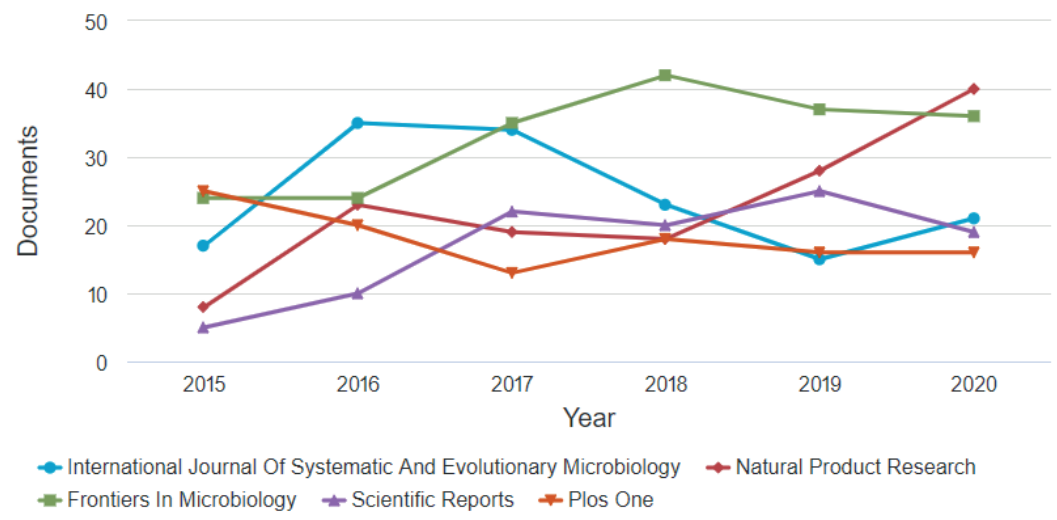

Fuente: Elaboración propia de acuerdo con la base de datos de Scopus (Elsevier, B.V. 2020). 


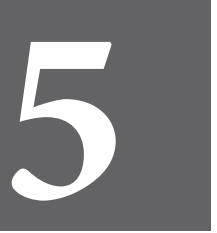

CAPÍTULO CINCO 


\section{Análisis de patentes relacionadas con microorganismos endofíticos.}

Para el análisis de patentes XE "Patentes" se realizaron consultas en dos bases de datos: Goldfire Innovator (licencia) y Patent Inspiration (versión demo); esta última permitió visualizar las instituciones líderes, inventores destacados, principales áreas del conocimiento, etc.

Para obtener un panorama general de la dinámica de patentes en el tema de microorganismos endofíticos, la consulta en las bases de datos antes mencionadas se realizó utilizando la ecuación de búsqueda general (TITLE-ABS-KEY (endophytic), con la que se obtuvo un total de 729 patentes.

Se realiza una búsqueda con la ecuación (TITLE-ABS-KEY (endophytic), para el periodo de 5 años en el rango de tiempo 2015 - 2020, con la que se pudo identificar un total de 1244 registros de patentes, lo que representa un incremento de las solicitudes de un $42 \%$ en los últimos 5 años, lo que puede ser coherente con el aumento observado de las investigaciones publicadas en los rangos de tiempo.

Desde la década del 80 al año 2020 se registran en este estudio 1973 registros de patentes, de los cuales en los últimos 5 años se ha incrementado en $42 \%$ las solicitudes relacionadas en diferentes campos como los de la agricultura, medicina, ingeniería química como resultado del estudio de los hongos y bacterias endofíticas. A continuación, se presentan los principales indicadores generados para el periodo de tiempo hasta el 2015; 
5.1 Dinámica general de patentes relacionadas con el tema de microorganismos endofíticos hasta el año 2015

Como se observa en la Figura 35, las patentes relacionadas con microorganismos endofíticos se presentan desde la década de los años 80; con un incremento en la concesión de patentes durante los últimos 10 años; sin embargo, es a partir del año 2011 hasta la actualidad donde se evidencia la mayor cantidad de patentes, con una representatividad del 65,5\% en el periodo 2011 - 2015.

Figura 35. Número de patentes por año en el tema de microorganismos endofíticos hasta 2015

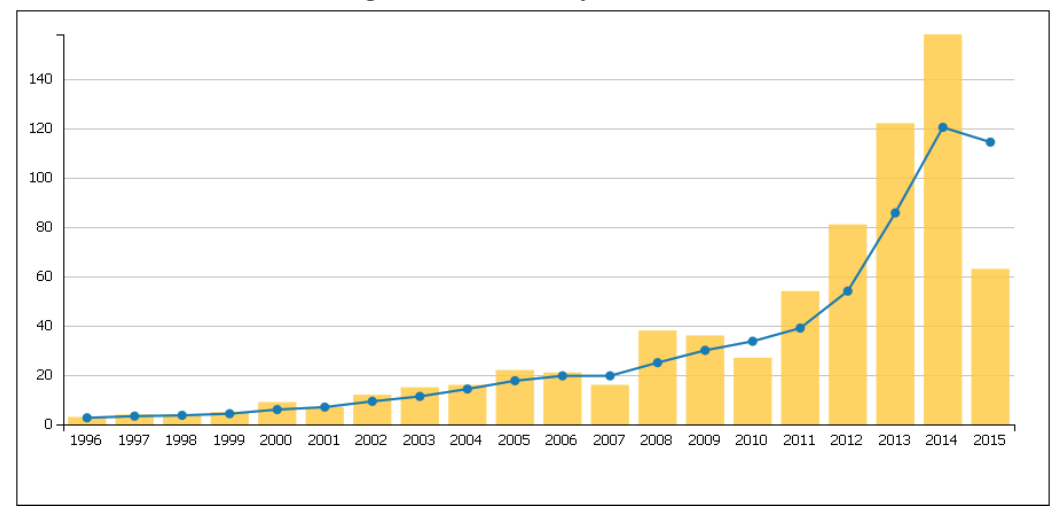

Fuente: Generado a partir de información de Patent Inspiration (agosto de 2015)

5.1.1 Solicitantes que lideran las patentes relacionadas con microorganismos endofíticos hasta 2015

En lo que respecta a las organizaciones que lideran las solicitudes de patentes cabe destacar a Grasslanz Technology Ltda con 36 patentes asignadas, seguido de Gary Strobel con 36 patentes, la Universidad del Estado de Montana con 25, Agriculture Victoria Services Pty Ltd con 23 patentes y la Universidad Jiliang de China con 21 patentes Figura 36.

En el caso de Grazzlanz Technology Ltda, se trata de una organización de Nueva Zelanda, cuyo principal objetivo es brindar soluciones innovadoras en el tema de forrajes XE "Forrajes". De 
otro lado, las innovaciones de Gary Strobel, que le confieren el segundo lugar en ranking de patentes, estan relacionadas especialmente con métodos de aislamiento y aplicaciones en bioremediación.

Figura 36. Número de patentes por solicitante en el tema de microorganismos endofíticos hasta 2015

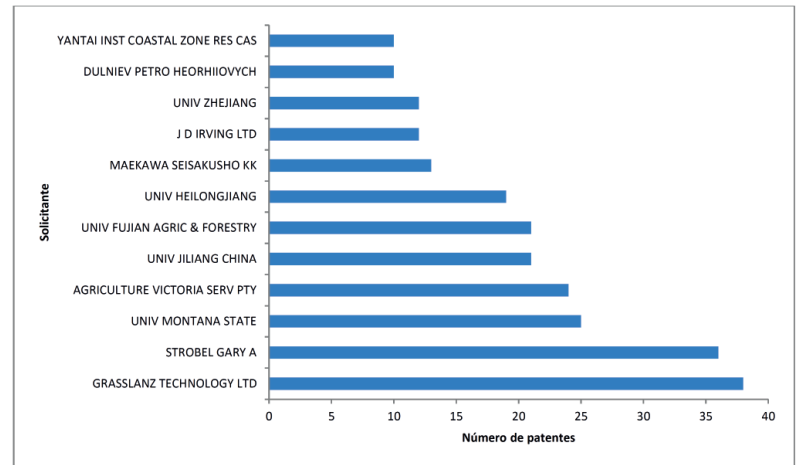

Fuente: Generado a partir de información de Patent Inspiration, agosto de 2015

\subsubsection{Países que lideran las patentes relacionadas con microorganismos endofíticos a 2015}

En relación a los países líderes, como se observa en la Figura 37, se encuentran la China con 331 patentes y los Estados Unidos con 150 como los países con más patentes asignadas.

Figura 37. Número de patentes por país en el tema de microorganismos endofíticos

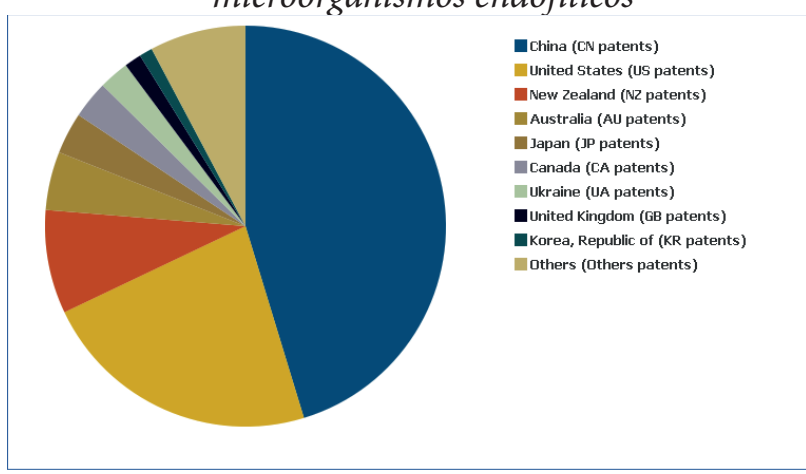

Fuente: Generado a partir de información de Patent Inspiration, agosto de 2015 


\subsubsection{Co-ocurrencia de palabras claves en las patentes relacionadas con microorganismos endofíticos hasta 2015.}

En la Figura 38, se observa la co-ocurrencia de palabras en las patentes, y sobresalen términos asociados a pastos, plagas, semillas "Semillas", especies, alcaloides "Alcaloides", tolerancia, entre otros, que permiten evidenciar un número importante de patentes relacionadas con la productividad "Productividad" de cultivos y control biológico "Control biológico" de plagas.

Figura 38. Ocurrencia de palabras claves en las patentes relacionadas con endofíticos

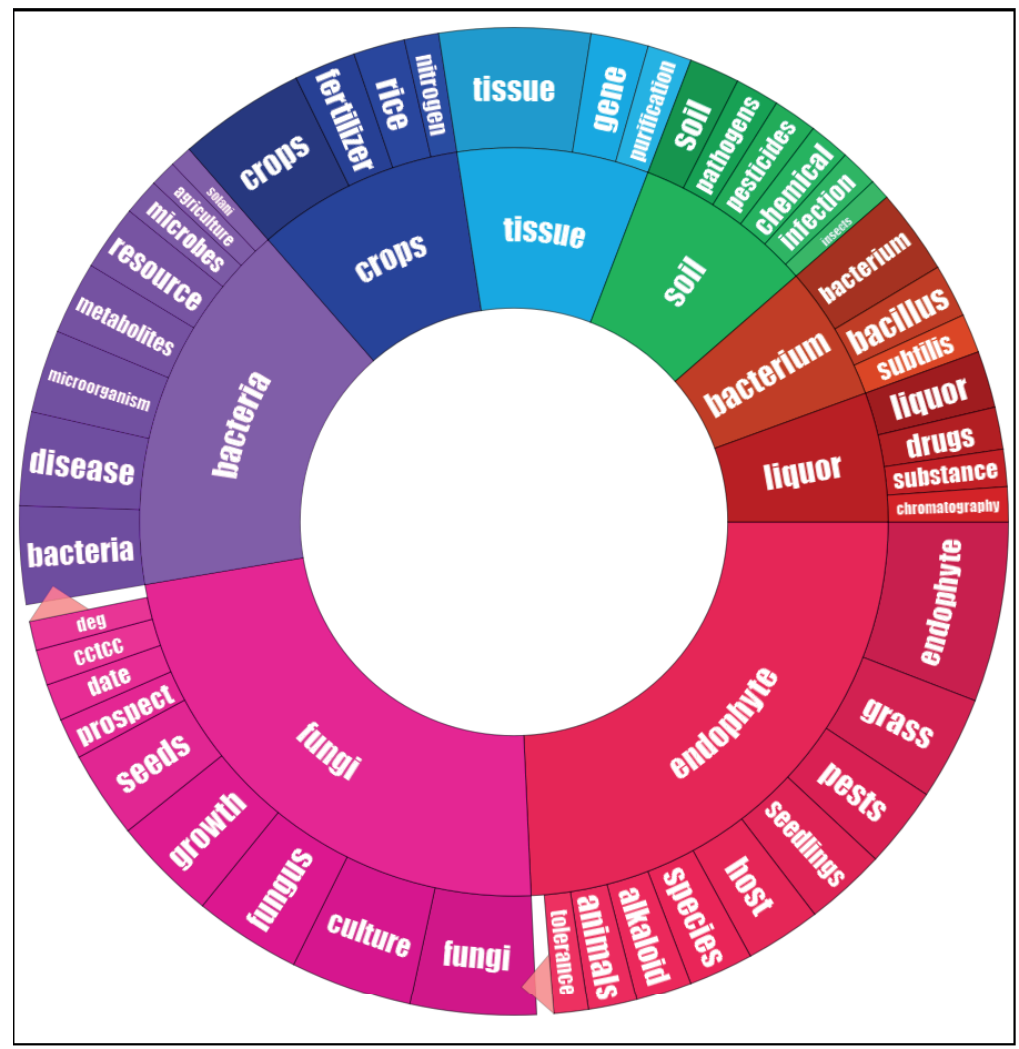

Fuente: Generado a partir de información de Patent Inspiration, agosto de 2015 


\subsubsection{Patentes relacionadas con microorganismos endofíticos según la clasificación internacional de patentes - IPC}

En lo que respecta al número de patentes por código IPC, es interesante observar en la Figura 39, que la mayor cantidad de patentes a lo largo del tiempo, se encuentran en clasificadas en la sección $\mathrm{A}$, relacionada con necesidades corrientes de la vida, específicamente A01, correspondiente a actividades rurales, tales como la Agricultura, "Agricultura" Silvicultura "Silvicultura", entre otros.

Figura 39. Dinámica de patentes relacionadas con organismos endofíticos por año e IPC

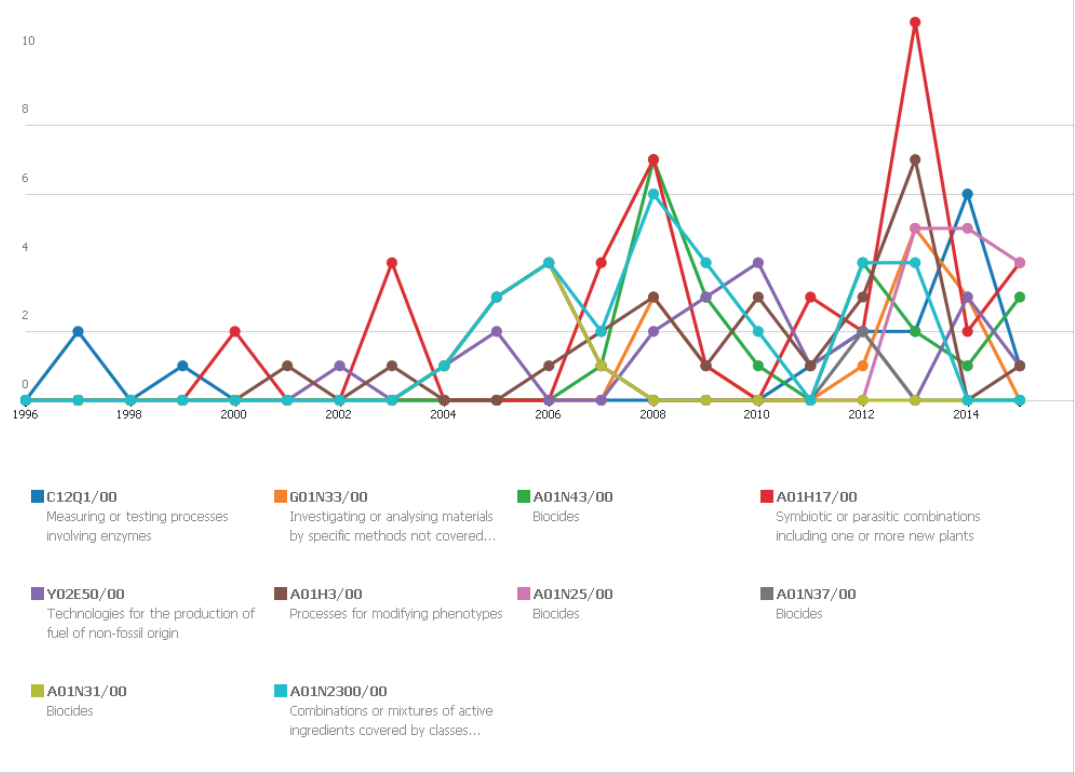

Fuente: Generado a partir de información de Patent Inspiration, agosto de 2015

Analizando de manera más detallada la clasificación IPC, se encuentra que las patentes se encuentran relacionadas con aplicaciones como el desarrollo de biocidas "Biocidas", reguladores del crecimiento de plantas, procesos de modificación de fenotipos, caracterización molecular, entre otros(Tabla 7). 
Tabla 7. Descripción de la clasificación IPC en las que se encuentran las patentes relacionadas con organismos endofiticos

\begin{tabular}{|c|c|}
\hline$\overline{\text { Código (IPC) }}$ & Descripción \\
\hline $\mathrm{A} 01 \mathrm{~N} 37 / 00$ & $\begin{array}{l}\text { Biocides, pest repellants or attractants, or plant growth regulators } \\
\text { containing organic compounds containing a carbon atom having three bonds } \\
\text { to hetero atoms with at the most two bonds to halogen, e.g. carboxylic acids }\end{array}$ \\
\hline $\mathrm{A} 01 \mathrm{~N} 25 / 00$ & $\begin{array}{l}\text { Biocides: Biocides, pest repellants or attractants, or plant growth } \\
\text { regulators, characterised by their forms, or by their non-active ingredients or } \\
\text { by their methods of application, \{e.g. seed treatment or sequential } \\
\text { application; }\} \text { (apparatus for the destruction of noxious animals or noxious } \\
\text { plants A01M; fungicidal, bactericidal, insecticidal, disinfecting or antiseptic } \\
\text { paper D21H); Substances for reducing the noxious effect of the active } \\
\text { ingredients to organisms other than pests. }\end{array}$ \\
\hline $\mathrm{A} 01 \mathrm{~N} 43 / 00$ & $\begin{array}{l}\text { Biocides: Biocides, pest repellants or attractants, or plant growth } \\
\text { regulators containing heterocyclic compounds. }\end{array}$ \\
\hline $\mathrm{A} 01 \mathrm{~N} 31 / 00$ & $\begin{array}{l}\text { Biocides: Biocides, pest repellants or attractants, or plant growth } \\
\text { containign organic oxygen or sulfur compounds }\end{array}$ \\
\hline A01H17 & $\begin{array}{l}\text { Combinaciones de simbióticos o parásitos que comprendan una o más } \\
\text { variedades nuevas, p. ej. micorrizas ( líquenes A01H 15/00) }\end{array}$ \\
\hline \multicolumn{2}{|r|}{ Otras clasificaciones dinamizadas en los últimos años $(2010-2015)$} \\
\hline $\mathrm{A} 01 \mathrm{H} 3 / 00$ & Processes for modifying phenotypes \\
\hline C12Q2600/00 & Oligonucleotides characterized by their use \\
\hline $\mathrm{C} 12 \mathrm{R} 1 / 00$ & Microorganismos \\
\hline Y02E50 & biofuels - bioethanol \\
\hline Código (IPC) & Descripción \\
\hline $\mathrm{A} 01 \mathrm{~N} 37 / 00$ & $\begin{array}{l}\text { Biocides, pest repellants or attractants, or plant growth regulators } \\
\text { containing organic compounds containing a carbon atom having three bonds } \\
\text { to hetero atoms with at the most two bonds to halogen, e.g. carboxylic acids }\end{array}$ \\
\hline
\end{tabular}




\begin{tabular}{|c|c|}
\hline $\mathrm{A} 01 \mathrm{~N} 25 / 00$ & $\begin{array}{l}\text { Biocides: Biocides, pest repellants or attractants, or plant growth } \\
\text { regulators, characterised by their forms, or by their non-active ingredients or } \\
\text { by their methods of application, \{ e.g. seed treatment or sequential } \\
\text { application; \}(apparatus for the destruction of noxious animals or noxious } \\
\text { plants A01M; fungicidal, bactericidal, insecticidal, disinfecting or antiseptic } \\
\text { paper D21H);Substances for reducing the noxious effect of the active } \\
\text { ingredients to organisms other than pests. }\end{array}$ \\
\hline $\mathrm{A} 01 \mathrm{~N} 43 / 00$ & $\begin{array}{l}\text { Biocides: Biocides, pest repellants or attractants, or plant growth } \\
\text { regulators containing heterocyclic compounds. }\end{array}$ \\
\hline $\mathrm{A} 01 \mathrm{~N} 31 / 00$ & $\begin{array}{l}\text { Biocides: Biocides, pest repellants or attractants, or plant growth } \\
\text { containign organic oxygen or sulfur compounds }\end{array}$ \\
\hline A01H17 & $\begin{array}{l}\text { Combinaciones de simbióticos o parásitos que comprendan una o más } \\
\text { variedades nuevas, p. ej. micorrizas ( líquenes A01H 15/00) }\end{array}$ \\
\hline \multicolumn{2}{|r|}{ Otras clasificaciones dinamizadas en los últimos años $(2010-2015)$} \\
\hline $\mathrm{A} 01 \mathrm{H} 3 / 00$ & Processes for modifying phenotypes \\
\hline $\mathrm{C} 12 \mathrm{Q} 2600 / 00$ & Oligonucleotides characterized by their use \\
\hline C12R1/00 & Microorganismos \\
\hline Y02E50 & biofuels - bioethanol \\
\hline
\end{tabular}

En la Figura 40, se puede observar la evolución en el tiempo del número de patentes por IPC. Teniendo en cuenta esta dinámica es interesante identificar que las patentes clasificadas con el código A01N63, relacionado con biocidas ${ }^{1}$ presentan una producción constante y creciente en el tiempo. De otro lado, algunos códigos que se han dinamizado en los últimos años son:

\section{- A01N25: biocidas}

- AO1H17: combinaciones de simbióticos o parásitos que comprenden una o más variedades nuevas.

1 Biocidas, productos que repelen o atraen a los animales perjudiciales, o reguladores del crecimiento de los vegetales, que contienen microorganismos, virus, hongos microscópicos, animales, p. ej. nematodos, o sustancias producidas por, u obtenidas a partir de microorganismos, virus, hongos microscópicos o animales, p.ej. encimas o productos de fermentación 
- C12N15: técnicas de mutación o ingeniería genética.

- C12R1: Microorganismos.

Figura 40. Evolución en el tiempo de las patentes relacionadas con organismos endofíticos a partir del IPC

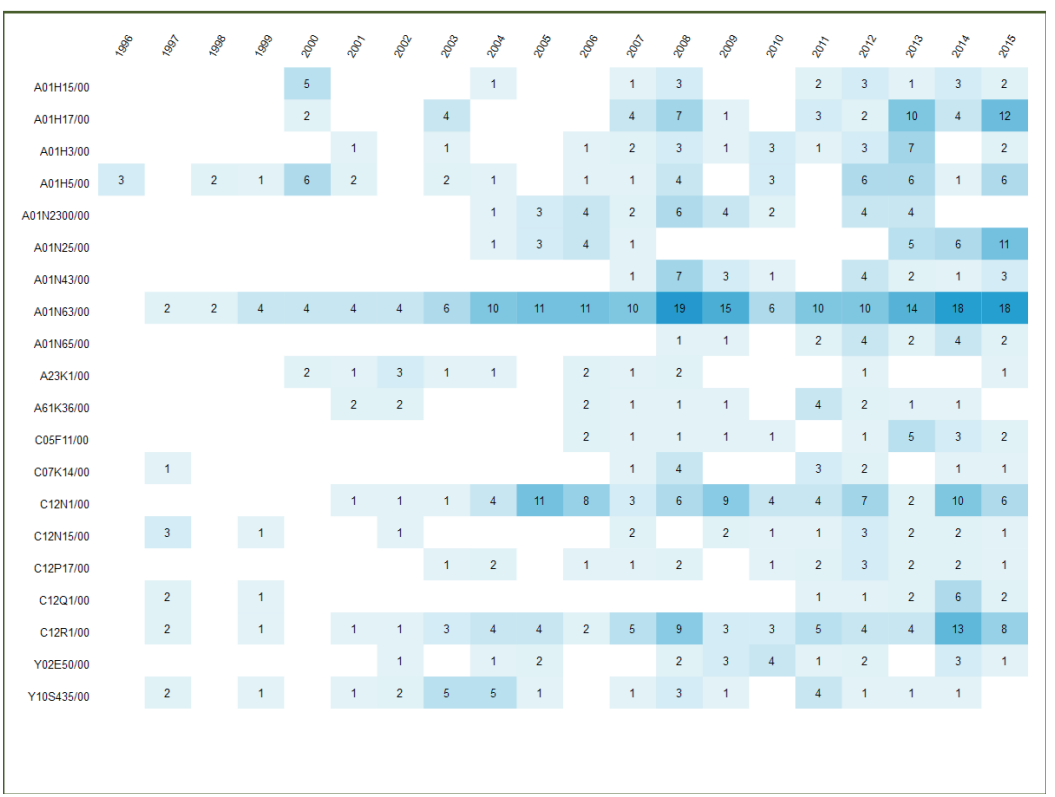

Fuente: Generado a partir de información de Patent Inspiration, agosto de 2015

5.2 Dinámica general de patentes relacionadas con el tema microorganismos endofíticos en el periodo de tiempo 2015 - 2020

La dinámica de patentes en el periodo de tiempo 2015 - 2020 relacionadas con endofíticos se reportan 1244 solicitudes, lo que comparado con el histórico representa un incremento del $41.2 \%$, la dinámica de este rango de tiempo se representa en la Figura 41, en todos los años el número de patentes es mayor a 160 registros por año, siendo notable el año 2019 con 286 registros y el año 2018 con 228 solicitudes. 
Figura 41. Número de patentes por año relacionados con microorganismos endofíticos 2015 - 2020

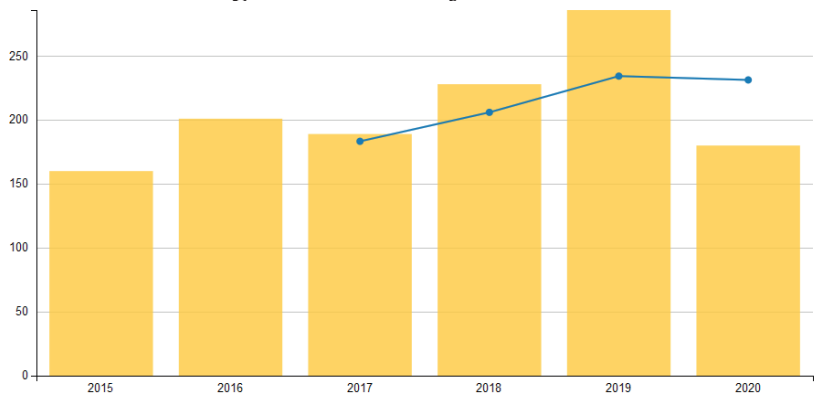

Fuente: Generado a partir de información de Patent Inspiration (marzo de 2021)

\subsubsection{Solicitantes que lideran las patentes relacionadas con microorganismos endofíticos en el periodo $2015-2020$}

Las organizaciones y o personas que lideran las solicitudes de patentes para este periodo de tiempo se puede destacar en primer lugar a Geoffreyn Von Maltzahn con 95 solicitudes en estos cinco años, en segundo lugar se encuentra Slavica Djonovic con 94 solicitudes de patentes, en tercer lugar Gerardo Toledo con 90 patentes, además se puede observar otras personas Luis Miguel Márquez (83), Craig Sadowski (73) y David Morris Johnston (72), como se observa en la Figura 42.

Figura 42. Número de patentes por solicitante relacionadas con microrganismos endofíticos 2015 - 2020

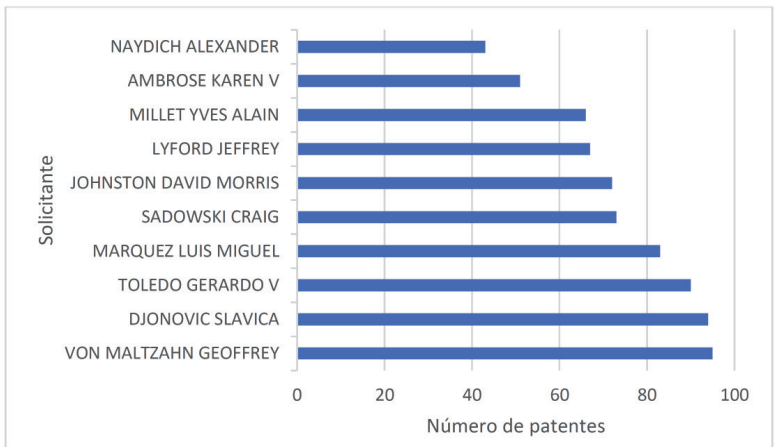

Fuente: generado a partir de información de Patent Inspiration, marzo 2021 


\subsubsection{Países que lideran patentes relacionadas con endofíticos en el periodo de 2015 - 2020}

Los países líderes se pueden observar en la Figura 43, se relaciona China con 540 patentes, Estados Unidos 250 patentes, sumados China y estados unidos representan el 63.5\% las patentes de este periodo de tiempo. Australia con 64 patentes se ubica en un tercer lugar.

Otros países como Nueva Zelanda (34), Canada (27), Austria (26) y Corea del Sur (14).

\subsubsection{Co-ocurrencia de palabras claves en las patentes relacionadas con endofíticos en el periodo 2015 2020}

En la Figura 44, se observa la co-ocurrencia en las patentes y sobresalen por su frecuencia se pueden encontrar relacionadas a endofíticos como pastos, cereales, nutrientes, semillas y germinación, la palabra clave cultivo se relaciona con tejidos, explante vegetal, acetato, hongo se relaciona con bacteria, prospección, enfermedades, crecimiento. Arroz se relaciona con tabaco, residuos, soya, arboles. La palabra alcaloide se relaciona con infección, animales, consumo, energía. La palabra tolerancia se relaciona con nematodos, y tabaco.

Figura 43. Número de patentes por país en el tema de microorganismos endofíticos en el periodo 2015 - 2020.

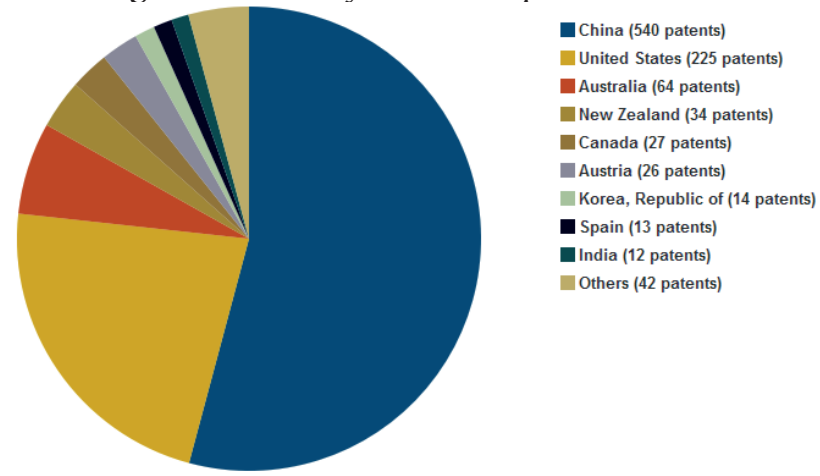

Fuente: generado a partir de información de Patent Inspiration, marzo de 2021 
Figura 44. Ocurrencia de palabras claves en las patentes relacionadas con endófitos en el periodo 2015 - 2020

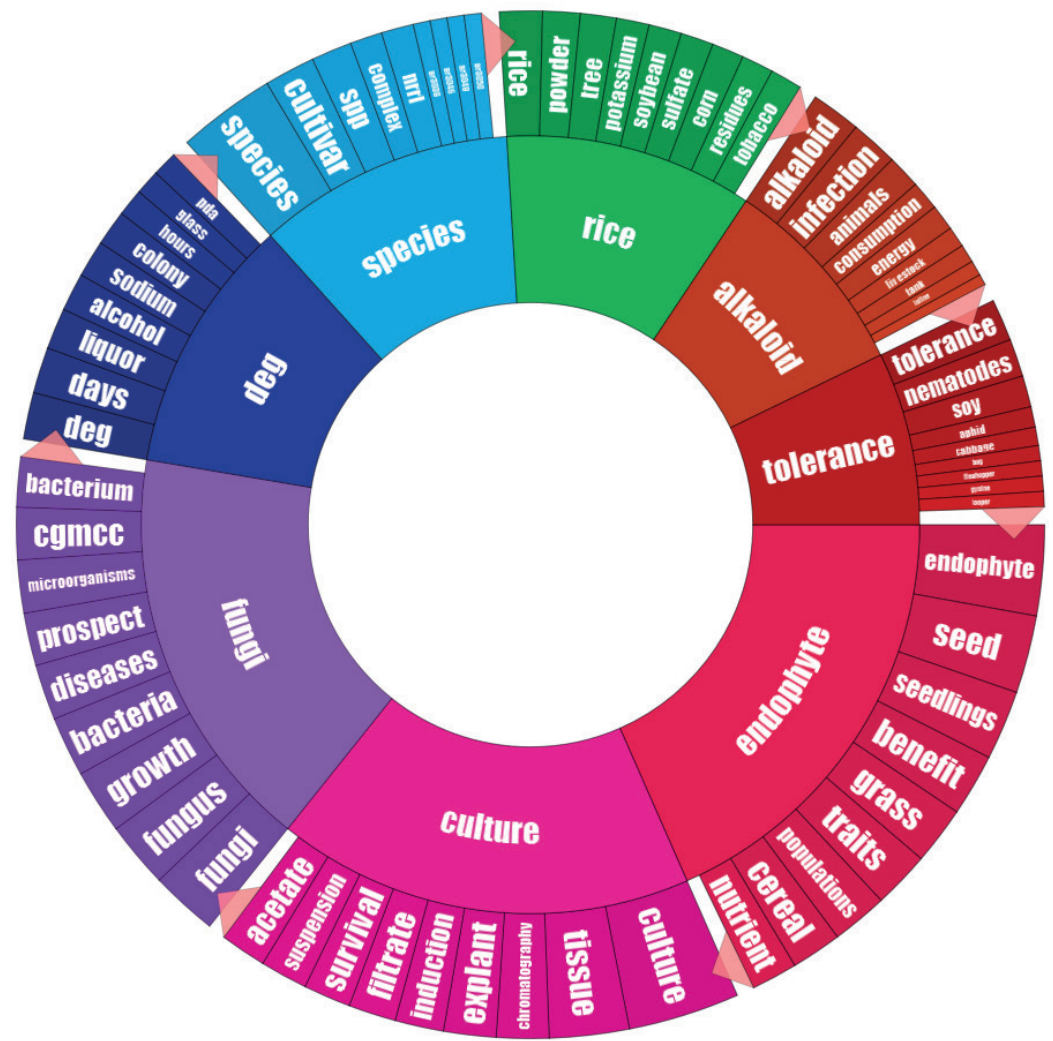

Fuente: Generado a partir de información de Patent Inspiration, marzo de 2021

\subsubsection{Patentes relacionadas con microorganismos según la clasificación internacional de patentes - IPC}

En relación con el código de clasificación de patentes IPC, se puede observar en la Figura 45, se encuentra el mayor número en la sección C. relacionada con la química y la metalurgia, en este caso se la categoría $\mathrm{C} 12 \mathrm{~N} 1 / 00$, relacionado con los microorganismos, preparaciones derivadas de microorganismos como bacterias, hongos, los procesos de preservación, propagación de los microorganismos y los procesos de aislamiento y cultivo 
de los microorganismos. La sección A está relacionada con las necesidades corrientes de la vida, especialmente, con biocidas, atracción o repelentes de parásitos o reguladores de crecimiento especialmente.

Figura 45. Patentes relacionadas con organismos endofíticos y los códigos IPC en el periodo 2015 - 2020

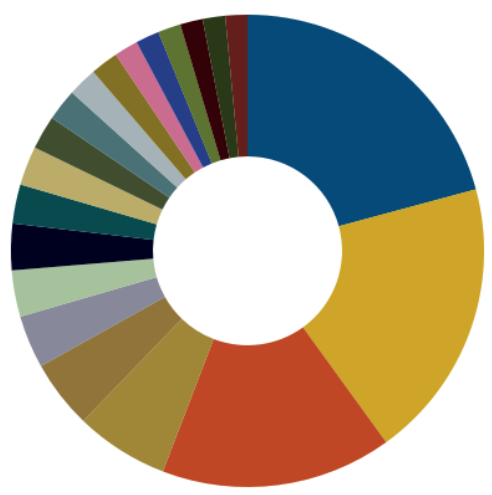

EC12N1/00 (622 patents, 21\%) Microorganisms C12R1/00 (575 patents, 19\%) Microorganisms

A01N63/00 (472 patents, 16\%) Biocides

A01P3/00 (191 patents, 6\%) Fungicides

A01P21/00 (140 patents, 5\%) Plant growth regulators

A01C1/00 (108 patents, 4\%) Apparatus

A01H17/00 (95 patents, 3\%) Symbiotic or parasitic combinations

including one or more new plants

C12P17/00 (95 patents, 3\%) Preparation of heterocyclic carbon

compounds with only $\mathrm{O}$

口 12Q1/00 (80 patents, 3\%) Measuring or testing processes involving enzymes

A01G7/00 (80 patents, 3\%) Botany in general

C12N15/00 (69 patents, 2\%) Mutation or genetic engineering

a $01 \mathrm{H} 5 / 00$ (65 patents, $2 \%$ ) Angiosperms

A01P1/00 (60 patents, 2\%) Disinfectants

- C05F11/00 (57 patents, $2 \%$ ) Other organic fertilisers

A01H4/00 (49 patents, 2\%) Plant reproduction by tissue culture

Fuente: Generado a partir de información de Patent Inspiration, marzo de 2021 


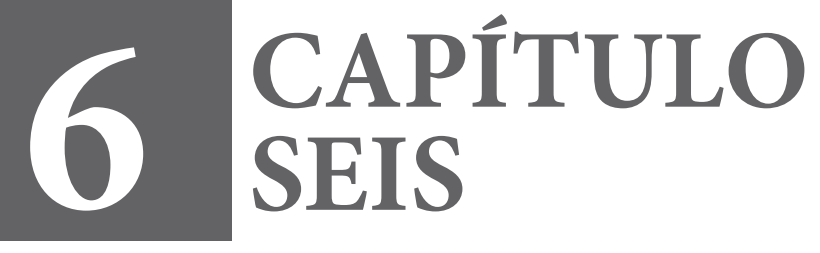




\section{Capacidades nacionales}

\subsection{Análisis de capacidades nacionales}

Para las analizar las capacidades nacionales a partir de las publicaciones indexadas en Scopus, se utilizó la ecuación de búsqueda TITLE-ABS-KEY (endophytic), limitando los resultados solo a Colombia, con el objetivo de cubrir todas las publicaciones que contengan este término. Los resultados obtenidos fueron 21 publicaciones en un periodo de tiempo comprendido entre el 2001 y el 2015. Para el periodo de tiempo 2015 - 2020 se registraron 32 publicaciones implicando un aumento del $60.4 \%$ en los últimos años.

De forma complementaria se realizó una búsqueda en bases de datos de Universidades Nacionales y en Redalyc, en donde se encontraron ocho publicaciones adicionales, para un total de $\mathbf{2 9}$ publicaciones nacionales ( Anexo 1).

\subsubsection{Dinámica general de publicaciones nacionales relacionadas con organismos endofíticos en Colombia hasta el 2015}

En la Figura 46, se muestra la dinámica que han tenido las publicaciones relacionadas con organismos endofíticos en Colombia, siendo los años 2009 y 2012 los que registran el mayor número de artículos. 
Figura 46. Número de publicaciones por año relacionadas con organismos endofiticos en Colombia

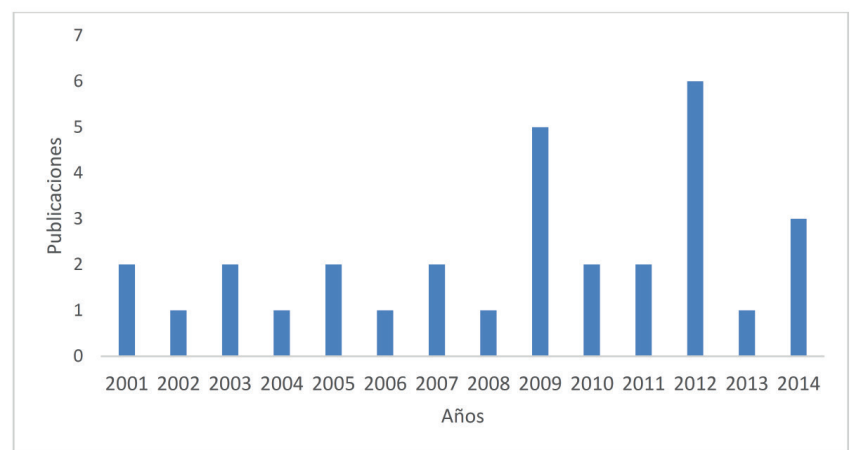

Fuente: elaboración propia de acuerdo con la base de datos de Scopus (Elsevier, B.V. 2015).

\subsubsection{Instituciones líderes - microorganismos endofíticos hasta el 2015}

En lo que respecta a las instituciones nacionales líderes en publicaciones relacionadas con organismos endofíticos, como se observa en la Figura 47, se destacan la Universidad Nacional de Colombia y el Centro Internacional de Agricultura Tropical - CIAT, seguido de la Universidad de los Andes y la Pontificia Universidad Javeriana.

Figura 47. Instituciones Colombianas con publicaciones en organismos endofíticos

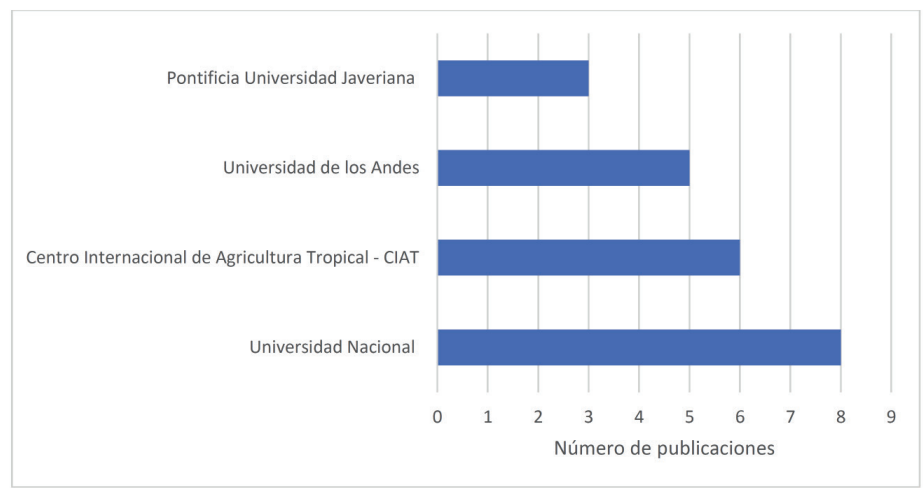

Fuente: elaboración propia de acuerdo con la base de datos de Scopus (Elsevier, B.V. 2015). 


\subsubsection{Dinámica general de publicaciones nacionales relacionadas con organismos endofíticos en Colombia 2015 al 2020}

Durante este periodo de tiempo, se registran 32 publicaciones, Figura 48. Número de publicaciones en Colombia por año en el tema organismos endófitos 2015 - 2020, se puede identificar del 2015 al 2016 una tendencia alcista, y bajista durante el periodo 2016 - 2017 (3.1\%).

A partir de este año 2017, se registran el $25.0 \%$ en 2019 y el 2020 con el $34 \%$ de las publicaciones con un crecimiento ascendente, especialmente en los dos últimos años donde se registran el $68.4 \%$ de las publicaciones de este periodo. Lo que denota una emergencia de publicaciones en el tema de los organismos endofíticos en el país.

Figura 48. Número de publicaciones en Colombia por año en el tema organismos endófitos 2015 - 2020

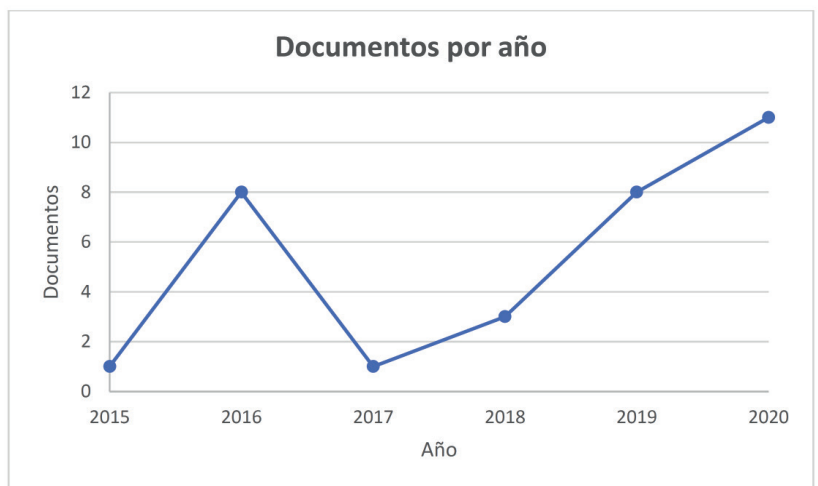

Fuente: elaboración propia de acuerdo con la base de datos de Scopus (Elsevier, B.V. 2020).

\subsubsection{Instituciones líderes - microorganismos endofíticos 2015 - 2020}

Las instituciones líderes en el desarrollo de investigaciones en organismos endofíticos se relacionan en la Figura 49, se aprecian las 11 primeras instituciones a nivel nacional que reportan al 
menos dos publicaciones en el rango del periodo de tiempo. Las cuales aportan 32 de las 32 publicaciones, las cuales encontramos seis son universidades públicas y dos universidades privadas y una corporación de investigación agrícola pública y el Centro de Investigación Agricultura Tropical CIAT.

Figura 49. Número de publicaciones por institución Nacionales relacionadas con el tema microorganismos endofíticos 2015 - 2020

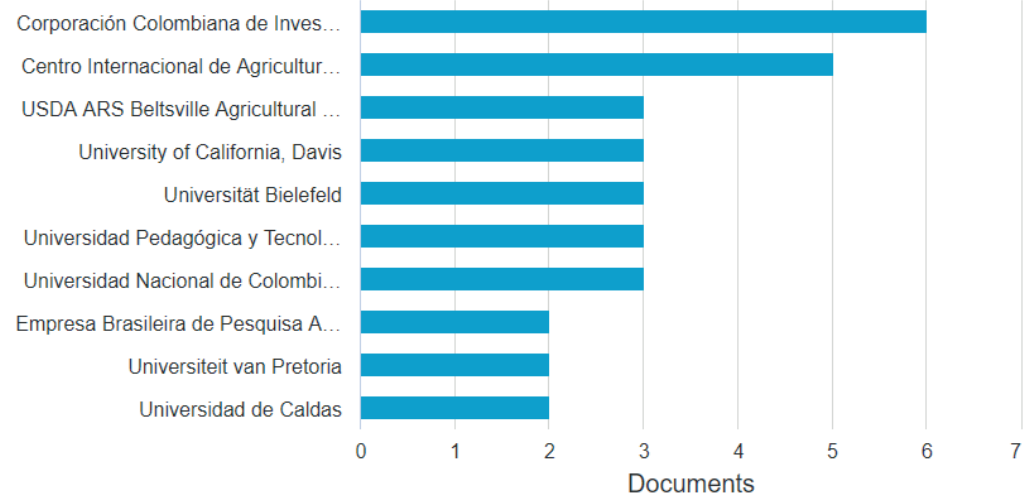

Fuente: elaboración propia de acuerdo con la base de datos de Scopus (Elsevier, B.V. 2020).

La institución que más publicaciones presenta es La Corporación Colombiana de Investigación Agropecuaria AGROSAVIA con el 18.8\% de las publicaciones, en segundo lugar, se encuentra El Centro Internacional de Agricultura Tropical, en tercer lugar, la Universidad Nacional de Colombia y sus sedes con el $14.3 \%$ para cada una.

Otras instituciones presentan publicaciones a nivel nacional, como la Universidad Pedagógica y Tecnología de Colombia (9.4\%), La Universidad de Caldas, La Universidad de Antioquia, y la Universidad del Valle, Universidad ICESI, Universidad de Santander y Universidad Simón Bolívar; cada una de ellas con el $6.23 \%$. 


\subsubsection{Autores a nivel nacional en investigación de organismos endófitos 2015 - 2020}

En la Figura 50, se encuentran destacados los 11 autores nacionales, relacionados con el número de publicaciones relacionadas con endofíticos, de los cuales sobresale con tres trabajos científicos publicados, Viviana Ortiz y Soroush Parsa adscritos al Centro Internacional de Agricultura Tropical CIAT, en Palmira - Valle del Cauca, con hongos endofíticos entomopatógenos. El segundo autor es Nelson Hernando Caicedo de la Universidad ICESI, en Cali - Valle del Cauca, el cual cuenta con dos publicaciones relacionadas la capacidad de biosíntesis y de bio-transformación de compuestos, especialmente actividad biocatalítica y actividad antioxidante de diferentes hongos endofíticos. En tercer lugar, se ubica Ehidy Rocio Peña Cañón de la Universidad Pedagógica y Tecnológica de Colombia UPTC, en Tunja - Boyacá. Con dos publicaciones, una de ellas sobresale por estar relacionada a la descripción de hongos endolicénicos o endoliquenico (hongos que habitan el interior de los líquenes) perteneciente al género Xylaria spp.

Viviana Ortiz y Soroush Parsa del CIAT, con tres publicaciones presenta sobresale investigación de hongos endofíticos aislados diferentes partes de plántulas de fríjol común (Phaseolus vulgaris), el segundo trabajo de investigación está relacionado con la planta de yuca (Cassava sp.), enfocado el diseño de tratamientos entomopatógenos con hongos endofíticos Beauveriana Bassiana y Metarhizium anisopliae a partir de inoculación de suspensiones de conidios en el suelo. El tercer trabajo continúa enfocado con los hongos endofíticos entomopatógenos Beauveriana Bassiana y Metarhizium anisopliae inoculados en semilla de fríjol común (Phaseolus vulgaris). 
Figura 50. Número de publicaciones nacionales por Autor relacionadas con el tema microorganismos endofíticos 2015 - 2020

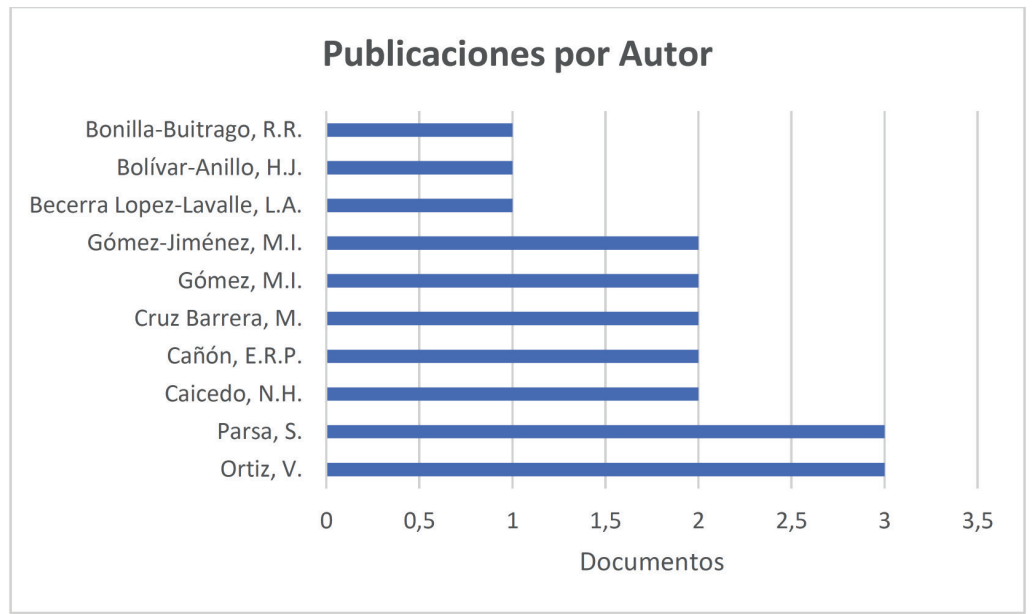

Fuente: Elaboración propia de acuerdo con la base de datos de Scopus (Elsevier, B.V. 2020).

Nelson Hernando Caicedo de la Universidad ICESI, con sus dos trabajos relacionados bioquímica hongos endofíticos basidiomicetos y ascomicetos. Se destaca una investigación para evaluar la capacidad antioxidante de los extractos crudos del hongo endofítico Fusarium oxysporum aislado de las hojas de el árbol medicinal Otoba gracilipes. Un trabajo más reciente de este autor está relacionado con la capacidad de biotransformación de sustratos para la generación de aromas con potencial implementación en diferentes sectores de la industria.

Ehidy Rocio Peña Cañón de la UPTC, cuenta con dos trabajos con microorganismos endofíticos, como hongos endofíticos y hongos endoliquenicos. Estas publicaciones resaltan debido que el estudio de hongos endofítico del género Juncaceicola aislado de un pasto nativo de la región antártica Deshampsia antárctica (Poaceae), La Antártica como zona de estudio es una región de extrema temperatura, poco explorada en vegetación y en hongos endofíticos. En su más reciente estudio se ha enfocado en el aislamiento en laboratorio de Xylaria sp., hongo endoliquenico 
aislado de Cladonia curta (cladoniaceae), resulta un interesante y poco explorado campo de estudio de microorganismos endofíticos.

Otros autores colombianos son reportados presentar al menos dos publicaciones relacionadas con microorganismos endofíticos como Mauricio Cruz Barrera y Martha I Gómez de Corporación Colombiana de Investigación Agropecuaria AGROSAVIA, Bogotá. María Isabel Gómez Jiménez de CIAT, Palmira. Carlos Alberto Rodas de la Universidad de Pretoria, Sudáfrica.

Los autores con una investigación publicada en el rango de tiempo de 2015 - 2020 son: Luis Augusto Becerra Lopez-Lavalle de CIAT, Palmira. Hernando José Bolívar-Anillo de Universidad Simón Bolívar, Barranquilla. Ruth Rebeca Bonilla-Buitrago de AGROSAVIA, Bogotá, entre algunos otros.

A continuación, en la Tabla 8, podemos encontrar a manera de resumen, la información asociada a los autores más representativos en publicación de hongos endofíticos en el periodo 2015 al 2020, con su afiliación completa, el total de citaciones de sus publicaciones y la cantidad de documentos en los que han sido citados, el número total de documentos publicados, el número de co-autores que han participado en sus publicaciones y las principales áreas temáticas. 
Tabla 8. Información de los principales autores que publican temas relacionados con organismos endofíticos 2015 - 2020 en Colombia.

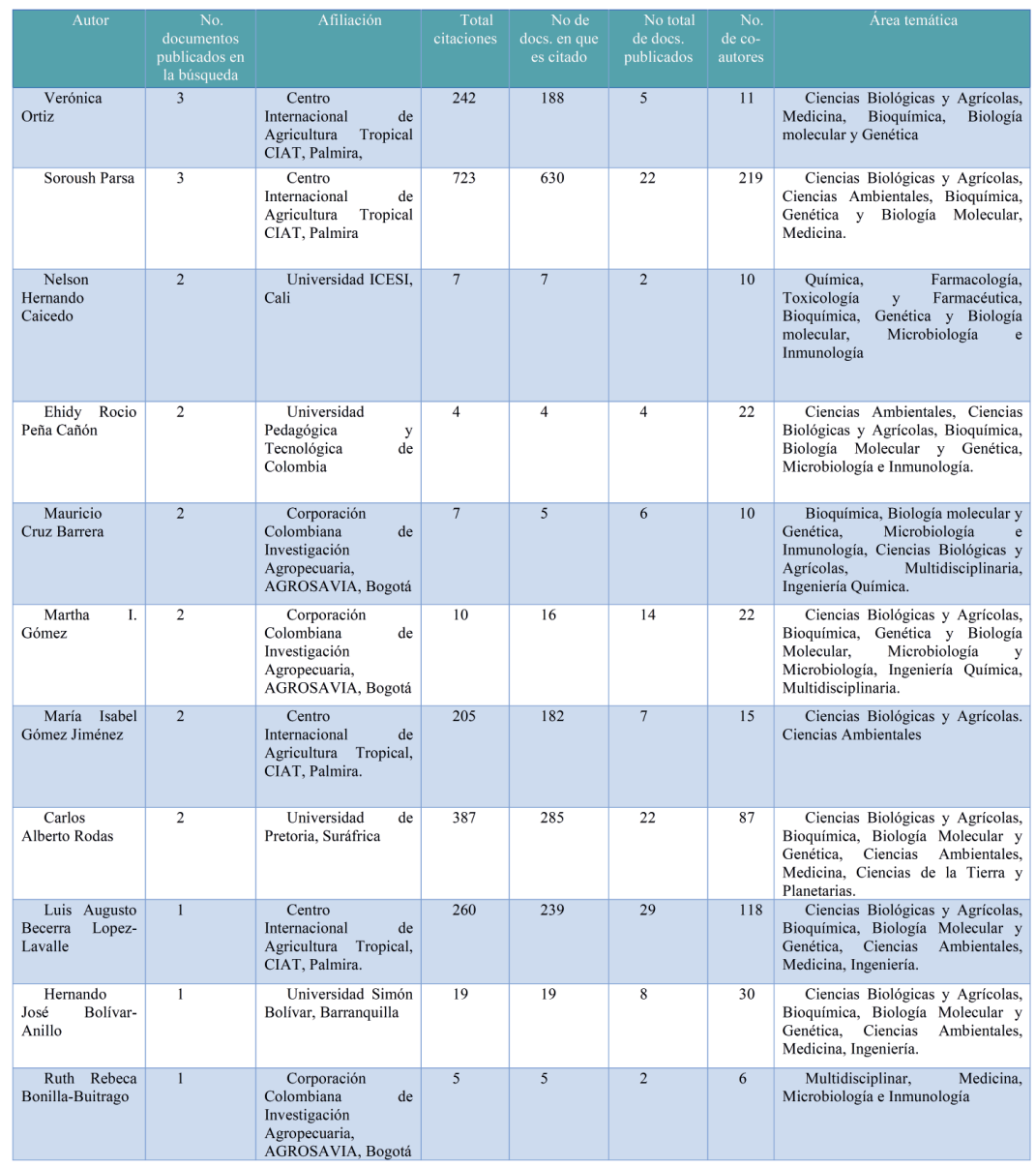

Fuente: Elaboración propia de acuerdo con la base de datos de Scopus (Elsevier, B.V. 2020)

\subsubsection{Principales áreas de conocimiento - Microorganismos endofíticos en Colombia 2015-2020}

En la Figura 51, se muestran las áreas del conocimiento en las que se catalogan las publicaciones relacionadas con Colombia en el periodo comprendido entre 2015 al 2020. La principal área es Ciencias Agrícolas y Biológicas con el 33.9\% de las publicaciones, 
seguidodeBioquímica, Genéticay Biología Molecular con el 18.6\%, Química (6.8\%), Ciencias Ambientales (6.8\%), Microbiología e inmunología (6.8\%), Medicina (6.8\%) Multidisciplinar (3.4\%), Farmacología, Farmacéutica y Toxicología (3.4\%), entre otros.

Figura 51. Distribución del número de publicaciones en Colombia por área del conocimiento relacionadas con el tema microorganismos endofítico 2015 - 2020

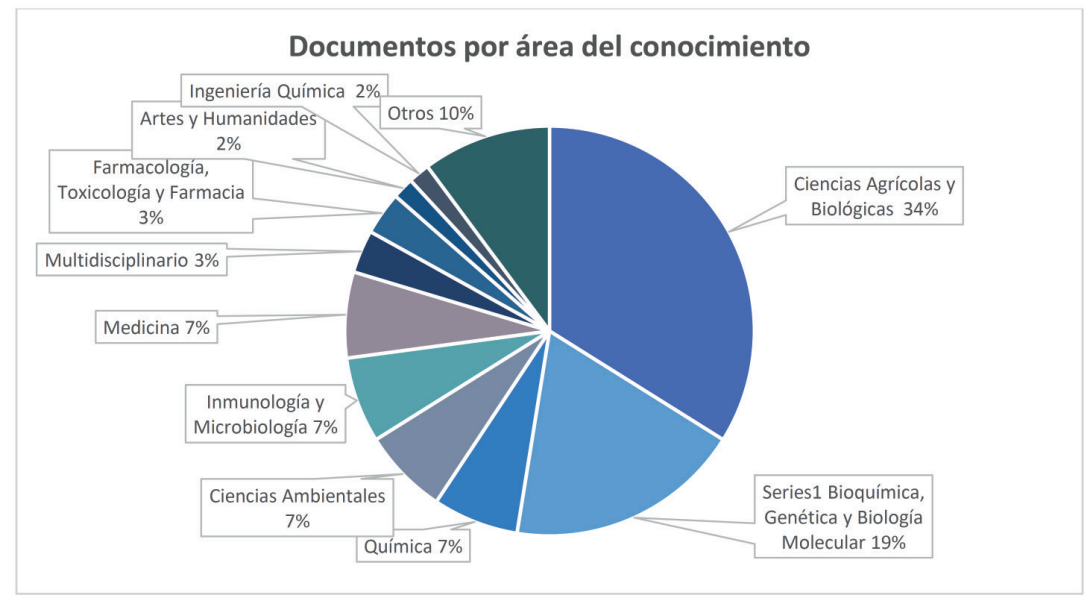

Fuente: Elaboración propia de acuerdo con la base de datos de Scopus (Elsevier, B.V. 2020).

\subsubsection{Principales journals con publicaciones relacionadas a microorganismos endofíticos 2015 - 2020 en Colombia.}

Las dinámicas de publicación de los Journal durante el periodo de tiempo son muy escasas e intermitentes en el tiempo tales como; Control Biological (2), Fungal Biology (2), Molecules (2), Acta Biológica Colombiana (1), Acta Botánica Hungarica (1), entre otras. Se puede interpretar que aún es escasa la dinámica de publicación y los temas variados no permiten que se concentren en el tiempo ni en temáticas específicas de los Journals. 


\subsubsection{Colaboración de Colombia con otros países en investigaciones de microorganismos endofíticos durante 2015 - 2020}

Durante la revisión de la información se ha detectado que los investigadores colombianos han trabajado con instituciones de otros países, en la Figura 52, se muestran países como Alemania (5), Estados Unidos (5), Brasil (4), Australia (3), Chile (2) y Sudáfrica (2). Otros países como Canadá, China, Costa Rica, Italia, Holanda, Nueva Zelanda y España figuran con una publicación en colaboración con autores colombianos.

Esta dinámica, puede describirse desde las estancias o pasantías de investigación de maestría y doctorado, lo que traduce en asesorías de trabajo de grado e intercambios profesionales en los diferentes grupos de investigación de estos países involucrados.

Figura 52. Países y número de publicaciones relacionadas con las publicaciones colombianas en el periodo 2015 - 2020

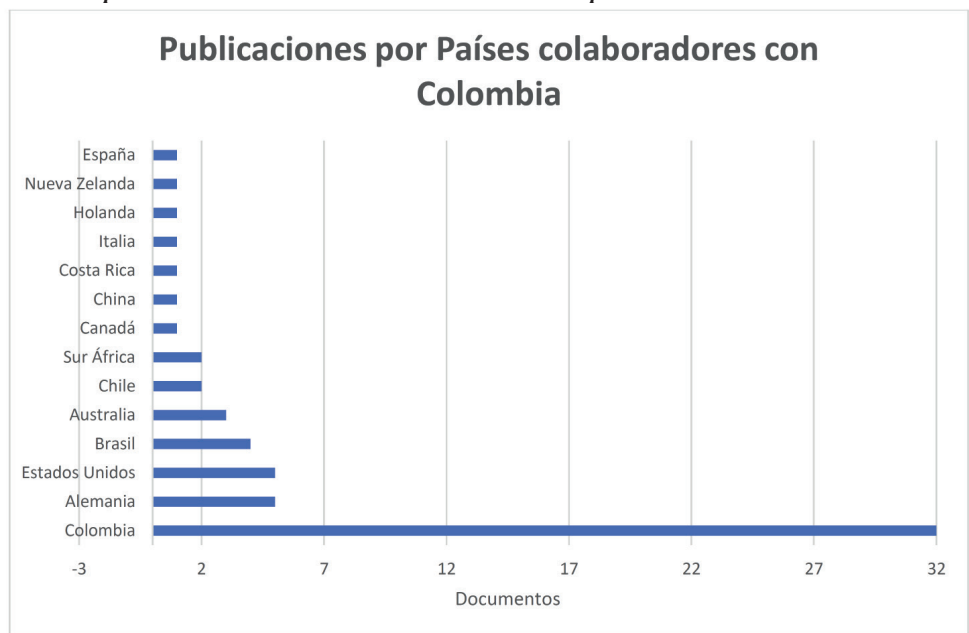

Fuente: Elaboración propia de acuerdo con la base de datos de Scopus (Elsevier, B.V. 2020). 


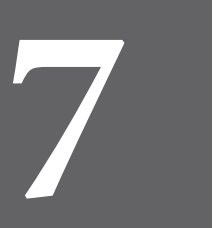

CAPÍTULO

SIETE 


\section{Perspectivas mundiales sobre las aplicaciones actuales y desarrollos de hongos y bacterias endofíticas.}

Muchos metabolitos bioactivos se originan a partir de organismos microbianos, los hongos son los principales grupos importantes de organismos eucariotas que tienen gran capacidad para producir numerosos metabolitos con actividad antimicrobiana y poseen potencial aplicación como fármacos (Fouda et al., 2015).

La estrecha relación que existe entre el endofítico y su planta hospedera se considera de gran importancia, ya que el hongo es capaz de producir metabolitos bioactivos "Metabolitos bioactivos", así como modificar los mecanismos de defens "Mecanismos de defensa" a de su hospedera, permitiendo e incrementando la sobrevivencia de ambos organismos. Estudios recientes demuestran la enorme capacidad que tienen los hongos endofíticos para producir compuestos activos que le confieren protección a su hospedera contra el ataque de patógenos y herbívoros, constituyendo una nueva vía para la obtención de diversos precursores o moléculas novedosas de utilidad en la agricultura y en la medicina (Sánchez-Fernández et al., 2013).

El análisis de tendencias, tanto a partir de publicaciones científicas como de patentes, logra hacer una aproximación a las diversas aplicaciones que se están llevando a cabo utilizando compuestos activos y características funcionales de hongos y bacterias endofíticas. A continuación, se describen algunas de las principales aplicaciones: 


\title{
7.1 Principales aplicaciones y desarrollos con hongos endofíticos
}

\author{
En la Tabla 9., se mencionan algunas de las aplicaciones más \\ destacadas en relación con hongos endofíticos.
}

Tabla 9. Principales Aplicaciones y desarrollos con hongos endofiticos

\begin{tabular}{|c|c|}
\hline Aplicación & Observaciones \\
\hline $\begin{array}{l}\text { Actividad } \\
\text { anti-bacterial }\end{array}$ & $\begin{array}{l}\text { Aegle marmelos, es una especie de árbol de la familia de las rutáceas, } \\
\text { de importancia medicinal y religiosa en la India. En un estudio, } \\
\text { publicado en 2015, por Patil y colaboradores del departamento de } \\
\text { Microbiología y Biotecnología de la R. C. Patel Arts, Commerce and } \\
\text { Science College, en Shirpur, India, aislaron, identificaron y evaluaron } \\
\text { las actividades biológicas de los hongos endofíticos de esta planta, } \\
\text { siendo uno de los identificados Aspergillus flavus. El extracto mostró } \\
\text { una excelente actividad antimicrobiana frente a bacterias y hongos } \\
\text { patógenos humanos comunes. El análisis HPLC confirmó la presencia } \\
\text { de rutina bioflavonoide en el extracto. El hongo endofítico A. flavus } \\
\text { obtenido de la planta A. marmelos podrían explorarse como un recurso } \\
\text { natural económico y potencial con actividades biológicas diversas y } \\
\text { farmacéutico. }\end{array}$ \\
\hline $\begin{array}{l}\text { Actividad } \\
\text { anti - cáncer }\end{array}$ & $\begin{array}{l}\text { En una publicación de Chandra, Sheela (India) en } 2013 \text { titulada: } \\
\text { "Endophytic fungi: Novel sources of anticancer lead molecules" se hace } \\
\text { referencia a compuestos derivados de plantas como fuente de sustancias } \\
\text { anti- cáncer clínicamente útiles. Estos incluyen vinblastina, vincristina, } \\
\text { camptotecina, podofilotoxina, y taxol. }\end{array}$ \\
\hline $\begin{array}{r}\text { Actividad } \\
\text { antioxidante }\end{array}$ & $\begin{array}{l}\text { Diversos estudios señalan que los hongos endofíticos son una fuente } \\
\text { importante de antioxidantes, Zeng, et al (2015), evaluaron la capacidad } \\
\text { antioxidante de } 163 \text { extractos de hongos endofíticos aislados de } \\
\text { Myricaria laxiflora, arrojó que particularmente, Aspergillus sp., no sólo } \\
\text { fue el más abundante entre los endofíticos, sino también con más } \\
\text { actividad antioxidante. Compuestos fenólicos podrían ser un factor } \\
\text { importante dado lugar a una alta actividad antioxidante. }\end{array}$ \\
\hline Biocombustibles & $\begin{array}{l}\text { Hongos endofíticos con potencial para el desarrollo de nuevas fuentes } \\
\text { de combustibles "verdes". }\end{array}$ \\
\hline
\end{tabular}

Fuente: Elaboración propia

\subsection{Principales aplicaciones y desarrollos con bacterias endofíticas}

En la Tabla 10, se mencionan algunas de las aplicaciones más destacadas relacionadas con bacterias endofíticas. 
Tabla 10. Aplicaciones y desarrollos a partir de bacterias endofíticas.

\begin{tabular}{|c|c|}
\hline Anti-malaria & $\begin{array}{l}\text { Algunas bacterias endofíticas tienen el potencial de actuar } \\
\text { como una fuente de nuevas moléculas bioactivas con } \\
\text { propiedades medicinales. } \\
\text { En el estudio publicado por Baba y colaboradores, en el } \\
2015 \text {, se tuvo como objetivo evaluar la actividad antimalárica de } \\
\text { extracto crudo aislado de varias cepas una bacteria endofítica } \\
\text { asociada a algunas plantas medicinales de Malasia. }\end{array}$ \\
\hline $\begin{array}{l}\text { Biorremediación } \\
\text { /fitorremediación }\end{array}$ & $\begin{array}{l}\text { Algunas aplicaciones en este campo están relacionadas con la } \\
\text { biorremediación de suelos contaminados con aceite. }\end{array}$ \\
\hline Biocontrol & $\begin{array}{l}\text { Diversos estudios hacen referencia al papel que las bacterias } \\
\text { endofíticas desempeñan en el control biológico de } \\
\text { microorganismos fitopatógenos; por ejemplo, en frijol. }\end{array}$ \\
\hline $\begin{array}{l}\text { Mejoramiento } \\
\text { productividad de } \\
\text { cultivos }\end{array}$ & $\begin{array}{l}\text { Fijación de nutrientes en suelos degradados. } \\
\text { Efectos sobre el crecimiento vegetal. }\end{array}$ \\
\hline Biocombustibles & $\begin{array}{l}\text { Bacterias endofíticas con potencial para el desarrollo de } \\
\text { nuevas fuentes de combustibles "verdes". } \\
\text { Producción de biomasa con fines energéticos. }\end{array}$ \\
\hline
\end{tabular}

Fuente: Elaboración propia 
CONCLUSIONES Y RECOMENDACIONES 


\section{Conclusiones y Recomendaciones}

Aunque se registran publicaciones relacionadas con organismos endofíticos desde la década de los 70, es a partir de finales de la década de los 90 que se empieza a evidenciar un incremento paulatino en el número de artículos por año, siendo el periodo comprendido entre 2005 y 2015 el más productivo; en estos últimos 10 años se concentra aproximadamente el $80 \%$ de la producción científica.

Partiendo de las publicaciones relacionadas tanto con hongos como con bacterias endofíticas en los últimos 5 años, se evidencia un potencial importante de la aplicación en diferentes sectores y procesos como la salud, la agricultura y la recuperación de ambientes contaminados (biorremediación); lo que demuestra la pertinencia de continuar fomentando la investigación de estos organismos a nivel nacional y regional.

A nivel nacional, los avances en la investigación relacionada con organismos endofíticos se encuentran relacionada principalmente con técnicas de aislamiento y caracterización de hongos endofíticos. Otros estudios recientes, permiten evidenciar interés en la búsqueda de aplicaciones enfocadas al control biológico de plagas y/o enfermedades de plantas.

Al observar la dinámica de patentes, teniendo en cuenta la Clasificación Internacional de Patentes (IPC) XE "Clasificación Internacional de patentes (IPC)" se observa que uno de los temas emergentes está relacionado con los biocombustibles. Como es el caso específico de las patentes del inventor Gary Strobel, de la Universidad de Montana. Este puede ser un indicador importante del potencial de los organismos endofíticos en este campo.

En lo que respecta a las aplicaciones de hongos y bacterias endofíticas, se observan dos tendencias interesantes. Por un lado, los hongos están siendo estudiados por presentar actividad biológica relacionada con controlbiológicoXE"Controlbiológico", 
propiedades anticancerígenas y antioxidantes. Mientras que las bacterias están siendo estudiadas para aplicaciones en áreas como la biorremediación (suelos contaminados), fijación de nutrientes XE "Fijación de nutrientes", producción de biomasa XE "Producción de biomasa" y biocombustibles. XE "Biocombustibles."

Actualmente, las publicaciones en las que participan países de América Latina y el Caribe representan el 12,5\% del total de publicaciones. Sin embargo, teniendo en cuenta la diversidad biológica que se concentra en América Latina y el Caribe, es posible que a esta biodiversidad XE "Biodiversidad" esté asociada una importante variedad de organismos endofíticos de diferentes especies de plantas, lo que se traduce en un campo de alto potencial para ser explorado a partir de proyectos de investigación básica y aplicada. 
BIBLIOGRAFÍA 


\section{Bibliografía}

Abello, J., Kelemu, S., y García, C. (2008). Agrobacteriummediated transformation of the endophytic fungus Acremonium implicatum associated with Brachiaria grasses. Mycological Research, 112, 407-413. http://dx.doi. org/10.1016/j.mycres.2007.10.008

Afzal, I., Shinwari, Z. K., Sikandar, S., y Shahzad, S. (2019). Plant beneficial endophytic bacteria: Mechanisms, diversity, host range and genetic determinants. Microbiological Research, 221, 36-49. https://doi.org/10.1016/j.micres.2019.02.001

Aly, Amal H., Debbab, A., Kjer, J., y Proksch, P. (2010). Fungal endophytes from higher plants: A prolific source of phytochemicals and other bioactive natural products. Fungal Diversity, 41(1), 1-16. https://doi.org/10.1007/ s13225-010-0034-4

Aly, Amal H., Edrada-Ebel, R., Wray, V., Müller, W. E. G., Kozytska, S., Hentschel, U., Proksch, P., y Ebel, R. (2008). Bioactive metabolites from the endophytic fungus Ampelomyces sp. Isolated from the medicinal plant Urospermum picroides. Phytochemistry, 69(8), 1716-1725. https://doi. org/10.1016/j.phytochem.2008.02.013

Aly, Amal Hassan, Debbab, A., y Proksch, P. (2011). Fungal endophytes: Unique plant inhabitants with great promises. Applied Microbiology and Biotechnology, 90(6), 1829-1845. https://doi.org/10.1007/s00253-011-3270-y

Andrade-Linares, D. R., Grosch, R., Franken, P., Rexer, K.-H., Kost, G., Restrepo, S., de Garcia, M. C. C., y Maximova, E. (2011). Colonization of roots of cultivated Solanum lycopersicum by dark septate and other ascomycetous endophytes. Mycologia, 103(4), 710-721. https://doi. org/10.3852/10-329

Andrews, J. H., y Hirano, S. S. (Eds.). (1991). Microbial Ecology of Leaves. Springer New York. http://link.springer. com/10.1007/978-1-4612-3168-4

Arias C, E. L., y Piñeros E, P. A. (2008). Aislamiento e identificación de hongos filamentosos de muestras de suelo de los páramos de Guasca y Cruz Verde. Pontificia Universidad Javeriana. 
Arnold, A. E., y Lutzoni, F. (2007). DIVERSITY AND HOST RANGE OF FOLIAR FUNGAL ENDOPHYTES: ARE TROPICAL LEAVES BIODIVERSITY HOTSPOTS? Ecology, 88(3), 541-549. https://doi.org/10.1890/05-1459

Arora, D., Sharma, N., Singamaneni, V., Sharma, V., Kushwaha, M., Abrol, V., Guru, S., Sharma, S., Gupta, A. P., Bhushan, S., Jaglan, S., y Gupta, P. (2016). Isolation and characterization of bioactive metabolites from Xylaria psidii, an endophytic fungus of the medicinal plant Aegle marmelos and their role in mitochondrial dependent apoptosis against pancreatic cancer cells. Phytomedicine, 23(12), 1312-1320. https://doi.org/10.1016/j.phymed.2016.07.004

Bazzicalupo, M., y Okon, Y. (2000). Associative and Endophytic Symbiosis. En F. O. Pedrosa, M. Hungria, G. Yates, y W. E. Newton (Eds.), Nitrogen Fixation: From Molecules to Crop Productivity (pp. 409-410). Springer Netherlands. https:// doi.org/10.1007/0-306-47615-0_219

Behie, S. W., y Bidochka, M. J. (2013). Potential agricultural benefits through biotechnological manipulation of plant fungal associations. BioEssays, 35(4), 328-331. https://doi. org/10.1002/bies.201200147

Behie, S. W., y Bidochka, M. J. (2014). Nutrient transfer in plantfungal symbioses. Trends in Plant Science, 19, 734-740.

Bérdy, J. (2005). Bioactive Microbial Metabolites: A Personal View. The Journal of Antibiotics, 58(1), 1-26. https://doi. org/10.1038/ja.2005.1

Bhattacharya, S., Debnath, S., y Saha, A. K. (2018). EVALUATION OFANTIOXIDANTACTIVITYOFTWOENDOPHYTIC FUNGI ISOLATED FROM ANANUS COMOSUS L. European Journal of Biomedical and Pharmaceutical Sciences, 5(1), 5.

Carroll, G. (1988). Fungal Endophytes in Stems and Leaves: From Latent Pathogen to Mutualistic Symbiont. Ecology, 69(1), 2-9. https://doi.org/10.2307/1943154

Carroll, G. C., y Carroll, F. E. (1978). Studies on the incidence of coniferous needle endophytes in the Pacific Northwest. Canadian Journal of Botany, 56(24), 3034-3043. 
Ceballos, I., Mosquera, S., Angulo, M., Mira, JohnJ., Argel, L., Uribe-Velez, D., Romero-Tabarez, M., Orduz-Peralta, S., y Villegas, V. (2012). Cultivable Bacteria Populations Associated with Leaves of Banana and Plantain Plants and Their Antagonistic Activity Against Mycosphaerella fijiensis. Microbial Ecology, 64, 641-653. https://doi. org/10.1007/s00248-012-0052-8

Compant, S., Clément, C., y Sessitsch, A. (2010). Plant growthpromoting bacteria in the rhizo- and endosphere of plants: Their role, colonization, mechanisms involved and prospects for utilization. Soil Biology and Biochemistry, 42(5), 669-678. https://doi.org/10.1016/j. soilbio.2009.11.024

Compant, S., Mitter, B., Sessitsch, A., Nowak, J., Clément, C., y Ait Barka, E. (2005). Endophytic Colonization of Vitis vinifera L. by Plant Growth-Promoting Bacterium Burkholderia sp. Strain PsJN. Applied and environmental microbiology, 71, 1685-1693. https://doi.org/10.1128/AEM.71.4.16851693.2005

Daley, D. K., Brown, K. J., y Badal, S. (2017). Fungal Metabolites. En Pharmacognosy (pp. 413-421). Elsevier. https:/doi. org/10.1016/B978-0-12-802104-0.00020-2

Dame, Z. T., Silima, B., Gryzenhout, M., y van Ree, T. (2016). Bioactive compounds from the endophytic fungus Fusarium proliferatum. Natural Product Research, 30(11), 1301-1304. https://doi.org/10.1080/14786419.2015.10530 89

de Medeiros, J. B. (2010). Avaliação do Potencial Biocatalítico de Fungos Endofíticos de Espécies Vegetais do Cerrado. Universidade Estadual Paulista.

Debbab, A., Aly, A. H., Edrada-Ebel, R., Wray, V., Müller, W. E. G., Totzke, F., Zirrgiebel, U., Schächtele, C., Kubbutat, M. H. G., Lin, W. H., Mosaddak, M., Hakiki, A., Proksch, P., y Ebel, R. (2009). Bioactive Metabolites from the Endophytic Fungus Stemphylium globuliferum Isolated from Mentha pulegium. Journal of Natural Products, 72(4), 626-631. https://doi.org/10.1021/np8004997 
del Pilar Infante, E., Marquínez, X., y Moreno, G. (2012). Colonización de la corteza del fruto de tomate (Solanum lycopersicum L.) por la levadura endofítica Candida guilliermondii (Castellani) Langeron et Guerra. Agronomía Colombiana, 30(3).

Demain, A. L. (2000). Small bugs, big business: The economic power of the microbe. Biotechnology Advances, 18(6), 499514. https://doi.org/10.1016/S0734-9750(00)00049-5

Dibut, B., Martínez, R., Ortega, M., Ríos, Y., y Fey, L. (2004). Presencia y uso de microorganismos endofíticos en plantas como perspectiva para el mejoramiento de la producción vegetal. Cultivos tropicales, 25(2), 13-18.

Dongyi, H., y Kelemu, S. (2004). Acremonium implication, a seed-transmitted endophytic fungus in Brachiaria grasses. plant disease, 88, 1252-1254.

Doty, S. L. (2008). Enhancing phytoremediation through the use of transgenics and endophytes. New Phytologist, 179(2), 318333. https://doi.org/10.1111/j.1469-8137.2008.02446.x

Esther, P., Li, C., y Bashan, Y. (2009). Endophytic Bacteria in Cacti Seeds Can Improve the Development of Cactus Seedlings. Environmental and Experimental Botany, 66, 402-408. https://doi.org/10.1016/j.envexpbot.2009.04.007

Firáková, S., Šturdíková, M., y Múčková, M. (2007). Bioactive secondary metabolites produced by microorganisms associated with plants. Biologia, 62(3). https://doi. org/10.2478/s11756-007-0044-1

Fouda, A. H., Hassan, S. E.-D., Eid, A. M., y Ewais, E. E.-D. (2015a). Biotechnological applications of fungal endophytes associated with medicinal plant Asclepias sinaica (Bioss.). Annals of Agricultural Sciences. http://dx.doi.org/10.1016/j. aoas.2015.04.001

Fouda, A. H., Hassan, S. E.-D., Eid, A. M., y Ewais, E. E.-D. (2015b). Biotechnological applications of fungal endophytes associated with medicinal plant Asclepias sinaica (Bioss.). Annals of Agricultural Sciences, 60(1), 95-104. https://doi. org/10.1016/j.aoas.2015.04.001 
Gamboa, MiguelA., Laureano, S., y Bayman, P. (2003). Measuring diversity of endophytic fungi in leaf fragments: Does size matter? Mycopathologia, 156, 41-45. https://doi. org/10.1023/A:1021362217723

Gamboa-Gaitán, M. (2014). Vainillas colombianas y su microbiota. II. Diversidad, cultivo y microorganismos endofíticos. Universitas Scientiarum, 19(3), 287-300. https://doi. org/10.11144/Javeriana.SC19-3.vcmd

Gamboa-Gaitan, M. A. (2006a). Hongos endofíticos tropicales: Conocimiento actual y perspectivas. Acta biológica colombiana, 11, 3-20.

Gamboa-Gaitan, M. A. (2006b). Tropical Endophytic Fungi: Current Knowledge and Perspectives. Acta Biológica Colombiana, 11(S 1.1), 3-20.

Germaine, K. J., Liu, X., Cabellos, G. G., Hogan, J. P., Ryan, D., y Dowling, D. N. (2006). Bacterial endophyte-enhanced phytoremediation of the organochlorine herbicide 2,4-dichlorophenoxyacetic acid. FEMS Microbiology Ecology, 57(2), 302-310. https://doi.org/10.1111/j.15746941.2006.00121.x

Germaine, K., Keogh, E., Garcia-Cabellos, G., Borremans, B., Lelie, D., Barac, T., Oeyen, L., Vangronsveld, J., Moore, F. P., Moore, E. R. B., Campbell, C. D., Ryan, D., y Dowling, D. N. (2004). Colonisation of poplar trees by gfp expressing bacterial endophytes. FEMS Microbiology Ecology, 48(1), 109-118. https://doi.org/10.1016/j.femsec.2003.12.009

Gunatilaka, A. A. L., y Wijeratne, E. M. K. (2000). Natural Products from Bacteria and Fungi. En Encyclopedia of life Support Systems (EOLSS) (p. 10). UNESCO - EOLSS.

Gupta, V. K. (Ed.). (2016). New and Future Developments in Microbial Biotechnology and Bioengineering: Aspergillus System Properties and Applications. Elsevier.

Hallmann, J., Quadt-Hallmann, A., Mahaffee, W. F., y Kloepper, J. W. (1997a). Bacterial endophytes in agricultural crops. Canadian Journal of Microbiology, 43(10), 895-914. https:// doi.org/10.1139/m97-131 
Hallmann, J, Quadt-Hallmann, A., Mahaffee, W. F., y Kloepper, J. W. (1997b). Bacterial endophytes in agricultural crops. Canadian Journal of Microbiology, 43(10), 895-914. https:// doi.org/10.1139/m97-131

Hallmann, Johannes. (2001). Plant interactions with endophytic bacteria. Biotic interactions in plant-pathogen associations, 87-119.

Hardoim, P. R., van Overbeek, L. S., y Elsas, J. D. van. (2008). Properties of bacterial endophytes and their proposed role in plant growth. Trends in Microbiology, 16(10), 463-471. https://doi.org/10.1016/j.tim.2008.07.008

Higgins, K. L., Arnold, A. E., Coley, P. D., y Kursar, T. A. (2014a). Communities of fungal endophytes in tropical forest grasses: Highly diverse host- and habitat generalists characterized by strong spatial structure. Fungal Ecology, $8,1-11$.

Higgins, K. L., Arnold, A. E., Coley, P. D., y Kursar, T. A. (2014b). Communities of fungal endophytes in tropical forest grasses: Highly diverse host- and habitat generalists characterized by strong spatial structure. Fungal Ecology, 8, 1-11. https://doi.org/10.1016/j.funeco.2013.12.005

Hoyos-Carvajal, L., Orduz, S., y Bissett, J. (2009). Growth stimulation in bean (Phaseolus vulgaris L.) by Trichoderma. Biological Control, 51, 409-416. http:// dx.doi.org/10.1016/j.biocontrol.2009.07.018

Huang, Q., An, H., Song, H., Mao, H., Shen, W., y Dong, J. (2015). Diversity and biotransformative potential of endophytic fungi associated with the medicinal plant Kadsura angustifolia. Research in microbiology, 166(1), 45-55.

Huang, W.-Y., Cai, Y.-Z., Xing, J., Corke, H., y Sun, M. (2007). A Potential Antioxidant Resource: Endophytic Fungi from MedicinalPlants.EconomicBotany,61(1),14-30.https://doi. org/10.1663/0013-0001(2007)61[14:APAREF]2.0.CO;2

Huang, Y., Wang, J., Li, G., Zheng, Z., y Su, W. (2001). Antitumor and antifungal activities in endophytic fungi isolated from pharmaceutical plants Taxus mairei, Cephalataxus fortunei and Torreya grandis. FEMS Immunology and Medical Microbiology, 5. 
Jia, M., Chen, L., Xin, H.-L., Zheng, C.-J., Rahman, K., Han, T., y Qin, L.-P. (2016). A Friendly Relationship between Endophytic Fungi and Medicinal Plants: A Systematic Review. Frontiers in Microbiology, 7. https://doi. org/10.3389/fmicb.2016.00906

Jiménez, C., Rivero, A. S., Pocasangre, L. E., Delgado, E., Rosales, F. E., González, O., y Romero, D. (2009). Efecto de la inoculación de dos tipos de semilla de bananos con dos aislados de Trichoderma atroviride en fase de vivero sobre el desarrollo de las plantas en campo bajo Sigatoka Negra. Revista Científica UDO Agrícola, 9(2), 403-413.

Kaul, S., Gupta, S., Ahmed, M., y Dhar, M. K. (2012). Endophytic fungi from medicinal plants: A treasure hunt for bioactive metabolites. Phytochemistry Reviews, 11(4), 487-505. https://doi.org/10.1007/s11101-012-9260-6

Kelemu, S., Fory, P. A., Zuleta, C., Ricaute, J., Rao, I., y Lascano, C. (2011). Detecting bacterial endophytes in tropical grasses of the Brachiaria genus and determining their role in improving plant growth. frican Journal of Biotechnology (Kenya). http://dx.doi.org/10.5897/AJB

Kelemu, S., White Jr, J. F., Muñoz, F., y Takayama, Y. (2001). An endophyte of the tropical forage grass Brachiaria brizantha: Isolating, identifying, and characterizing the fungus, and determining its antimycotic properties. Canadian Journal of Microbiology, 47, 55-62. https://doi.org/10.1139/w00127

Khan, A. A., Bacha, N., Ahmad, B., Lutfullah, G., Farooq, U., y Cox, R. J. (2014). Fungi as chemical industries and genetic engineering for the production of biologically active secondary metabolites. Asian Pacific Journal of Tropical Biomedicine, 4, 859-870.

Khan, S., Hamayun, M., Yoon, H., Kim, H.-Y., Suh, S.-J., Hwang, S.-K., Kim, J.-M., Lee, I.-J., Choo, Y.-S., Yoon, U.-H., Kong, W.-S., Lee, B.-M., y Kim, J.-G. (2008). Plant growth promotion and Penicillium citrinum. BMC Microbiology, 8(1), 231. https://doi.org/10.1186/1471-2180-8-231 
Kusari, S., Lamshöft, M., y Spiteller, M. (2009). Aspergillus fumigatus Fresenius, an endophytic fungus from Juniperus communis L. Horstmann as a novel source of the anticancer pro-drug deoxypodophyllotoxin. Journal of Applied Microbiology, 107(3), 1019-1030. https://doi.org/10.1111/ j.1365-2672.2009.04285.x

Kusari, Souvik, Pandey, S. P., y Spiteller, M. (2013). Untapped mutualistic paradigms linking host plant and endophytic fungal production of similar bioactive secondary metabolites. Phytochemistry, 91, 81-87. https://doi. org/10.1016/j.phytochem.2012.07.021

Kusari, Souvik, Singh, S., y Jayabaskaran, C. (2014). Biotechnological potential of plant-associated endophytic fungi: Hope versus hype. Trends in Biotechnology, 32(6), 297-303. https://doi.org/10.1016/j.tibtech.2014.03.009

Lacava, P. T., y Azevedo, J. L. (2013). Endophytic Bacteria: A Biotechnological Potential in Agrobiology System BT - Bacteria in Agrobiology: Crop Productivity (D. K. Maheshwari, M. Saraf, y A. Aeron, Eds.; pp. 1-44). Springer Berlin Heidelberg. https://doi.org/10.1007/978-3-64237241-4_1

Liu, J. Y., Song, Y. C., Zhang, Z., Wang, L., Guo, Z. J., Zou, W. X., y Tan, R. X. (2004). Aspergillus fumigatus CY018, an endophytic fungus in Cynodon dactylon as a versatile producer of new and bioactive metabolites. Journal of Biotechnology, 114(3), 279-287. https://doi.org/10.1016/j. jbiotec.2004.07.008

Lizarazo, L. M. (2017). Manual Fundamentos y técnicas Básicas en microbiología (2. ed.). UPTC.

Lu, H., Zou, W. X., Meng, J. C., Hu, J., y Tan, R. X. (2000). New bioactive metabolites produced by Colletotrichum sp., an endophytic fungus in Artemisia annua. Plant Science, 151(1), 67-73. https://doi.org/10.1016/S01689452(99)00199-5

Lu, Y., Chen, C., Chen, H., Zhang, J., y Chen, W. (2012). Isolation and Identification of Endophytic Fungi from Actinidia macrosperma and Investigation of Their Bioactivities. 
Evidence-Based Complementary and Alternative Medicine, 2012, 1-8. https://doi.org/10.1155/2012/382742

Marquez-Santacruz, H. A., Hernandez-Leon, R., OrozcoMosqueda, M. C., Velazquez-Sepulveda, I., y Santoyo, G. (2010). Diversity of bacterial endophytes in roots of Mexican husk tomato plants (Physalis ixocarpa) and their detection in the rhizosphere. Genetics and Molecular Research: GMR, 9(4), 2372-2380. https://doi.org/10.4238/ vol9-4gmr921

Miles, L. A., Lopera, C. A., González, S., de García, M. C. C., Franco, A. E., y Restrepo, S. (2012). Exploring the biocontrol potential of fungal endophytes from an Andean Colombian Paramo ecosystem. BioControl, 57, 697-710. https://doi.org/10.1007/s10526-012-9442-6

Mishra, Y., Singh A, Batra A, y Sharma MM. (2014). Understanding the Biodiversity and Biological Applications of Endophytic Fungi: A Review. Journal of Microbial y Biochemical Technology, s8 (01). https://doi.org/10.4172/1948-5948. S8-004

Nisa, H., Kamili, A. N., Nawchoo, I. A., Shafi, S., Shameem, N., y Bandh, S. A. (2015). Fungal endophytes as prolific source of phytochemicals and other bioactive natural products: A review. Microbial Pathogenesis, 82, 50-59. https://doi. org/10.1016/j.micpath.2015.04.001

Ownley, B. H., Gwinn, K. D., y Vega, F. E. (2010). Endophytic fungal entomopathogens with activity against plant pathogens: Ecology and evolution. BioControl, 55(1), 113128. https://doi.org/10.1007/s10526-009-9241-x

Panaccione, D. G., Beaulieu, W. T., y Cook, D. (2014). Bioactive alkaloids in vertically transmitted fungal endophytes. Functional Ecology, 28(2), 299-314. https://doi. org/10.1111/1365-2435.12076

Pandey, P. K., Singh, S., Yadav, R. N. S., Singh, A. K., y Singh, M. C. K. (2014). Fungal Endophytes: Promising Tools for Pharmaceutical Science. 25, 12. 
Park, Y.-H., Chung, J. Y., Ahn, D. J., Kwon, T. R., Lee, S. K., Bae, I., Yun, H. K., y Bae, H. (2015). Screening and characterization of endophytic fungi of Panax ginseng Meyer for biocontrol activity against ginseng pathogens. Biological Control, 91, 71-81. https://doi.org/10.1016/j.biocontrol.2015.07.012

Partida-Martínez, L. P., y Heil, M. (2011). The microbe-free plant: Fact or artifact? Frontiers in Plant Science, 2, 100. https:// doi.org/10.3389/fpls.2011.00100

Petrini, O. (1991). Fungal Endophytes of Tree Leaves. En J. H. Andrews y S. S. Hirano (Eds.), Microbial Ecology of Leaves (pp. 179-197). Springer New York. https://doi. org/10.1007/978-1-4612-3168-4_9

Petrini, O., Stone, J., y Carroll, F. E. (1982). Endophytic fungi in evergreen shrubs in western Oregon: A preliminary study. Canadian Journal of Botany, 60(6), 789-796. https://doi. org/10.1139/b82-102

Pinheiro, E. A. A., Pina, J. R. S., Feitosa, A. O., Carvalho, J. M., Borges, F. C., Marinho, P. S. B., y Marinho, A. M. R. (2017). Bioprospecting of antimicrobial activity of extracts of endophytic fungi from Bauhinia guianensis. Revista Argentina de Microbiología. https://doi.org/10.1016/j. ram.2016.08.005

Prada, H., Ávila, L., Sierra, R., Bernal, A., y Restrepo, S. (2009). Caracterización morfológica y molecular del antagonismo entre el endofito Diaporthe sp. Aislado de frailejón (Espeletia sp.) y el fitopatógeno Phytophthora infestans. Revista Iberoamericana de Micología, 26(3), 198-201. http://dx.doi.org/10.1016/j.riam.2009.01.002

Prats, G. (2006). Microbiología Clínica (1. a ed.). Editorial Médica Panamericana.

Puente, M. E., Bashan, Y., Li, C. Y., y Lebsky, V. K. (2004). Microbial populations and activities in the rhizoplane of rock-weathering desert plants. I. Root colonization and weathering of igneous rocks. Plant Biology (Stuttgart, Germany), 6(5), 629-642. https://doi. org/10.1055/s-2004-821100 
Qin, J.-C., Zhang, Y.-M., Gao, J.-M., Bai, M.-S., Yang, S.-X., Laatsch, H., y Zhang, A.-L. (2009). Bioactive metabolites produced by Chaetomium globosum, an endophytic fungus isolated from Ginkgo biloba. Bioorganic y Medicinal Chemistry Letters, 19(6), 1572-1574. https://doi.org/10.1016/j. bmcl.2009.02.025

Rodriguez, R. J., White Jr, J. F., Arnold, A. E., y Redman, R. S. (2009). Fungal endophytes: Diversity and functional roles: Tansley review. New Phytologist, 182(2), 314-330. https:// doi.org/10.1111/j.1469-8137.2009.02773.x

Rosa, L. H., Almeida Vieira, M. de L., Santiago, I. F., y Rosa, C. A. (2010). Endophytic fungi community associated with the dicotyledonous plant Colobanthus quitensis (Kunth) Bartl. (Caryophyllaceae) in Antarctica: Endophytic fungi associated with Colobanthus quitensis. FEMS Microbiology Ecology, no-no. https://doi.org/10.1111/ j.1574-6941.2010.00872.x

Rosenblueth, M., y Martínez-Romero, E. (2006). Bacterial Endophytes and Their Interactions with Hosts. Molecular Plant-Microbe Interactions ${ }^{\oplus}$, 19(8), 827-837. https://doi. org/10.1094/MPMI-19-0827

Ruggiero, M. A., Gordon, D. P., Orrell, T. M., Bailly, N., Bourgoin, T., Brusca, R. C., Cavalier-Smith, T., Guiry, M. D., y Kirk, P. M. (2015). A higher level classification of all living organisms. PloS one, 10(4), e0119248.

Ryan, R. P., Germaine, K., Franks, A., Ryan, D. J., y Dowling, D. N. (2008). Bacterial endophytes: Recent developments and applications. FEMS Microbiol Lett, 9.

Salazar, C. S., y de García, M. C. C. (2005). Aislamiento de hongos endofitos en rosa (Rosa hybrida) en Bogotá, Colombia. Revista Iberoamericana de Micología, 22, 99-101. http:// dx.doi.org/10.1016/S1130-1406(05)70016-4

Salgado, C., Cepero, M. C., Realpe, E., y Restrepo, S. (2007). Histological analyses of the fungal endophytes in Rosa hybrida. Revista Iberoamericana de Micología, 24, 323324. 
Sánchez-Fernández, R. E., Sánchez-Ortiz, B. L., SandovalEspinosa, Y. K. M., Ulloa-Benítez, Á., ArmendárizGuillén, B., García-Méndez, M. C., y Macías-Rubalcava, M. L. (2013). Hongos endofíticos: Fuente potencial de metabolitos secundarios bioactivos con utilidad en agricultura y medicina. TIP. Revista especializada en ciencias químico-biológicas, 16(2), 132-146.

Schulz, B., y Boyle, C. (2005). The endophytic continuum. Mycological Research, 109(6), 661-686. https:/doi. org/10.1017/S095375620500273X

Schulz, B., y Boyle, C. (2006). What are Endophytes? En B. J. E. Schulz, C. J. C. Boyle, y T. N. Sieber (Eds.), Microbial Root Endophytes (pp. 1-13). Springer Berlin Heidelberg. https:// doi.org/10.1007/3-540-33526-9_1

Segenet, K., Huang, D., Huang, G., y Yuka, T. (2003). Detecting and differentiating Acremonium implicatum: Developing a PCR-based method for an endophytic fungus associated with the genus Brachiaria. Molecular Plant Pathology, 4(2), 115-118.

Sharma P., Sarita, S., y Prell, J. (2005). Isolation and characterization of an endophytic bacterium related to Rhizobium/ Agrobacterium from wheat (Triticum aestivum L.) roots. Current Science, 89, 608-610.

Silva-Hughes, A. F., Wedge, D. E., Cantrell, C. L., Carvalho, C. R., Pan, Z., Moraes, R. M., Madoxx, V. L., y Rosa, L. H. (2015). Diversity and antifungal activity of the endophytic fungi associated with the native medicinal cactus Opuntia humifusa (Cactaceae) from the United States. Microbiological Research, 175, 67-77. https://doi. org/10.1016/j.micres.2015.03.007

Slippers, B., Burgess, T., Pavlic, D., Ahumada, R., Maleme, H., Mohali, S., Rodas, C., y Wingfield, M. (2009). A diverse assemblage of Botryosphaeriaceae infect Eucalyptus in native and non-native environments. Southern Forests: A Journal of Forest Science, 71(2), 101-110. https://doi. org/10.2989/SF.2009.71.2.3.818 
Solomon, E., Berg, L., y Martin, D. (2013). Los Hongos. En Biología (1 ra ed). Cengage Learning Editores.

Stępniewska,Z.,yKuźniar,A.(2013).EndophyticmicroorganismsPromising applications in bioremediation of greenhouse gases. Applied Microbiology and Biotechnology, 97(22), 9589-9596. https://doi.org/10.1007/s00253-013-5235-9

Stierle, A.A., ySTIERLE, D.B.(2000). BIOACTIVECOMPOUNDS FROM FOUR ENDOPHYTIC PENICILLIUMSF. OF A NORTHWEST PACIFIC YEW. Studies in Natural Products Chemistry, 24, 933-977.

Stierle, A., Strobel, G., Stierle, D., y others. (1993). Taxol and taxane production by Taxomyces andreanae, an endophytic fungus of Pacific yew. SCIENCE-NEW YORK THEN WASHINGTON-, 260, 214-214.

Stinson, M., Ezra, D., Hess, W. M., Sears, J., y Strobel, G. (2003). An endophytic Gliocladium sp. Of Eucryphia cordifolia producing selective volatile antimicrobial compounds. Plant Science, 165(4), 913-922. https://doi.org/10.1016/ S0168-9452(03)00299-1

Strobel, G. A. (2003). Endophytes as sources of bioactive products. Microbes and Infection, 5(6), 535-544. https:// doi.org/10.1016/S1286-4579(03)00073-X

Suárez Contreras, L. Y., y Rangel Riaño, A. L. (2013). Aislamiento de microorganismos para control biológico de Moniliophthora roreri. Acta Agronómica, 62(4), 370-378.

Suryanarayanan, T. S., Senthilarasu, G., y Muruganandam, V. (2000). Endophytic fungi from Cuscuta reflexa and its host plants. Fungal Diversity, 4, 117-123.

Suryanarayanan, T. S., Thirunavukkarasu, N., Govindarajulu, M. B., Sasse, F., Jansen, R., y Murali, T. S. (2009). Fungal endophytes and bioprospecting. Fungal Biology Reviews, 23(1-2), 9-19. https://doi.org/10.1016/j.fbr.2009.07.001

Tan, R. X., y Zou, W. X. (2001a). Endophytes: A rich source of functional metabolites (1987 to 2000). Natural Product Reports, 18(4), 448-459. https://doi.org/10.1039/b100918o

Tan, R. X., y Zou, W. X. (2001b). Endophytes: A rich source of functional metabolites (1987 to 2000). Natural Product Reports, 18(4), 448-459. https://doi.org/10.1039/b100918o 
Vanegas Berrouet, K., Gutiérrez Sanchez, P., y Marín Montoya, M. (2014). IDENTIFICACIÓN MOLECULAR DE HONGOS AISLADOS DE TEJIDOS DE FRÍJOL CON SÍNTOMAS DE ANTRACNOSIS. Acta Biológica Colombiana, 19(2), 143-154.

Vaz, A. B. M., Sampedro, I., Siles, J. A., Vasquez, J. A., GarcíaRomera, I., Vierheilig, H., Rosa, C. A., y Ocampo, J. A. (2012). Arbuscular mycorrhizal colonization of Sorghum vulgare in presence of root endophytic fungi of Myrtus communis. Applied Soil Ecology, 61, 288-294. http:// dx.doi.org/10.1016/j.apsoil.2011.10.017

Verma, A., Johri, B. N., y Prakash, A. (2014). Antagonistic Evaluation of Bioactive Metabolite from Endophytic Fungus, Aspergillusflavipes KF671231. Journal of Mycology, 2014, 1-5. https://doi.org/10.1155/2014/371218

Vessey, J. K. (2003). Plant growth promoting rhizobacteria as biofertilizers. Plant and Soil, 255(2), 571-586. https://doi. org/10.1023/A:1026037216893

Vinicius P, S. (2012). Avaliação química e biológica de fungos endofíticos associados à alga marinha Padina gymnospora. Universidade Estadual Paulista.

Volk, T. J. (2013). Fungi. En S. A. B. T.-E. of B. (Second E. Levin (Ed.), Encyclopedia of Biodiversity (2. ${ }^{a}$ ed., pp. 624-640). Academic Press.

Webster, J., y Weber, R. (2007). Introduction to fungi. Cambridge University Press. http://dx.doi.org/10.1017/ CBO9780511809026

Y. Ahmed, H., H. El Shikh, H., A. Ghoneimy, E., M. Ragab, A., A. Saad, A., M. Hashem, A., M. El Sayed, R., y Eldin M. El Shikh, M. (2010). Fungal Secondary Metabolites: A Promising Source of Antineoplastic Drugs. Current Cancer Therapy Reviews, 6(3), 222-228. https://doi. org/10.2174/157339410791698223

Zhang, H. W., Song, Y. C., y Tan, R. X. (2006). Biology and chemistry of endophytes. Natural Product Reports, 23(5), 753. https://doi.org/10.1039/b609472b 
Zhang, W., Krohn, K., Draeger, S., y Schulz, B. (2008). Bioactive Isocoumarins Isolated from the Endophytic Fungus Microdochium bolleyi. Journal of Natural Products, 71(6), 1078-1081. https://doi.org/10.1021/np800095g

Zhang, X., Li, C., y Nan, Z. (2010). Effects of cadmium stress on growth and anti-oxidative systems in Achnatherum inebrians symbiotic with Neotyphodium gansuense. Journal of hazardous materials, 175(1-3), 703-709. https://doi.org/10.1016/j.jhazmat.2009.10.066

Zinniel, D. K., Lambrecht, P., Harris, N. B., Feng, Z., Kuczmarski, D., Higley, P., Ishimaru, C. A., Arunakumari, A., Barletta, R. G., y Vidaver, A. K. (2002). Isolation and Characterization of Endophytic Colonizing Bacteria from Agronomic Crops and Prairie Plants. Applied and Environmental Microbiology, 68(5), 2198 LP - 2208. https:// doi.org/10.1128/AEM.68.5.2198-2208.2002 
ANEXOS 


\section{Anexos}

\section{Anexo 1: Listado de publicaciones nacionales relacionadas con organismos endofíticos.}

\begin{tabular}{|c|c|c|c|c|}
\hline Título del artículo & $\begin{array}{c}\text { Fecha de } \\
\text { publicación }\end{array}$ & Palabras claves & Resultados relevantes & Referencia \\
\hline $\begin{array}{l}\text { 1. Vainillas colombianas } \\
\text { y su microbiota. Diversidad, } \\
\text { cultivo y microorganismos } \\
\text { endofíticos }\end{array}$ & 2014 & $\begin{array}{l}\text { Colletotrichum, cultivo de } \\
\text { vainilla, endofiticos, } \\
\text { Fusarium, Phomopsis, } \\
\text { trópicos, } \\
\text { Vanilla planifolia; Xylaria }\end{array}$ & Hallazgo de 60 morfoespecies de microorganismos endofíticos & $\begin{array}{l}\text { (Gamboa-Gaitán, } \\
\text { 2014) }\end{array}$ \\
\hline $\begin{array}{l}\text { 2. Identificación } \\
\text { molecular de hongos } \\
\text { aislados de tejidos de frijol } \\
\text { con síntomas de antracnosis }\end{array}$ & 2014 & $\begin{array}{l}\text { ADNr, endofiticos, } \mathrm{PCR} \text {, } \\
\text { Phaseolus vulgaris. }\end{array}$ & $\begin{array}{l}\text { Aislamiento del Colletotrichum lindemuthiamum agente causal } \\
\text { de antracnosis, aislamiento e identificación de } 17 \text { hongos } \\
\text { endofíticos Ascomycetes: Leptosphaerulina (3), Diaporthe (3), } \\
\text { Gibberella (1), Plectosphaerella (1), Biscogniauxia (1); } \\
\text { Géneros mitospóricos: Phoma (1), Alternaria (2) y Stemphylium } \\
\text { (1); Fusarium (2), Curvularia lunata (1) }\end{array}$ & $\begin{array}{l}\text { (Vanegas Berrouet } \\
\text { et al., 2014) }\end{array}$ \\
\hline $\begin{array}{l}\text { 3. Aislamiento de } \\
\text { microorganismos para } \\
\text { control biológico de } \\
\text { Moniliophthora roreri }\end{array}$ & 2013 & $\begin{array}{l}\text { Antagonistas, antibiosis, cacao } \\
\text { control biológico, } \\
\text { Moniliophthora roreri }\end{array}$ & $\begin{array}{l}\text { Aislamiento de } 17 \text { cepas de Moniliophthora roreri y } 20 \text { entre } \\
\text { hongos y bacterias endofiticas de plantas de cacao. } \\
\text { Los hongos con mayor actividad antagónica contra } \\
\text { Moniliophthora roreri fueron: Paecilomyces sp. (HC002) 80,72 }\end{array}$ & $\begin{array}{l}\text { (Suárez Contreras } \\
\text { y Rangel Riaño, } \\
\text { 2013) }\end{array}$ \\
\hline & & & $\begin{array}{l}\% \text {, Paecilomyces sp. (HZ002) } 79.45 \% \text {, y la bacteria Bacillus } \\
\text { brevis (BZ005) mostro una antibiosis superior a } 89 \%\end{array}$ & \\
\hline $\begin{array}{l}\text { 4. Colonización de la } \\
\text { corteza del fruto de tomate } \\
\text { (Solanum lycopersicum L.) } \\
\text { por la levadura endofítica } \\
\text { Candida guilliermondii } \\
\text { (Castellani) }\end{array}$ & 2012 & $\begin{array}{l}\text { Postcosecha, histología, } \\
\text { apoplasto, biocontrol }\end{array}$ & $\begin{array}{l}\text { Se estandarizó una metodología con el fin de analizar, bajo } \\
\text { condiciones controladas, el proceso de la colonización de la } \\
\text { epidermis y de la región subepidérmica de fruto de tomate } \\
\text { después de ser inoculados con la levadura Candida } \\
\text { guilliermondii }\end{array}$ & $\begin{array}{l}\text { (del Pilar Infante } \\
\text { et al., 2012) }\end{array}$ \\
\hline $\begin{array}{l}\quad 5 . \quad \text { Arbuscular } \\
\text { mycorrhizal colonization of } \\
\text { Sorghum vulgare in } \\
\text { presence of root endophytic } \\
\text { fungi of Myrtus communis }\end{array}$ & 2012 & $\begin{array}{l}\text { Crecimiento de las plantas, } \\
\text { Drechslera sp., DSE, } \\
\text { Endofitico septado oscuro, } \\
\text { Glomus, Hongos hialinos }\end{array}$ & $\begin{array}{l}\text { Se obtuvo un total de } 150 \text { aislamientos de hongos endofiticos a } \\
\text { partir de raíces de Myrtus communis, de estos solamente Phoma } \\
\text { schachtii y Cylindrocarpon destructans aumentaron } \\
\text { significativamente el peso seco del sorgo cultivado en suelo no } \\
\text { esterilizado }\end{array}$ & (Vaz et al., 2012) \\
\hline $\begin{array}{l}\text { 6. Exploring the } \\
\text { biocontrol potential of } \\
\text { fungal endophytes from an } \\
\text { Andean Colombian Paramo } \\
\text { ecosystem. }\end{array}$ & 2012 & $\begin{array}{l}\text { Aureobasiditum pullulans, } \\
\text { Control biológico, Espeletia } \\
\text { spp, hongos endofiticos, } \\
\text { Rhizoctonia solani }\end{array}$ & $\begin{array}{l}\text { Aislamiento de } 100 \text { hongos endofiticos de la especie Espeletia } \\
\text { spp. Los aislamientos identificados como pullulans } \\
\text { Aureobasidium y Paraconiothyrium sporulosum protegieron a } \\
\text { plantas de tomate del patógeno } R \text {. solani, además las plantas } \\
\text { inoculadas exhibieron crecimiento y desarrollo similar a el } \\
\text { control }\end{array}$ & (Miles et al., 2012) \\
\hline $\begin{array}{l}\quad \text { 7. Cultivable Bacteria } \\
\text { Populations Associated with } \\
\text { Leaves of Banana and } \\
\text { Plantain Plants and Their } \\
\text { Antagonistic Activity } \\
\text { Against Mycosphaerella } \\
\text { fijiensis }\end{array}$ & 2012 & & $\begin{array}{l}\text { Algunas de las bacterias aisladas de } \text { Musa spp afectan el micelio } \\
\text { y la morfologia de las ascosporas del hongo Mycosphaerella } \\
\text { fijiensis }\end{array}$ & $\begin{array}{l}\text { (Ceballos et al., } \\
\text { 2012) }\end{array}$ \\
\hline $\begin{array}{l}\text { 8. Colonization of } \\
\text { roots of cultivated Solanum } \\
\text { lycopersicum by dark } \\
\text { septate and other } \\
\text { ascomycetous endophytes }\end{array}$ & 2011 & $\begin{array}{l}\text { Ascomycota, Colonización de } \\
\text { la raíz, Endofitico septado } \\
\text { oscuro, Interacciones planta- } \\
\text { hongo, tomate Solanum } \\
\text { lycopersicum L. }\end{array}$ & $\begin{array}{l}\text { Se obtuvieron } 11 \text { nuevos aislamientos de la raiz de Solanum } \\
\text { bycopersicum L, siete mostraron caracteristicas de endofíticos } \\
\text { negros septados, cuatro aislamientos con morfotipos conocidos y } \\
\text { seis aislamientos con morfotipos de especies desconocidas }\end{array}$ & $\begin{array}{l}\text { (Andrade-Linares } \\
\text { et al., 2011) }\end{array}$ \\
\hline $\begin{array}{l}\text { 9. Detecting Bacterial } \\
\text { Endophytes in tropical } \\
\text { Grasses of the Brachiaria } \\
\text { genus and determining } \\
\text { their role in improving } \\
\text { plant growth. }\end{array}$ & 2011 & $\begin{array}{l}\text { Bacterias fijadoras de } \\
\text { nitrógeno, Brachiaria sp., } \\
\text { endofiticas, fijación de } \\
\text { nitrógeno, gramíneas } \\
\text { forrajeras, nutrientes }\end{array}$ & $\begin{array}{l}\text { Tres sepas de bacterias endofiticas fueron aisladas del hibrido } \\
\text { Brachiaria CIAT } 36062 \text {, e introducidas en Brachiaria hibrido } \mathrm{cv} \text {. } \\
\text { Mulato y en Brachiaria brizantha CIAT } 6294 \text {, los resultados } \\
\text { sugieren que estas bacterias endofiticas benefician el crecimiento } \\
\text { de las plantas }\end{array}$ & $\begin{array}{l}\text { (Kelemu et al., } \\
\text { 2011) }\end{array}$ \\
\hline $\begin{array}{l}\text { 10. Efecto de la } \\
\text { inoculación de dos tipos de } \\
\text { semilla de bananos con dos } \\
\text { aislados de Trichoderma } \\
\text { atroviride en fase de vivero } \\
\text { sobre el desarrollo de las } \\
\text { plantas en campo bajo } \\
\text { Sigatoka Negra }\end{array}$ & 2009 & $\begin{array}{l}\text { Banano, Hongos endofíticos, } \\
\text { protección de plantas, Sigatoka } \\
\text { Negra, Trichoderma atroviride, }\end{array}$ & $\begin{array}{l}\text { Se inocularon cormos y vitroplantas de banano (cv. Gran } \\
\text { Enano), con cepas de Trichoderma atroviride identificadas como } \\
\text { (E1 y E2) respectivamente. En el hongo E2 proveniente de Costa } \\
\text { Rica, se encontraron los mejores resultados para ejercer control } \\
\text { e sobre Sigatoka negra en banano. Con la aplicación de E1, la } \\
\text { 'tendencia fue de reducir los valores de estado de evolución y de } \\
\text { índice de infección y E2 estimuló el Número total de hojas y el } \\
\text { Ritmo de emisión foliar }\end{array}$ & $\begin{array}{l}\text { (Jiménez et al., } \\
\text { 2009) }\end{array}$ \\
\hline
\end{tabular}


11. Growth stimulation in bean Phaseolus vulgaris L. by Trichoderma

12. Caracterización morfologica y molecular del antagonismo entre el endofítico Diaporthe sp. aislado de frailejón (Espeletia sp.) y el fitopatógeno Phytophthora infestan

13. A diverse assemblage of Botryosphaeriaceae infect Eucalyptusin native and non-native environments

14. Agrobacteriummediated transformation of the endophytic fungus Acremonium implicatum associated with Brachiaria grasses

15. Histological analyse of the fungal endophytes in Rosa hybrida.

16. Aislamiento de hongos endofíticos en rosa (Rosa hybrida) en Bogotá, Colombia

\section{Acremonium} implication, a seedtransmitted endophytic fungus in Brachiaria grasses

18. Measuring diversity of endophytic fungi in leaf fragments: Does size matter?

19. Detecting and differentiating Acremoniun implicatum: Developing a PCR-based method for an endophytic fungus associated with the genus Brachiaria

20. An endophyte of the tropical forage grass Brachiaria brizantha: Isolating, identifying, and characterizing the fungus, and determining its antimycotic properties ciat
De 101 aislamientos de Trichoderma de Colombia El veinte por ciento fueron capaces de producir formas solubles de fosfato de roca fosfórica. El $8 \%$ mostraron capacidad constante para Auxinas, endofitico, Phaseolus, , producir sideróforos para convertir el hierro férrico a formas Sideroforos, Solubilización de producir sideroforos para convertir el hierro ferrico a folación. fosfato, Trichoderma $\quad$ análogos de la auxina., la producción de estas sustancias no se correlacionó con el aumento del crecimiento en plántulas de frijol
Acremonium, Brachiaria Control biológico, endofítico infestans, Pruebas de antagonismo

Botryosphaeria, Botryosphaeriaceae, canker, muerte por sequedad, endofitico, Eucalyptus, Patogeno latente

Endofíticos, proteína verde fluorescente (GFP), reparto de genes, Simbiosis

Endofitico; Rosa sp

asociación planta endofítico, endofitico brachiaria,

Biodiversidad, diversidad fúngica, endofítico, filosfer
El hongo endofitico Diaporthe phaseolorum aislado de Espeletic

Diaporthe $\mathrm{sp}$, Hongos endofiticos, Phytophthor $s p$ mostro efecto antagónico contra el crecimiento de $P$. infestans (Prada et al., 2009) de acuerdo al medio usado

Se analizan diferentes de especies nativas e introducidas de eucaliptos alrededor del mundo, aislando y diferentes especies de Botryosphaeriaceae hongo patógeno que en sus primeros estadios es endofitico, e identificando capacidad de infección en relación a su distribución. Se identifican Diplodia pinea, $D$. scrobiculata, Neofusicoccum eucalyptorum, N. eucalypticola, N. ribis, N. australe, siendo los más comunes en todos los continentes.

Desarrollo de un sistema de transformación mediado por plicatum, usando una proteína de expresión verde fluorescente (GFP) y el vector pSK 1019 (trpC promoter) o pCAMBIA1300 (CaMV35S promoter)

Análisis histológico, Hongos $\quad$ El estudio sirvió como prueba confirmatoria del hábitat endofiticos, Rosa hybrida endofítico de los hongos aislados de hojas de Rosa hybrida

Los hongos endofiticos más abundantes aislados de plantas de rosa (Rosa hybrida) fueron los pertenecientes a los géneros: Nigrospora oryzae, Xylaria spp, Aureobasidium spp Nigrospora oryzae, Xylaria spp, Aureobasidium $\mathrm{spp}$
yAcremonium. Los hongos Nodulisporium $\mathrm{sp}$, Gliocladium virens, Cladosporium sp,Alternaria sp, Phoma sp y Chaetomium globosum se aislaron una única vez cada uno

Se determinó que Acremonium implication se transmite a través de las semillas de pastos Brachiaria

(Dongyi y Kelemu,

2004)

Se encontró que la reducción del tamaño y aumentar el número de fragmentos de hojas incrementará el número de especies de hongos aislados

(Gamboa et al.,

Desarrollo de un ensayo basado en la reacción de la cadena de la polimerasa que permite la detección rápida y precisa de

(Segenet et al., 2003)

endofíticos en plantas de Brachiaria y permite una diferenciación entre hongos endofiticos y no endofiticos

De B. brizantha se aisló el hongo endófitico Acremonium implicatum, se observó que en la planta $B$. brizantha infectada con este endofitico se redujeron las lesiones causadas por el hongo patógeno Drechslera

Slippers et al. 2009) (Abello et al. 2008)

algado et al., 2007 
ÍNDICE ALFABÉTICO 


\section{Indice Alfabético}

A

Actividad anti-cáncer

Actividad Anti-bacterial

Actividad antibacteriana

Actividad antioxidante

Actividad biológica

Agricultura

Aislamientos

Alcaloides

Algas

Amilasa

Análisis de tendencias

Antagonista

Anti-malaria

aplicaciones agroindustriales

Aplicaciones en salud

Asexual

Asociaciones mutualistas

Asparaginasa

B

Bacteria

\section{Biocidas}

Biocombustible

Biocombustibles

Biocombustibles

Biodiversidad

Biología Molecular

Bioquímica

Biorremediación

Biorremediación de suelos 
C

Capacidades nacionales

Celulasa

Cianobacteria

\section{Ciencias Biológicas}

Clasificación Internacional de patentes (IPC)

Compuesto activo

Compuestos activos

Control biológico

Control de plagas

Corteza

Cultivos orgánicos

D

Datos cienciométricos

Dinámica de publicaciones

División binaria

E

Ecosistema

Ensayos biológicos

Enzima

Espora

Espora haploide

Eucariota

$$
\text { F }
$$

Factores ambientales

Farmacéutica

Farmacología

Fijación de nutrientes

Flores

Forrajes

Frutas

Función ecológica 
G

Gelatinasa

Genética

Glutaminasa

H

Heterótrofo

Hifas

Hojas

Hongo

Hongo endofítico

I

Inmunología

Inteligencia competitiva

Investigación y Desarrollo (I+D)

$L$

Levadura

Lipasa

Líquenes

M

Macroalgas

Mecanismos de defensa

Medicina

Medio Ambiente

Metabolito secundario

Metabolitos bioactivos

Metabolitos secundarios

Métodos de aislamiento

Micelio

Micorrizas

Microbiología

$P$

Patente 


\section{Patentes}

Pecíolos

Plantas hospedera

Producción de biomasa

Productividad

productividad de cultivos

Prospección

Pseudomicelio

Publicaciones indexadas

$\boldsymbol{R}$

Raíz

Rama

$S$

Semillas

Silvicultura

Simbiosis

$T$

Tallo

Taxol

Técnicas moleculares

Tejidos

Toxicología

V

Vigilancia tecnología

Vigilancia tecnológica 


\section{PERFIL BIOGRÁFICO}

\section{Oscar Marino Mosquera Martínez}

Químico egresado de la Universidad del Valle, cursó los estudios de maestría en Agroquímica en la Universidad Federal de Viçosa de Brasil y docente de la Universidad Tecnológica de Pereira y director del Grupo en Biotecnología-Productos Naturales GB-PN. Ha dirigido más de 40 trabajos de grado y ha participado y liderado proyectos de investigación relacionados con temas de bioprospección, actividad biológica, caracterización de hongos, identificación y evaluación de extractos vegetales con actividad antioxidante y neuroprotectora, caracterización de metabolitos secundarios. Actualmente, participa con el Grupo de Investigación en el Proyecto "Desarrollo de capacidades científicas y tecnológicas en biotecnología aplicada a los sectores de la salud y la agroindustria en el departamento de Risaralda" financiado por el Sistema Regional de Regalías. 


\section{Juan Pablo Diaz Echeverry}

Biólogo egresado de la Universidad del Cauca, cursó estudios de maestría en Ecotecnología en la Universidad Tecnológica de Pereira, desarrollando su trabajo de grado titulado "Aislamiento e identificación de hongos endofíticos de Witheringia coccoloboides (dammer) hunz. (Solanaceae), como aporte a su conocimiento y usos potenciales" en el Grupo de BiotecnologíaProductos Naturales GB-PN de la Escuela de Tecnología Química de la Universidad Tecnológica de Pereira. Este estudio fue financiado por el Sistema Regional de Regalías y el Consejo Profesional de Biología. Desde el 2012 y hasta la actualidad, se desempeña como docente catedrático e investigador de la Universidad Tecnológica de Pereira. 


\section{Angélica María Pineda Botero}

Administradora Ambiental de la universidad Tecnológica de Pereira. Coordinadora de la Unidad de Vigilancia y Prospectiva Tecnológica del Centro de Investigaciones y Estudios en Biodiversidad y Recursos Genéticos - CIEBREG en el periodo 2005- 2012. Asesora en temas de direccionamiento estratégico, gestión del conocimiento, trasferencia tecnológica y vigilancia tecnológica e inteligencia competitiva. Con experiencia en la elaboración y ejecución de proyectos de investigación relacionados con uso y conservación de la biodiversidad y cambio climático. Entre el 2011 y el 2016, asesora de la Vicerrectoría de Investigaciones, Innovación y Extensión de la Universidad Tecnológica de Pereira y del proyecto "Desarrollo de capacidades científicas y tecnológicas en biotecnología aplicadas a los sectores de la salud y la agroindustria en el Departamento de Risaralda", auspiciado con los recursos del Sistema Nacional de Regalías de Colombia (2014 - 2019), en temas relacionados con vigilancia tecnológica y gestión de la $\mathrm{I}+\mathrm{D}$ de cara a la transferencia tecnológica. 


\section{Víctor Alfonso Mejía Restrepo}

Nacido en Pereira. Cursó sus estudios de pregrado en la Universidad Tecnológica de Pereira, donde a sus 24 años obtuvo el título de Químico Industrial presentando un trabajo acerca de la evaluación de actividades biológicas en hongos endofíticos aislados de la especie Piper umbellatum. 
En este universo, aumenta cada vez más, el gran potencial ecológico, químico, farmacológico e industrial de los organismos endofíticos, todavía poco conocidos, ya que están escondidos en el interior de las plantas. En este documento sobre "Tendencias en investigación y desarrollo $(I+D)$ en organismos endofíticos", los autores presentan este universo de especies endofíticas, abordando no solamente la importancia y las aplicaciones de estas especies, si no que ofrecen un mapa de países, instituciones e incluso investigadores que trabajan en esta área, en una visión global y equilibrada sobre el tema. Además, este material recopila diversos aspectos relevantes en la investigación sobre organismos endofíticos, como las tendencias en el área de patentes, aspectos metodológicos y análisis de producción cientíca en el área de endofiticos. Es un trabajo exhaustivo, completo y que puede conducir a discusiones políticas, cientícas y académicas sobre este tema, tan relevante en el área de biotecnología industrial en la actualidad. Espero que la lectura pueda agradarles a todos, de la misma manera que me agradó a mí; en especial a los jóvenes investigadores, para incentivarlos a embarcarse en el estudio de organismos endofíticos sobre las más diversas ópticas del trabajo cientíco. Hay un mundo de informaciones ecológicas, químicas y farmacológicas para ser descubierto en esta área. 